Ulrich Thilo Hoffmann

Normen der deutschen Bühnenaussprache in der Fachliteratur des 19. Jahrhunderts

Wagner-Lesarten. Aufführungspraktische Miszellen

Online-Version 
Online-Version verfügbar unter der Lizenz:

Creative Commons Namensnennung - Nicht kommerziell -

Keine Bearbeitungen 4.0 International Lizenz (CC BY-NC-ND 4.0).

Veröffentlichungsjahr: 2021

Wagner-Lesarten. Aufführungspraktische Miszellen.

Hrsg. von Kai Hinrich Müller

Im Rahmen von »Wagner-Lesarten. Richard Wagners `Der Ring des Nibelungen in historisch informierter Aufführungspraxis - ein wissenschaftlich-künstlerisches

Projekt von Kent Nagano, Concerto Köln und der Kunststiftung NRW«

Mit freundlicher Unterstützung der

KUNST

STIFTUNG

NRW 


\title{
Normen der deutschen Bühnenaussprache \\ in der Fachliteratur des 19. Jahrhunderts
}

\author{
Ulrich Thilo Hoffmann
}

\section{Einleitung}

Der Aufsatz stellt die gekürzte Fassung meiner Master-Thesis dar, welche 2018 zum Abschluss meines Studiums der Sprechwissenschaft an der Martin-Luther-Universität Halle-Wittenberg entstand. Die Arbeit trägt den Titel Zur deutschen Bühnenaussprache im 19. Jahrhundert. Ein solchermaßen historisch orientiertes und musiknahes Thema ist an der Abteilung für Sprechwissenschaft und Phonetik in Halle eher selten, da sich die aktuellen Forschungsvorhaben vor allem auf gegenwärtige Phänomene gesprochener Sprache ausrichten. Der Anlass für das Thema war die Zusammenarbeit von Musik-, Theater- und Sprechwissenschaft im Rahmen des Projekts Wagner-Lesarten, die auch die Frage nach der Bühnenaussprache zu Richard Wagners Zeit als inhaltliches Ziel hat. Als Sprechwissenschaftler ging es mir um die phonetische Perspektive auf die Aussprache auf der Bühne und aufgrund des begrenzten Rahmens einer Masterarbeit zudem um den Fokus auf das Bühnensprechen (mit der Hoffnung, einige der Ergebnisse auch hinsichtlich der Aussprache im Gesang anwenden zu können). Das Ziel war es, möglichst klar definierte Aussprachemerkmale zu erarbeiten, die die Bühnenaussprache im 19. Jahrhundert kennzeichnen und die sich heute auf der Bühne reproduzieren lassen. Bei diesen Merkmalen handelt es sich um Vokale und Konsonanten sowie eine Auswahl suprasegmentaler, also mehrere Laute übergreifende Merkmale: Wort- und Satzakzentuierung, Rhythmisierung und Melodisierung.

Eine im Rahmen von Wagner-Lesarten zusammengetragene digitale Quellenbibliothek, in der sich auch über 120 Dokumente zur Aussprache im 19. Jahrhundert befinden, wurde nach Aussagen zu phonetischen Merkmalen durchsucht. Es handelt sich hierbei um Schauspiel- und Gesangslehrwerke, Deutschlehrwerke, Wörterbücher, sprachwissenschaftliche Arbeiten und Zeitschriftenartikel, wobei das Gros idealisierte Normen deutscher Aussprache beinhaltet. Besonders in der zweiten Hälfte des 19. Jahrhunderts haben sich zahlreiche Autor:innen mit der Frage nach deutschen Aussprachenormen beschäftigt (im Folgenden kurz »Autoren « genannt, da die wenigen Texte von Verfasserinnen für diese Untersuchung nicht relevant waren). Dabei wurden jedoch nicht nur die Bühnen in den Blick genommen. Im Gegenteil: Es finden sich Titel wie Die dialektfreie Aussprache des Hochdeutschen (Grabow 1875), Die richtige Aussprache des Hochdeutschen (Rocca 1889) oder German pronunciation: practice and theory (Viëtor 1885), wobei die Autoren u. a. versuchen, Schuldeutsch und Deutsch als Fremdspracheunterricht 
(DaF) auf der Grundlage physiologischer, sprachgeschichtlicher und schriftsprachlicher Gegebenheiten in den Blick zu nehmen. Regelmäßig wird darauf hingewiesen, dass dialektfreies Deutsch vor allem auf der Bühne zu finden sein solle; auch die Erarbeitung von Regeln schließt hier an. Eine Exklusivität der Normen für den jeweiligen Fachbereich des Autors wird in der Regel nicht beansprucht.

Hieraus ergab sich das Untersuchungsdesign: Zunächst wurden allgemeine Ausspracheregeln zu Vokalen, Konsonanten, Akzentuierung und Rhythmisierung zu finden versucht. Dann wurden sie untereinander und mit dem heutigen Aussprachestandard verglichen. Im Anschluss wurden diese Normen in den Rahmen der Ansprüche der Bühnenaussprache gesetzt. Aufgrund des begrenzten Rahmens dieser Untersuchung wurde nur eine Auswahl von Werken einbezogen, deren Autoren ebenjene Aussagen relativ eindeutig und unmissverständlich zu formulieren wussten. Die meisten der hier vielfach zitierten Autoren (z. B. Siebs, Viëtor, Hey) galten damals wie heute als Autoritäten ihrer jeweiligen Disziplin.

Verinnerlichte Ausspracheregeln können zwar bis zu einem gewissen Grad gelehrt werden; das Ergebnis auf der Bühne wird jedoch von zahlreichen weiteren Faktoren beeinflusst und kann so nicht dem Lehrbuchideal entsprechen. Damit müssen Sprecherzieher:innen heute wohl ebenso rechnen, wie es damals beispielsweise der Gesangspädagoge Julius Hey tun musste, als er in Bayreuth Richard Wagners Sänger:innen schulte. Die im Folgenden dargestellten Aussprachenormen stellen also sicherlich nicht die tatsächliche Bühnenaussprache zu Wagners Zeiten dar. Trotzdem ist die Untersuchung dieser Normen ein Schritt auf dem Weg zu einer historisch informierten Sprachbehandlung von Wagners Werk.

Im Folgenden möchte ich nun meine Untersuchung der ausgewählten Arbeiten hinsichtlich ihrer Aussagen zu Vokal- und Konsonantgestaltung sowie zu suprasegmentalen Gestaltungsmitteln darstellen. Im Anschluss geht es mir um die praktische Anwendung auf heutige Aspekte der Bühnenaussprache. Ein sprechwissenschaftlich-phonetisches Glossar nebst Anhang, in dem sich zwecks Illustration einige Schaubilder aus den genannten Werken befinden, runden den Aufsatz ab. 


\section{Allgemeine Aussprachenormen in der Fachliteratur des 19. Jahrhunderts}

\subsection{Vokale}

Die Fachliteratur des 19. Jahrhunderts bietet einige Aussagen zu Natur und Beschaffenheit der Vokale sowie Versuche, sie zu systematisieren. Grabow (1875, 375 ff.) ordnet z. B. jedem Vokal eine Tonhöhe zu, die sich beim Flüstern des Lautes auditiv abnehmen und bestimmen lässt. Auch Trautmann (1886, 39 ff.) versucht die Vokale in ein musikalisches System zu ordnen, indem er vier Reihen nennt, die jeweils harmonische Akkorde ergeben. Behaghel $(1886,150)$ konzentriert sich auf die Herleitung der neuhochdeutschen Vokale aus sprachhistorischen Gegebenheiten. Viëtor (1885, 9 ff.) unterteilt sie der Richtung der Zungenhebung entsprechend in »Front Vowels«, »Back Vowels« und »Mixed Vowel« und kommt damit der heutigen Ordnung der deutschen Vokale nach ihren distinktiven Merkmalen (s. Krech et al. 2010, 24 ff.) am nächsten. Obwohl diese Arbeiten in einem Zeitraum von nur elf Jahren erschienen sind, unterscheiden sich ihre Systeme voneinander. Fast alle Autoren berufen sich auf physiologische Gegebenheiten. Trotzdem sind beispielsweise bei Viëtor (1885) 14 deutsche Vokale genannt, während es bei Grabow (1875) 24 sind. Um einen besseren Überblick über ihre Gemeinsamkeiten wie Unterschiede zu bekommen, möchte ich die beschriebenen Vokale zwecks Vergleich in Kategorien zusammenfassen:
a) A-Vokale,
b) E-Vokale,
c) I-Vokale,
d) O-Vokale,
e) U-Vokale,
f) Ö- und Ü-Vokale.

Ebenso verglichen werden Diphthonge sowie Aussagen zu Vokaleinsatz und Nasalität:

g) Diphthonge,

h) Vokaleinsatz,

i) Nasalität.

Die Kategorien a) bis f) basieren zum Teil auf phonetischen und zum Teil auf orthografischen Gemeinsamkeiten der ihnen zugehörigen Laute. So werden innerhalb der Kategorie b) E-Vokale auch Laute verglichen, die dem heutigen Schwa [ə] entsprechen. Dieser Laut ist zwar phonetisch gesehen kein E-Vokal, hat mit diesem aber die Beziehung zum Graphem <e > gemein. Die in der Literatur des 19. Jahrhunderts beschriebenen Laute werden anhand verschiedener Hinweise den hier erstellten Kategorien zugeordnet. Bei diesen Hinweisen handelt es sich um:

- eindeutige Bezeichnungen in Überschriften oder Fließtext (»de[r] Vokal A«, Hey 1882, 20),

- phonetische Beschreibungen (»low-back-(wide) vowel«, Viëtor 1885, 21),

- $\quad$ phonetische Transkriptionen und Beispielwörter (siehe Abbildung 1): 


\begin{tabular}{|c|c|c|c|c|}
\hline $\begin{array}{l}\text { Kurze } \\
\text { Laute }\end{array}$ & Beispiele & $\begin{array}{l}\text { Lange } \\
\text { Latute }\end{array}$ & Beispiele & Tonhöhe \\
\hline $\begin{array}{l}a \\
a\end{array}$ & $\begin{array}{l}\text { damit, Fremdw. Schafott } \\
\text { Mann, Wall }\end{array}$ & a & Mahl, Aar & $\begin{array}{l}d^{\prime \prime \prime} \\
\text { d-dis }\end{array}$ \\
\hline
\end{tabular}

Abb. 1: Die einfachen Vokale der deutschen Wörter mit Tonhöhe (Auszug). Grabow 1875, 378.

\section{a) A-Vokale}

Das Deutsche Aussprachewörterbuch beschreibt für die heutige deutsche Standardaussprache die beiden Vokalphoneme /a:/ und /a/. Ersterer ist lang, Letzterer kurz. In der Qualität unterscheiden sie sich nicht: Beide sind flache Mittelzungenvokale (vgl. Krech et al. 2010, 24).

Die Laute, die in der Literatur des 19. Jahrhunderts beschrieben werden, kommen den heutigen A-Vokalen relativ nahe. Guttmann $(1882,98)$, Viëtor $(1885,21)$, Hoffmann $(1888,22)$ und Rocca $(1889,51)$ beschreiben die Zunge als tief, flach oder in der Ruhelage befindlich. Von einem Mittelzungenvokal ist nicht die Rede. Viëtor (ebd.) ordnet das A in die Kategorie der Hinterzungenvokale ein. Mehrfach wird auf eine große Kieferöffnung hingewiesen (Benedix 1859, 7; Guttmann 1882, 98; Hoffmann 1888, 22; Rocca 1889, 51). Ebenso scheint über die Ruhelage der Lippen Konsens zu bestehen. Lediglich Benedix (ebd.) hält Sprecher:innen mit dickeren Lippen dazu an, diese etwas über die Zähne zurückzuziehen. Verschiedene dunklere oder hellere Färbungen des A, wie sie bei Grabow $(1875,378)$ vorkommen, finden in anderen Werken kaum Erwähnung. Nur Hoffmann $(1888,23)$ behauptet, das A könne offen und geschlossen auftreten. Die Ansicht, dass dialektfreies Deutsch - die A-Vokale betreffend - zwar verschiedene Quantitäten, aber nur eine Qualität beinhalte, scheint in der verwendeten Literatur zu überwiegen. Tatsächlich beschreiben die meisten Autoren genau eine artikulatorische Bildung des Vokals. Viëtors Bezeichnung des Lautes als Hinterzungenvokal lässt vermuten, dass hier ein dunkleres A beschrieben wird als das der anderen, die auf die Ruhelage oder durchgehende Flachheit der Zunge hinweisen. Die Mehrzahl der Autoren scheint die Mittelzungenvokale [a] und [a:] zu beschreiben, Viëtor hingegen die Hinterzungenvokale [a] und [a:].

Weitestgehend Einigkeit herrscht darüber, welche Grapheme durch einen A-Vokal realisiert werden. Wiederkehrend werden folgende genannt: $<\mathrm{a}>($ Lack $),<\mathrm{aa}>(\boldsymbol{A a l}),<\mathrm{ah}>(W \boldsymbol{a h} n),<$ ha $>$ (That) (vgl. Viëtor 1885, 22; Hoffmann 1888, 23 f.; Siebs 1900, 11 f.). Viëtor (ebd.) ergänzt weitere Möglichkeiten aus ursprünglich englischen oder französischen Wörtern: $<$ aw $>$ (Shawl), $<\mathrm{i}>$ (Boudoir). Weniger Klarheit herrscht darüber, in welchen Positionen ein langer bzw. kurzer Vokal zu verwenden sei. Die meisten Autoren beziehen sich auf das Schriftbild, wo ein langer Vokal durch Verdopplung (Paar) oder Hinzufügen von $<\mathrm{h}>$ (sah, That), ein kurzer Vokal durch Doppelkonsonanten (Latte) angezeigt werde. Davon abgesehen, glauben verschiedene Autoren unterschiedliche Regelhaftigkeiten feststellen zu können. So sei der Vokal z. B. lang im Wortauslaut (Anna) (vgl. Viëtor 1885, 22) oder in offener Silbe (Abend) (vgl. Rocca 1889, 52). Laut 
Benedix $(1859,4)$ sei A lang vor einfachen Konsonanten (Schlaf) oder vor Konsonantenhäufungen, bei denen der erste stimmhaft ist (Adler). Rocca $(1889,52)$ grenzt dies ein, indem er langes A bei folgendem $\langle\mathrm{b}\rangle,\langle\mathrm{g}\rangle,<\mathrm{m}>$ oder $\langle\mathrm{r}\rangle$ empfiehlt (Habsucht, lag, Scham, bar, darf). Benedix $(1859,5)$ empfiehlt bei folgendem $<\mathrm{m}>,<\mathrm{r}>,<\mathrm{l}>$ oder $<\mathrm{n}>$ einen kurzen Vokal (Amt, Art, Sal $z$, Tanz). Das gelte auch bei folgenden stimmlosen Konsonanten. Laut Hoffmann $(1888,24)$ trete der kurze Vokal generell in geschlossenen Silben auf.

\section{b) E-Vokale \& Schwa}

Der heutige Aussprachestandard beinhaltet die nichtlabialen, mittelhohen Vokalphoneme /e:/, $/ \varepsilon: /, / \varepsilon /$ und /ə/. /e:/ ist lang und gespannt, / $/ \varepsilon /$ kurz und ungespannt. / $\varepsilon: /$ ist als langer ungespannter Vokal in der Kombination dieser Eigenschaften eine Besonderheit des deutschen Vokalsystems. Bei diesen drei Lauten handelt es sich um Vorderzungenvokale. /ə/ - auch als "Schwa-Laut « bezeichnet - ist ein kurzer ungespannter Mittelzungenvokal (vgl. Krech et al 2010, 24). Darüber hinaus kann in eingedeutschten Wörtern in nicht akzentuierter Position auch ein kurzes gespanntes [e] auftreten (elegant [eleg'ant]) (vgl. ebd. 59).

Grabow $(1875,378)$ nennt verschiedene dunkle und helle Vokale, die sich in ihrer Anzahl kaum in das heutige System deutscher Vokale einordnen lassen. Ähnlich verhält es sich mit Benedix' $(1859,9)$ doppelter Erscheinungsform von langem E, dem halbgeschlossenen E sowie den zwei verschiedenen Endsilben-E von Hey (1882, 25 ff.). Die Artikulation, wie sie u. a. bei Viëtor (1885, 15 ff., 19 ff.) beschrieben wird, kommt allerdings dem heutigen Aussprachestandard so nahe, dass sich jedem der von ihm genannten Laute eine gegenwärtige Entsprechung zuordnen lässt. So beschreibt er zwei mittelhohe Vorderzungenvokale, von denen einer geschlossen und der andere offen sei. Der offene Vokal könne lang oder kurz sein $\left(\rightarrow\left[e_{i}\right],\left[\varepsilon^{\prime}\right],[\varepsilon]\right)$. Der mittelhohe Mischvokal (vgl. ebd. 29 ff.) entstehe bei gleichzeitiger Anhebung von Vorder- und Hinterzunge, was eine Umschreibung für einen Mittelzungenvokal sein könnte $(\rightarrow[\ni])$. Auch Roccas (1889, 52 ff.) und Hoffmanns (1888, 26 ff.) Beschreibungen ähneln den heute verwendeten Vokalen. Beide Autoren erwähnen gegenüber dem von ihnen beschriebenen A-Vokal eine zunehmende Hebung des mittleren Zungenrückens, wobei eine geschlossene und eine offenere Variante entstünden. Auch hier könne der offene Vokal lang oder kurz sein. Rocca weist auf die Existenz eines Lautes hin, der dem heutigen [ə] entsprechen könnte (ohne genauere Erklärung zur Artikulation). Hoffmann beschreibt einen »Neutralvokal«, der durch einfaches Öffnen des Mundes gebildet werde.

Bei den Phonem-Graphem-Beziehungen der E-Vokale sind sich die Autoren teilweise uneinig. Recht klar ist, dass die Verdopplung des Vokal-Graphems (leer) oder das Hinzufügen von $<\mathrm{h}>$ (wehen) eine Längung anzeigt, folgende Doppelkonsonanten (Wette) hingegen eine Kürzung anzeigen. Unklar ist jedoch, wann langes [e:] und wann langes [ $\left.\varepsilon_{\mathrm{i}}\right]$ realisiert werden sollen. Für Viëtor $(1885,19)$ könne [ع:] nur bei dem Graphem <ä> realisiert werden (Fremd- und Lehnwörter ausgenommen). Laut Hoffmann (1888, 27 f.) verlangen auch Dresden oder Beere nach 
langem offenen [ع:], während Reh oder Seele langes gespanntes [e:] haben. Welche Regelung dem zugrunde liegt, lässt er offen. Die Ausführungen des Deutschen Wörterbuchs (vgl. Grimm 1859, Bd. 3, Sp. 1 f.) legen die Vermutung nahe, dass es sich bei offenem [ $\varepsilon$ :], bei dem heute gespanntes [e:] realisiert werden würde (Gewehr, Kehle, Beere), um Reste mittelhochdeutscher Lautung handelt, die sich im 19. Jahrhundert im Wandel befand. Scheinbar bewerteten Autoren diesen Wandel auf unterschiedliche Weise.

Kurzes geschlossenes [e] (Sekretär) wird nur einmal erwähnt und stellt eine Ausnahme dar (vgl. Viëtor 1885,16$)$. Wann genau $<$ e $>$ oder $<$ ä $>$ als kurzes $[\varepsilon]$ realisiert werden müssten, ist relativ unklar. Hoffmann $(1888,27)$ formuliert die Regel, dies geschehe vor einem, mehreren oder doppelten Konsonanten (es, bremsen, fett). Die von ihm gegebenen Beispiele lassen vermuten, dass es sich um geschlossene Silben handelt. Die Regeln zur Phonem-Graphem-Beziehung der Laute, die vermutlich am ehestem dem heutigen Schwa [ə] entsprechen, sind ebenfalls nicht deckungsgleich. Laut Viëtor $(1885,71)$ werde der Mischvokal [ə] realisiert: in den Vorsilben $<$ be- $>,<$ ge- $>$ (behalten, gehabt); in den Endsilben $<-\mathrm{e}\rangle,<-\mathrm{el}\rangle,<-\mathrm{em}>,<-\mathrm{en}\rangle,<-\mathrm{end}\rangle,<-\mathrm{er}>$, $<$-ern >, <-es>, <-est>, <-et>, <-ele> (Atem, lieben, rasend, Vater, eisern, alles, leidet, handele); in nicht akzentuiertem der, dem, den, des, es. Siebs $(1900,16)$ empfiehlt für der, dem, den langes [e:], für des, es kurzes [ $\varepsilon$ ]. Schwa werde in Nebensilben gesprochen (geredetes), was mit Viëtor übereinzustimmen scheint. Weiterhin weist Viëtor (1885, 30 f.) darauf hin, dass bei <-el>, $<-e m>,<-e n>,<-e r>$ oft schwer zu unterschieden sei, ob [ə] realisiert oder elidiert und damit der finale Konsonant silbisch gesprochen wird. In diesem Fall sei es wichtig, silbisches [n] nicht zu assimilieren (leben $\rightarrow$ [l'e:bn] und nicht [l'e:bm] ). Laut Hey $(1882,26)$ treten die zwei Vokale, die heutigem [ə] vermutlich am ehesten entsprechen, bloß in Endsilben auf (gehen, Zwinger, Gesinde). Rocca $(1889,54)$ meint, das vermutliche [ə] werde gesprochen bei <e $>$ oder $<\mathrm{e}>$ mit folgendem stimmhaften Konsonanten im Wortauslaut (gebe, belastet). Er behauptet als einziger, dass [ə] bei folgendem stimmhaften Konsonanten fast immer elidiert werde (Atem).

\section{c) I-Vokale}

Heutiges Standarddeutsch beinhaltet die beiden Vokalphoneme /i:/ und /I/. Es handelt sich um hohe Vorderzungenvokale, wobei der erste lang und gespannt, der zweite kurz und ungespannt ist (vgl. Krech et al 2010, 24). In eingedeutschten Wörtern kann in nicht akzentuierter Position ein kurzes gespanntes [i] auftreten (Brigade [bsig'a:də]). Außerdem kann ebenfalls in eingedeutschten Wörtern ein unsilbischer I-Laut [i] auftreten (grandios [gваndi'ors]) (vgl. ebd. 57).

Im Gegensatz zu den A- und E-Vokalen beschreibt kein Autor mehr als drei Erscheinungsformen von I-Vokalen. Benedix (1859, 12 f.), Grabow (1875, 378), Hey (1882, 33), Viëtor (1885, 10, 14), Hoffmann $(1888,28$ f.) und Siebs $(1900,18)$ unterscheiden mindestens zwei I-Vokale, wobei die Termini oder Transkriptionszeichen meist eindeutig auf die Unterscheidung von Qualität (geschlossen/offen) oder Quantität (lang/kurz) hinweisen. Grabow, Viëtor und Siebs 
weisen darüber hinaus auf den kurzen bzw. gekürzten geschlossenen Vokal hin, der in Fremdwörtern auftreten könne. In Bezug auf den Grad der Zungenhebung ähneln die Beschreibungen der heutigen Aussprache. So habe »die Zunge die höchste Wölbung gegen den harten Gaumen « (Hey 1882, 32) oder sie sei beim geschlossenen Vokal so weit zum mittleren harten Gaumen gehoben, wie es ohne Geräuschbildung möglich sei (vgl. Viëtor 1885, 10), beim offenen Vokal nur etwas weniger (vgl. ebd. 14). Auch Viëtors Kategorisierung des geschlossenen und des offenen Vokals als Vorderzungenvokale (ebd. 10) stimmt mit dem heutigen Verständnis der Vokalbildung überein. Darüber hinaus werden von den Autoren Lippenstellungen genannt, die heute als antiquiert gelten dürften. Dabei handelt es sich um Lippenbreitzug (vgl. Benedix 1859, 12; Hoffmann 1888, 28) und das Anheben der Lippen bzw. der Oberlippe (ebd.). Die weitgehende Übereinstimmung von Anzahl und Bildung der I-Vokale lassen für die weitere Arbeit durchaus direkte Vergleiche mit den I-Vokalen des heutigen Standards zu: [ii] (bzw. [i]) und [I].

Für die graphemische Darstellung verschiedener I-Vokale existieren weniger gegenläufige Meinungen, als es bei den E-Vokalen der Fall ist. Leider bieten dafür nur wenige Autoren Regeln für die Verwendung des einen oder des anderen Vokals. Für die Verwendung von [i:] werden folgende Grapheme genannt: <i $>(m \boldsymbol{i} r),<\mathrm{ie}>(\boldsymbol{i} \boldsymbol{i} b),<\mathrm{ih}>(\boldsymbol{i} h n),<\mathrm{ieh}>($ Vieh) (vgl. Viëtor 1885, 10; Hoffmann 1888, 28 f.; Siebs 1900, 19). Viëtor und Siebs sind sich darüber einig, dass der Vokal in nicht akzentuierter Silbe (mit höchstens einem folgenden Konsonanten) gespannt, aber gekürzt als [i] realisiert werde (Militär). Kurzes offenes [I] werde laut Hey $(1882,33)$ und Hoffmann $(1888,29)$ einfach bei $<\mathrm{i}>$ mit einem oder mehreren folgenden Konsonanten gesprochen (im, List, Lippe). Viëtor $(1885,14)$ nennt außer $<\mathrm{i}>$ die Grapheme $<$ ie $>$ (vierzehn) und $<y>($ Hyrtl), ohne weitere Regeln anzuführen. Laut Siebs $(1900,19)$ werde immer [I] verwendet, wenn $<\mathrm{i}>$ kein graphemisches Längenzeichen hinzugefügt ist. Außerdem nennt er Einzelwörter, für die die Verwendung von [ii] oder [I] geregelt sei. Dazu zählen auch die Numerale vierzehn und vierzig, für die Siebs das kurze [I] vorschreibt. Hoffmann $(1888,28)$ nennt nun genau diese Wörter als Beispiele für den langen gespannten Vokal, während Viëtor $(1885,14)$ vierzehn als Beispiel für den kurzen, offenen Vokal angibt und damit wiederum Siebs zustimmt. Es kann demnach angenommen werden, dass hinsichtlich der Aussprache dieser Numerale allgemeine Uneinigkeit herrschte.

\section{d) 0-Vokale}

Heutiges Standarddeutsch beinhaltet die gerundeten mittelhohen Hinterzungenvokale /o:/ und / /. Ersterer ist gespannt und lang, Letzterer ungespannt und kurz (vgl. Krech et al 2010, 24). In eingedeutschten Wörtern kann in nicht akzentuierter Position ein kurzes gespanntes [o] (Pho-

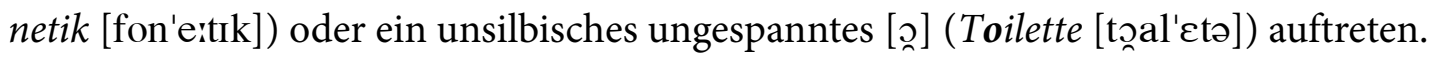

Die Fachliteratur des 19. Jahrhunderts stimmt die O-Vokale betreffend weitestgehend mit dem heutigen Vokalsystem überein. So unterscheiden die meisten Autoren zwischen langem und kurzem bzw. geschlossenem und offenem O (vgl. Grabow 1875, 378; Hey 1882, 43; Viëtor 1885, 
24 f., Hoffmann 1888, 26; Siebs 1900, 20). Darüber hinaus weisen einige Autoren auf die Kürzung des geschlossenen $\mathrm{O}$ hin, das in nicht akzentuierten, offenen Silben auftreten könne (vgl. Grabow 1875, 387; Viëtor 1885, 27; Siebs 1900, 22). Siebs beschreibt dieses Phänomen für Fremdwörter, während Viëtor und Grabow diese Eingrenzung nicht vornehmen. So nennt Letzterer je ein Wortbeispiel deutscher und fremder Herkunft: womit, Pokal (vgl. Grabow 1875, 387). Hey (1882) beschreibt als einziger ein »[g]eschlossenes $\mathrm{O}$ «, ein »[h]albgeschlossenes $\mathrm{O}$ « und ein »[g]anz offenes $\mathrm{O}$ « (ebd. 45), über deren Verwendung die folgenden Konsonanten bestimmen. Die artikulatorische Bildung der O-Vokale betreffend, herrscht bei den Autoren weitgehende Einigkeit. Hey (1882, 44), Viëtor (1885, 24 ff.) und Hoffmann (1888, 26) beschreiben eine Hebung des hinteren Zungenrückens zum weichen Gaumen. Rocca $(1889,56)$ behauptet, der mittlere Zungenrücken würde sich heben, sei jedoch weiter zurückgezogen als bei E und I. Viëtor (1885, 24 ff.) nimmt als einziger eine genauere artikulatorische Unterscheidung von offenem und geschlossenem $O$ vor und sagt, dass die Zunge bei Letzterem noch weiter gehoben werden müsse. Benedix $(1859,14)$, Hey $(1882,44)$, Viëtor $(1885,24$ ff.), Hoffmann $(1888,26)$ und Rocca $(1889,56)$ nennen das Merkmal der sich zuspitzenden, vorgestülpten oder gerundeten Lippen. Hey $(1882,44)$ fügt hinzu, dass die Unterlippe nicht die Zähne verlasse, was zur Senkung der Oberlippe führe. Für Rocca $(1889,56)$ hingegen seien die Lippen von den Zahnreihen abgehoben, womit er sich auf alle gerundeten Vokale bezieht. Weitere, nur jeweils einmal genannte artikulatorische Merkmale sind der im Vergleich zum A gehobene Unterkiefer (Hey 1882, 44), der wenig über die Ruhelage gehobene Kehlkopf (Hoffmann 1888, 26) und die genäherten Mundwinkel (Rocca 1889, 56). Die beschriebenen Vokale scheinen mit den heutigen deutschen O-Vokalen in den distinktiven Merkmalen Zungenhebung, Labialität, Qualität und Quantität große Übereinstimmung zu haben. Deshalb werden ihnen für die weitere Arbeit die heute gängigen IPA-Transkriptionen [o:] (bzw. [o]) und [o] zugeordnet.

Die Ausführungen zur graphemischen Darstellung der O-Vokale der einzelnen Autoren ähneln bis auf wenige Unterschiede den jeweiligen Regelungen für die I-Vokale, was aufgrund der analogen Gegenüberstellung von langem geschlossenen und kurzem offenen Vokal nicht verwundert. So werde langes [o:] manchmal durch $<0>(s o)$, eindeutig jedoch durch $<$ oo $>$ (Boot), $<$ oh> (roh) (vgl. Hey 1882, 45; Viëtor 1885, 26; Internetquelle 1) oder <ho > (Thor) (vgl. Hoffmann 1888, 26; Siebs 1900, 21) angezeigt. Viëtor $(1885,26)$ nennt darüber hinaus weitere Graphemkombinationen aus regionalen deutschen Eigennamen oder dem Englischen und Französischen, die durch [o:] realisiert werden müssten. Für kurzes [๑] geben die meisten Autoren lediglich das Graphem $<0>$ an $(\boldsymbol{o} b)$. Dieses könne jedoch in verschiedenen Positionen sowie Laut- bzw. Graphemumgebungen entweder lang und gespannt, kurz und ungespannt oder selten gespannt und gekürzt sein. Wie bei den anderen Vokalen legen die Autoren jeweils verschiedene Regelungen zugrunde. Laut Hey $(1882,45)$ sei [o:] bei Hinzufügen eines einfachen Konsonanten zwar gedehnt (schon), bei <oo> habe der Laut aber seine größte Dehnung (Moos). Bei graphemischem Hinzufügen von doppelten oder mehreren Konsonanten sei der Vokal kurz, aber je nach Art und Kombination der Konsonanten mehr oder weniger offen (Wonne, sonst). Viëtor 
$(1885,27)$ erwähnt wie schon zuvor, dass der gespannte Vokal im nicht akzentuierten Silbenauslaut als [o] gespannt und gekürzt sein könne (Salomo), im Wortauslaut jedoch als [o:] immer lang und gespannt sei (Salomo). Während Siebs (1900, 20 ff.) unter Einbezug von Ausnahmen sowie Wörtern fremder Herkunft die komplexeste und genaueste Darstellung der PhonemGraphem-Beziehung der I-Vokale (bzw. der Vokale generell) liefert, bleiben bei anderen Autoren Fragen offen. So gibt Hoffmann $(1888,26)$ an, dass kurzes [0] vor einem oder mehreren "Mundschliessern" auftrete, nennt dann aber für langes [o:] ebenfalls Wortbeispiele mit dem entsprechenden Vokal in geschlossener Silbe mit Konsonantenclustern: Obst, Trost. Es kann davon ausgegangen werden, dass die Vokale hier tatsächlich lang sind.

\section{e) U-Vokale}

Heutiges Standarddeutsch beinhaltet die beiden Vokalphoneme /u:/ und /v/. Es handelt sich um gerundete hohe Hinterzungenvokale, wobei der erste lang und gespannt, der zweite kurz und ungespannt ist (vgl. Krech et al 2010, 24). In eingedeutschten Wörtern kann in nicht akzentuierter Position ein kurzes gespanntes [u] auftreten (Musik [muz'ik]). Ebenso kann in eingedeutschten Wörtern ein unsilbisches [u] auftreten (Linguist [lingư⿱'ıst]) (vgl. ebd. 66).

Wie die I- und O-Vokale sind auch die in der Fachliteratur des 19. Jahrhunderts dargestellten U-Vokale in Systematisierung und beschriebener Artikulation den heutigen Vokalen ähnlich. Grabow (1875, 378), Viëtor (1885, 27 ff.), Hoffmann $(1888,25)$ und Siebs $(1900,24)$ unterscheiden zwischen langem geschlossenen und kurzem offenen U-Vokal. Erneut weisen Grabow, Viëtor und Siebs auf die Existenz eines kurzen bzw. gekürzten geschlossenen U-Vokals hin. Während einige Autoren auf den dunklen Klang und die erschwerte Tonerzeugung beim Sprechen oder Singen von U eingehen (Hey 1882, 52 ff.), äußern sich insgesamt weniger zur genauen Artikulation der entsprechenden Laute. Laut Viëtor $(1885,29)$ müsse für [u:] der hintere Zungenrücken so weit zum weichen Gaumen gehoben werden, wie es möglich sei, ohne einen Konsonanten zu erzeugen. Beim offenen [ $\mathrm{v}]$ befinde sich der hintere Zungenrücken in der Mitte der Positionen für [o:] und [u:] (vgl. ebd. 27). Laut Hoffmann $(1888,25)$ sei die Zunge sehr zurückgezogen und habe sehr wenig Abstand zum hinteren Gaumen. Während die Zunge für [u:] am weitesten zum weichen Gaumen gehoben und zurückgezogen sei, trete sie bei [ $\mathrm{U}$ ] weiter nach vorn. Außerdem wird auf eine Lippenrundung hingewiesen: »mit spitzer Mundstellung " (Benedix 1859, 14); »runde Lippenstellung « (Hey 1882, 52); »sehr weit vorgestülpt « (Hoffmann 1888, 25). Für die weitere Arbeit werden den im 19. Jahrhundert beschriebenen Lauten wieder die heute gängigen IPA-Transkriptionen [u:] und [v] zugeordnet.

Im Vergleich zu den anderen Vokalen äußern sich weniger Autoren zu der Phonem-GraphemBeziehung der U-Vokale. Da die wenigen vorhandenen Aussagen größtenteils mit denen übereinstimmen, die die Autoren für die O-Vokale getroffen haben, soll an dieser Stelle nur kurz darauf eingegangen werden: Während einfaches $\langle\mathrm{u}>$ in verschiedenen Umgebungen als [u:] oder $[\mho]$ realisiert werden könne, seien $<\mathrm{uh}>(\boldsymbol{K u h})$ oder $<\mathrm{hu}>(\boldsymbol{t h u} n)$ eindeutige Anzeiger für 
langes [u:] (vgl. Viëtor 1885, 27 ff.; Hoffmann 1888, 25; Siebs 1900, 24). Siebs' Bühnenaussprache liefert erneut die umfassendsten und genauesten Regelungen, in welchen Positionen und Umgebungen welcher Laut realisiert werden müsse.

\section{f) 0̈- und Ü-Vokale}

Bei den Vokalgruppen Ö und Ü zeigen sich weitere Gemeinsamkeiten. Bei den Ö-Vokalen des gegenwärtigen deutschen Aussprachestandards handelt es sich um die mittelhohen labialen Vorderzungenvokale / $\emptyset: /$ und /œ/. Bei den Ü-Vokalen sind es die hohen labialen Vorderzungenvokale /y:/ und /Y/. Der je Erstere ist lang und gespannt, der Zweitere kurz und ungespannt (Krech et al. 2010, 24). Zudem können in eingedeutschten Wörtern in nicht akzentuierter Position ein kurzes gespanntes [ $\phi]$ (Ökologie [ $\phi$ kolog'ii]) und ein ebensolches [y] (Büro [byв'o:]) sowie ein unsilbisches [Ц̆] (Etui [ety̆'ii]) auftreten (ebd. 63 f.).

Vergleichbare Vokale lassen sich in der Fachliteratur des 19. Jahrhunderts finden. Grabow (1875, 378), Viëtor (1885, 12 ff.), Hoffmann (1888, 29 f.) und Siebs (1900, 23 ff.) nennen jeweils zwei Ö- bzw. Ü-Vokale, wovon einer lang und geschlossen, der andere kurz und offen sei. Erneut sind es Grabow, Viëtor und Siebs, bei denen sich ebenfalls Hinweise auf einen kurzen bzw. gekürzten geschlossenen Vokal finden lassen. Die artikulatorische Bildung dieser Vokale wird meist von einem anderen Vokal aus beschrieben. So gehen Benedix (1859, 8 ff.) und Hey (1882, 48 ff.) für die Bildung des Ö vom $\mathrm{O}$, und für die Bildung des Ü vom $U$ aus. Laut Benedix müsse für den Zielvokal in beiden Fällen der Zungenrücken gehoben werden. Laut Hey erreiche man ihn durch Anheben und Vorrücken der Zungenspitze. Bei Hoffmann $(1888,29)$ entstehe Ö, wenn man die Zungenstellung von $\mathrm{E}$ und die Lippenstellung von $\mathrm{O}$ kombiniert. Ü entstehe bei Zungenstellung von I und Lippenstellung von U (vgl. ebd. 30). Viëtor unterscheidet im Gegensatz zu den anderen Autoren die Bildungen von geschlossenen und offenen Vokalen, welche sich hier gleich besser durch die Verwendung von IPA-Zeichen darstellen lassen. So entstünden geschlossenes [ $\varnothing:$ ] durch die Zungenposition von [e:] (vgl. ebd. 17), offenes [œ] durch die Zungenposition von $[\varepsilon]$ (vgl. ebd. 21) bei jeweiligem Hinzufügen von Lippenrundung. Ebenso werde aus geschlossenem [ii] ein [y:] (vgl. ebd. 12) und aus offenem [I] ein [y] (vgl. ebd. 15), wenn man jeweils die nötige Lippenrundung hinzufüge. Viëtor klassifiziert die Ö- und ÜVokale als Vorderzungenvokale (»FRONT VOWELS«, ebd. 10), was mit der heutigen Klassifikation im Einklang steht. Heys (1882) Beschreibung, laut der »die Zungenspitze sich hebt und mehr nach vorne strebt « (ebd. 49), scheint ebenfalls mit dieser Klassifikation übereinzustimmen. Ebenso führt einfaches Nachahmen der oben genannten Ableitungen von anderen Vokalen zu der Annahme, dass die in der Literatur beschriebenen Ö- und Ü-Vokale zumindest grob mit denen des heutigen Aussprachestandards übereinstimmen (in Abhängigkeit der Qualität der Ausgangsvokale). Aufgrund dieser wahrscheinlichen Ähnlichkeit werden für die weitere Arbeit auch hier die IPA-Transkriptionen [ $\varnothing:]$ und [œ] bzw. [y:] und [Y] verwendet. 
Die Phonem-Graphem-Beziehung erinnert stark an die zuvor behandelten Vokalkategorien: Langer gespannter Vokal werde durch Hinzufügen von $<\mathrm{h}>$ oder $<$ th $>$ angezeigt. Langes [ $\left.\phi_{\mathbf{r}}\right]$ werde also bei <öh> (Höhle) oder <thö> (thöricht), langes [y:] bei < üh> (kühn) oder <thü> (Thür) realisiert (vgl. Viëtor 1885, 12, 15, 18; Hoffmann 1888, 30 f.; Siebs 1900, 23, 26). Einfaches $<\ddot{o}>$ bzw. $<\ddot{u}>$ können je nach Position und folgenden Konsonanten entweder lang und gespannt oder kurz und ungespannt sein. Umfassende Regelungen sind Siebs (1900, 23 ff.) zu entnehmen. Darüber hinaus nennen Viëtor und Siebs weitere Grapheme, bei denen in Wörtern französischen Ursprungs entsprechende Vokale gesprochen werden müssten. So werde $<\mathrm{u}>$ in einigen Positionen als [y:] (Solitude) oder [y] (Budget), <eu> und <oeu> immer als [ $\phi:$ ] (adieu, Coeur) realisiert. Im Bereich der Ü-Vokale weisen Viëtor (ebd.), Hoffmann (ebd.) und Siebs (ebd.) auf die Realisation von schriftsprachlichem $<y>$ hin. Viëtor $(1885,12,15)$ nennt diese Schreibung sowohl für [y:] (Asyl) als auch für [Y] (Myrte) und verweist auf Wörter griechischen Ursprungs. Auch Hoffmann $(1888,31)$ nennt $<y>$ für beide Vokale, ohne, mit Ausnahme einiger Beispielwörter, darauf einzugehen, wann der lange und wann der kurze realisiert werden sollen.

\section{g) Diphthonge}

Heutiges Standarddeutsch enthält die drei Diphthonge [aع्]], [ån] und [oœ]. Jeder der zwei Laute eines Diphthongs ist kurz. Der jeweils erste Laut ist silbisch, der zweite unsilbisch. Der Übergang vom einen zum anderen geschieht mit abnehmender Intensität (vgl. Krech et al. 2010, 72 f.).

Die in der Fachliteratur dargestellten Diphthonge unterscheiden sich mehr oder weniger stark von denen des heutigen Standards, wobei sich auch Gemeinsamkeiten finden lassen. So weisen Viëtor $(1885,32)$ und Rocca $(1889,63)$ darauf hin, dass der erste Laut eines deutschen Diphthongs mehr Intensität und Quantität habe als der zweite. Insgesamt lassen sich die beschriebenen Diphthonge trotz der Unterschiede recht eindeutig ihren heutigen Pendants zuordnen: Die Entsprechungen des heutigen Diphthongs [aع्] beginnen bei allen Autoren mit einem AVokal (vgl. Benedix 1859, 16; Grabow 1875, 379; Hey 1882, 36; Viëtor 1885, 32; Rocca 1889, 59; Siebs 1900, 27). Bei fast keinem Autor scheint die Klangfarbe des A-Vokals getrübt zu sein, vielmehr sei er »neutral $[\ldots]$ « (Hey 1882, 36), »rein [...]« (Rocca 1889, 59) oder »hell [...] «(Siebs $1900,27)$. Lediglich Grabow $(1875,380)$ behauptet, keiner der Laute eines deutschen Diphthongs würde seine eigentliche Tonhöhe erreichen. Der zweite Laut ist bei fast jedem Autor ein anderer. Benedix $(1859,16)$ und Hey $(1882,35$ f.) unterscheiden der Schreibung nach verschiedene Laute. Benedix weist darauf hin, dass $<$ ei $>$ etwas heller klingen müsse als $<$ ai $>$. Laut Hey müsse $<$ ai $>$ mit einem I-Vokal mit geringster Rachenweite $(\rightarrow$ [ai $]$ ), $<$ ei $>$ hingegen mit einem EVokal realisiert werden $(\rightarrow[\mathrm{ae}])$. Bei Konsonantenanschluss sei der E-Vokal eher offen $(\rightarrow[a \varepsilon]])$. Laut Viëtor $(1885,32)$ und Rocca $(1889,59)$ ende der Diphthong auf einem offenen bzw. gedämpften I-Vokal ( $\rightarrow$ [aI] $)$. Viëtor weist zwar darauf hin, dass auch von guten Sprechern oft [aع्n] realisiert werde, [ai] sei jedoch zu bevorzugen. Laut Siebs $(1900,27)$ ende der Diphthong auf einem geschlossenen E-Vokal $(\rightarrow[\mathrm{a}]$ ]). Für die Schreibung der Diphthonge nennen alle Autoren $<$ ai> (Mai) und <ei> (Eier). Viëtor $(1885,32)$ und Siebs $(1900,27)$ argumentieren, dass der 
Diphthong bei einigen deutschen Eigennamen die Schreibungen <ay> (Bayern) oder <ey> (Meyer) haben könne, während er in englischen Lehnwörtern manchmal durch <i> (Strike) angezeigt werde.

Alle zitierten Autoren beschreiben je nur einen Diphthong, der dem heutigen [as] entspricht. Meist beginnt dieser mit einem A-Vokal (vgl. Benedix 1859, 15; Grabow 1875, 379; Viëtor 1885, 33), der »neutral [...]« (Hey 1882, 38) oder »hell [...]« (Siebs 1900, 28) sei. Anders bei Rocca $(1889,59)$ : Hier beginne der Diphthong mit einem offenen O-Vokal $(\rightarrow[0])$. Für Benedix (1859, $15)$, Grabow $(1875,379)$ und Hey $(1882,38)$ handele es sich beim zweiten Laut um einen UVokal (ob gespannt oder ungespannt, bleibt unklar). Viëtor $(1885,33)$ nennt ein offenes $U(\rightarrow$ [av]), das dem oft verwendeten offenen $\mathrm{O}(\rightarrow$ [ån]) vorzuziehen sei. Laut Rocca $(1889,59)$ sei der zweite Laut ein reines $U(\rightarrow[\underset{n}{u}])$, wodurch der Diphthong [ov ] entstehen würde. Siebs' (1900, 28) Diphthong endet hingegen auf einem geschlossenen $\mathrm{O}(\rightarrow[\mathrm{ao}])$. Bei der Schreibung des jeweiligen Diphthongs sind sich die Autoren einig: <au> (Auge). Lediglich Siebs (ebd.) weist darauf hin, dass auch bei <ou> in englischen Lehnwörtern der beschriebene Diphthong realisiert werden müsse (Stout).

Auch bei den Entsprechungen von heutigem [oœ] sind sich die zitierten Autoren in Bezug auf den ersten Laut einig. Grabow $(1875,380)$, Viëtor $(1885,34)$, Rocca $(1889,59)$ und Siebs $(1900$, 28) liefern Hinweise darauf, dass es sich hier um den offenen O-Vokal [o] handelt. Laut Hey $(1882,40)$ sei es ein etwas zurückverlagerter A-Vokal $(\rightarrow[\underline{a}]$ oder $[a])$, während der zweite Laut »ein zum Ü assonirendes I« werde. Gemeint ist hier, dass dieser zweite Laut sich zwischen I und $\ddot{U}$ bewege, in Abhängigkeit des nächsten Vokals oder folgenden Konsonanten. Eine konkrete Transkription kann hier nicht abgeleitet werden. Benedix $(1959,17)$ macht den Unterschied von hellem oder dunklem Charakter des Diphthongs von der Schreibung abhängig: heller bei <eu> (Feuer), dunkler bei <äu> (Räuber). Bei Grabow $(1875,380)$ und Rocca $(1889,59)$ handelt es sich beim zweiten Vokal um ein offenes Ü $(\rightarrow[\mathrm{oy}])$. Laut Viëtor $(1885,34)$ sei der zweite Laut ein offenes I $(\rightarrow[\supset \mathrm{I}]$ ), laut Siebs $(1900,28)$ ein geschlossenes Ö $(\rightarrow[\supset \emptyset])$. Die Autoren nennen für diesen Diphthong die Schreibungen <eu> (Heu) und <äu> (gläubig). Beide weisen noch auf das französische Wort Lieutenant hin, in dem <ieu> ebenfalls durch den beschriebenen Diphthong realisiert werden müsse.

\section{h) Vokaleinsatz}

Silbenanlautende Vokale, die im Stamm- oder Präfixanlaut stehen, beginnen in der heutigen deutschen Standardaussprache mit einem Glottisschlageinsatz (Glottisplosiv) (vgl. Krech et al. 2010, 52).

Der anlautende Glottisschlag wird auch im 19. Jahrhundert erwähnt. Er wird beschrieben als "ein den Verschluss im Kehlkopfe durchbrechender Luftstrom mit entsprechendem Geräusch « (Hoffmann 1888, 54), als »Kehlverschlusslaut « (Viëtor 1898, 18) oder als »feste[r] Stimmeinsatze« (Siebs 1900, 10). Laut Hey $(1882,121)$ sei ein »unvollkommener Glottisschluss« ebenso 
ein Fehler wie »überschüssig entweichende, sogenannte wilde Luft beim Vokaleinsatz«. Viëtor $(1898,18)$ und Siebs $(1900,10)$ weisen darauf hin, dass der beschriebene Ansatz nicht nur im Wortanlaut, sondern auch nach Vorsilben auftrete, genauer nach $\langle$ er- $>$, $\langle$ ver- $>,\langle$ be- $\rangle,\langle$ ge- $\rangle$ (erinnern, veralten, beerben, geekelt).

\section{i) Nasalität}

Zusätzlich zu den oralen Vokalphonemen kommen (hauptsächlich in aus dem Französischen stammenden Wörtern) im heutigen Aussprachestandard nasalierte Vokale vor. Diese sind: [ع:]

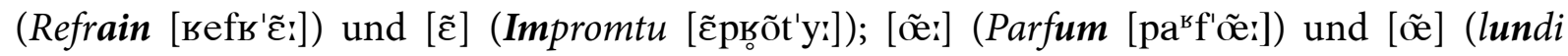

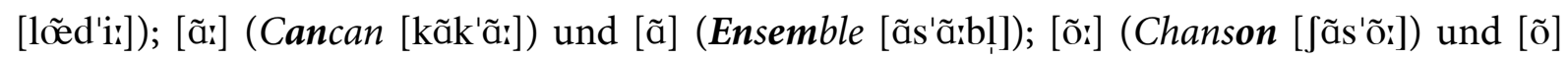
(Komtess [kõt'عs]). In einigen Fällen können diese aber auch durch Hinzufügen nasaler Konsonanten als nicht nasaliert realisiert werden (vgl. Krech et al. 2010, 70 ff.).

Die sich hierzu äußernden Autoren sind sich darüber einig, dass die deutschen Vokale bzw. Vokale in Wörtern deutschen Ursprungs nicht nasal seien (vgl. Hey 1882, 18; Viëtor 1885, 35; Rocca 1889, 56). Trotzdem seien Nasalvokale in Wörtern fremden Ursprungs existent und müssten nasal realisiert werden. »[S]prachlich nicht Gebildete« (Hoffmann 1888, 32) würden Nasalvokale durch die Verbindung vom rein oralen Vokal und einem weiteren Laut ersetzen, bei dem es sich wahrscheinlich um den postpalatal/velaren Nasalkonsonanten [y] handelt (Hoffmann nutzt hier eine sehr ähnliche Transkription). Aufmerksame Sprecher:innen würden eher den Nasalvokal verwenden (vgl. Viëtor 1885, 35). 


\subsection{Konsonanten}

Wie bei den Vokalen sollen auch die Konsonanten in Kategorien zusammengefasst und vergleichend betrachtet werden. Die Kategorien ergeben sich hier aus Artikulationsmodus (frikativ, plosiv, nasal, lateral) und Artikulationsstelle (labial, alveolar, präpalatal, palatal, velar, glottal). Davon wird nur abgewichen, wenn es Gemeinsamkeiten der Phonem-Graphem-Beziehungen einiger Laute nahelegen, sie trotz unterschiedlicher Artikulationsstelle zusammenzufassen, oder wenn aufgrund diverser Besonderheiten eine eigene Kategorie erstellt werden muss:

a) Labiale Frikative: /f/, /v/ oder [ $\beta]$,

b) Alveolare Frikative: /s/, /z/,

c) Präpalatale Frikative: $/ \int /, / 3 /$,

d) palatale Frikative: /ç/, /j/ und velarer Frikativ: /x/,

e) das R: /в/, /r/ oder /R/,

f) Glottaler Frikativ: /h/,

g) Labiale Plosive: /p/, /b/,

h) Alveolare Plosive: /t/, /d/,

i) Velare Plosive: $/ \mathrm{k} /, \mathrm{g} /$,

j) Nasale: $/ \mathrm{m} /, / \mathrm{n} /, / \mathrm{h} /$,

k) Lateral: /1/,

l) Aussprache von $<\mathrm{g}>$.

Die letzte Kategorie wurde eingefügt, da die Aussprache des schriftsprachlichen $<$ g $>$ in den verschiedenen Positionen wohl den größten Streitpunkt im Bereich der Konsonanten des 19. Jahrhunderts darstellt.

\section{a) Labiale Frikative}

Das heutige Standarddeutsch enthält die labialen frikativen Konsonantenphoneme /f/ (fortis) und /v/ (lenis) (vgl. Krech et al. 2010, 29). Der Fortisfrikativ ist stimmlos, der Lenisfrikativ stimmhaft. Beide werden labio-dental, also durch eine Enge zwischen Unterlippe und oberen Schneidezähnen gebildet. Darüber hinaus kann nach stimmlosen Konsonanten ein entstimmlichtes [v] auftreten (Hausvisite [h'aọsvizi,itə]) (vgl. ebd. 79).

In der Literatur des 19. Jahrhunderts werden meist zwei labio-dentale Konsonanten beschrieben, von denen einer stimmlos und der andere stimmhaft ist (vgl. Benedix 1859, 25; Grabow 1877a, 48; Viëtor 1885, 39; Hoffmann 1888, 34; Siebs 1900, 34 f.). Die beschriebenen Laute werden hier durch die IPA-Zeichen [f] und [v] dargestellt. Zusätzlich beschreiben Grabow, Viëtor und Hoffmann (ebd.) aber noch einen bilabialen Laut, für den im Folgenden das IPAZeichen $[\beta]$ verwendet werden soll. Dieser werde laut Viëtor und Hoffmann vornehmlich in Süddeutschland verwendet, laut Grabow müsse er immer in den Verbindungen <qu> (quer) und $<$ schw $>$ (schwer) auftreten. In diesen Verbindungen finde der Konsonant laut Viëtor auch 
in Norddeutschland Verwendung, verliere jedoch durch die vorhergehenden stimmlosen Konsonanten seine Stimmhaftigkeit $\left(\rightarrow\left[\beta_{0}\right]\right)$.

Die Phonem-Graphem-Beziehung ist recht eindeutig. In deutschen Wörtern werde bei $<\mathrm{f}>,<\mathrm{ff}>$ und $<\mathrm{v}>$ der Fortisfrikativ [f] gesprochen (vgl. Siebs 1900, 34). Ebenso werde [f] bei $<\mathrm{ph}>$ in griechischen Wörtern realisiert (vgl. Viëtor 1885, 39). Der Lenisfrikativ [v] werde immer bei $<$ W $>$ oder in vielen Wörtern fremden Ursprungs auch bei $<\mathrm{v}>$ realisiert (z. B. Vasall, Vokal). Lediglich bei den oben genannten Verbindungen $<$ qu $>$ und $<$ schw $>$ oder auch bei $<$ zv $>$ werden unterschiedliche Empfehlungen gegeben. Siebs (1900, 35) empfiehlt stimmhaftes (also nicht wie heute entstimmlichtes) [v] zu nutzen: [kv] (Qual); [Jv] (schwarz); [tsv] (zwei). Grabow (1877a, 48) empfiehlt bei <qu> einen bilabialen Laut: [k $\beta]$ (quer). Viëtor $(1885,39$ f.) empfiehlt bei <qu> eigentlich $[\mathrm{kv}](\mathbf{Q u a l})$, weist aber auf die weit verbreitete Form $\left[\mathrm{k} \beta_{0}\right]$ hin, ohne sie als unangemessen zu bezeichnen.

\section{b) Alveolare Frikative}

Die heutige Standardaussprache enthält die alveolaren frikativen Konsonantenphoneme /s/ (fortis) und /z/ (lenis) (vgl. Krech et al. 2010, 29). Der Fortisfrikativ ist stimmlos, der Lenisfrikativ stimmhaft. Sie werden durch eine Enge zwischen oberem Zahndamm und Zunge gebildet. Dabei kann bei apikaler Bildung die Zungenspitze oder bei dorsaler Bildung der Zungenrücken verwendet werden (vgl. ebd. 79 f.). Darüber hinaus kann nach stimmlosen Konsonanten ein entstimmlichtes [z] auftreten (ratsam [в'a:tza:m]) (vgl. ebd. 81).

In der untersuchten Literatur wurden keine Abweichungen vom heutigen Aussprachestandard entdeckt. Hey $(1882,78)$, Viëtor $(1885,42)$ und Hoffmann $(1888,36)$ beschreiben eine schmale Rinne zwischen Zungenrücken und Gaumen, die den Luftstrom an die oberen Schneidezähne führe. Ein vorderer Teil der Zunge befinde sich dabei an den Alveolen. Laut Hoffmann könne dies der Vorderzungenrücken oder die Zungenspitze sein. Laut Hey sei die Zungenspitze nach unten gesenkt. Während Hoffmann also sowohl die dorsale als auch die apikale Bildung von [s] bzw. [z] anerkennt, beschreibt Hey ausschließlich die dorsale. Für stimmloses [s] werden folgende Grapheme angegeben: $<\mathrm{s}>($ Hals $),<\mathrm{ss}>$ (flüssig), $<\mathrm{fs}>(\mathrm{Ma} / \mathrm{s} s),<\mathrm{st}>($ rasten $),<\mathrm{ts}>($ Rätsel), $<\mathrm{sp}>$ (raspeln), $<\mathrm{z}>$ (ziehen), $<\mathrm{tz}>$ (Witz), $<\mathrm{x}>$ (Axt) (vgl. Siebs 1900, 35). Viëtor $(1885,43)$ ergänzt hier $<\mathrm{c}>$ und $<c ̧>$ in französischen Wörtern (Annonce, Façon) und $<\mathrm{t}>$ vor nicht akzentuiertem I-Vokal (Nation). Stimmhaftes [z] werde gesprochen bei $<\mathrm{s}>$ im Anlaut vor Vokalen (sehen), im Inlaut zwischen Vokalen (Rasen) oder zwischen $<\mathrm{m}, \mathrm{n}, \mathrm{l}, \mathrm{r}>$ und Vokal (emsig) (vgl. Schmolke 1890, 17 f.; Siebs 1900, 36 f.). Die Phonem-Graphem-Beziehung unterscheidet sich also kaum vom heutigen Standard. Auffällig ist die Existenz des heute selten verwendeten langen $\mathrm{S}<\mathrm{f}>$ (als Gegenstück zum runden $\mathrm{S}<\mathrm{s}>$ ), das vornehmlich, aber nicht ausschließlich, in gebrochenen Schriftarten zu finden ist (s. Benedix 1859; Michaelis 1862). Hoffmann $(1888,36)$ nennt außerdem das später weiter verbreitete Graphem $<ß>(M u ß e)$. In verschiedenen Texten 
des 19. Jahrhunderts sind also unterschiedliche Konventionen $\mathrm{zu}$ finden: nur rundes S; rundes und langes $S$ (Letzteres vermehrt in gebrochenen Schriftarten); rundes $S$ und $<\beta>$.

\section{c) Präpalatale Frikative}

Die gegenwärtige deutsche Standardaussprache enthält das Konsonantenphonem / $/$. Es handelt sich dabei um einen präpalatalen stimmlosen Fortisfrikativ mit zusätzlicher Lippenrundung. Der entsprechende stimmhafte Lenisfrikativ /3/ wird nur in Wörtern fremdsprachlichen Ursprungs verwendet (Garage [gав'a:3ə]). Darüber hinaus kann nach stimmlosen Konsonanten

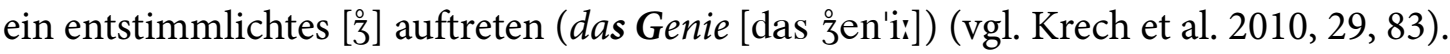

Im 19. Jahrhundert existierten vergleichbare stimmlose und stimmhafte Laute. Grabow (1877a, 47) und Hoffmann $(1888,37)$ beschreiben eine breitere Zungenrinne als beim [s], die bei dorsaler Bildung durch leichtes Anheben bzw. bei apikaler Bildung durch Zurückziehen der Zungenspitze entstehe. Zusätzlich werde das entstehende Geräusch durch Lippenrundung verstärkt. Viëtor $(1885,44)$ beschreibt ebenfalls eine Lippenrundung, jedoch werde der Frikativ ohne relevante Zungenbeteiligung artikuliert. Das nötige Geräusch entstehe nur zwischen den oberen und unteren Zähnen. Der Fortiskonsonant [ $\left.\int\right]$ könne durch diverse Grapheme und Graphemkombinationen dargestellt werden: $<$ sch $>$ (schade), außer in Diminutivformen mit -chen (Mäuschen, Hänschen); $<\mathrm{s}>$ im Anlaut vor $<\mathrm{p}>$ und $<\mathrm{t}>$ (spielen, sprechen); $<\mathrm{ch}>$ in französischen Wörtern (Chaise); $<\mathrm{c}>$ in italienischen Wörtern, wobei hier [t $\mathrm{t}]$ realisiert werde (Cicerone). Der Leniskonsonant [3] trete nur in fremdsprachlichen Wörtern auf: bei $\langle j\rangle$ oder $\langle\mathrm{g}\rangle$ in französischen Wörtern (Jalousie, Genie); bei $<j>$ in englischen Wörtern, wobei hier [d3] realisiert werde (Jockey) (vgl. Viëtor 1885, 47; Hoffmann 1888, 37; Siebs 1900, 37 f.). Einige Autoren weisen darauf hin, dass in nordwestdeutschen Regionen $<$ s $>$ im Anlaut vor $<\mathrm{p}>$ und $<\mathrm{t}>$ (sprechen, stehen) als [s] realisiert werde. Die Genauigkeit, mit der sich die Autoren diesem Phänomen widmen, lässt vermuten, dass die Richtigkeit im 19. Jahrhundert durchaus strittig war. Die Autoren, die sich damit auseinandersetzten, empfehlen jedoch in diesen Positionen das weiter verbreitetere [J] zu verwenden (vgl. Diederichs 1884, 29; Hey 1882, 84 f., Viëtor 1885, 45 f.).

\section{d) Palatale Frikative}

Heutiges Standarddeutsch enthält die Konsonantenphoneme /ç/ (fortis) und / $\mathrm{j} /$ (lenis). Der Fortiskonsonant ist stimmlos, der Leniskonsonant stimmhaft. Letzterer kann bei vorhergehendem Fortiskonsonanten entstimmlicht werden (z. B. Schaltjahr [ ['altja: $\left.{ }^{\mathrm{B}}\right]$ ). Es handelt sich um dorsal-palatale Frikative (vgl. Krech et al. 2010, 29, 83 f.). Zusätzlich soll hier das Konsonanten-

phonem /x/ verglichen werden, da es sich mit /ç/ die Schreibung <ch > teilt. Es geht hier um einen dorsal-velaren Frikativ (vgl. ebd. 84). 
Erneut lassen sich in der früheren Fachliteratur vergleichbare Laute finden. Die Autoren beziehen sich bei den Äquivalenten zu [ç] und [j] auf die ähnlich dem [i] gewölbte Zunge bzw. die Rinne zwischen mittlerem Zungenrücken und hartem Gaumen (vgl. Michaelis 1862, 27 f., Hey 1882, 74, 76; Viëtor 1885, 52, 54; Hoffmann 1888, 38). Das [x] werde mit einer stark gewölbten, dem [u] ähnlichen Zunge am weichen Gaumen (vgl. Viëtor 1885, 56; Hoffmann 1888, 38) oder ähnlich einem [k] mit kleiner Öffnung (vgl. Michaelis 1862, 27) gebildet.

Wie erwähnt, kann $<\mathrm{ch}>$ u. a. durch $[\mathrm{ç}]$ oder $[\mathrm{x}]$ realisiert werden. Ausschlaggebend ist die Umgebung. [ç] werde realisiert bei <ch>: nach <e, i, ä, ö, ü, ai, ei, äu, eu> (ich, Gespräch, Eiche); nach <l, r, n> (Molch, Storch, Mönch); in der Endung -chen (Mäuschen). [x] werde realisiert bei $<\mathrm{ch}>$ nach <a, o, u, au> (Bach, Loch, Buch, Bauch) (vgl. Michaelis 1862, 30; Grabow 1877c, 351; Hoffmann 1888, 38; Siebs 1900, 40). Oder etwas knapper nach Viëtors $(1885,53,56)$ phonetischer Regelung: [ç] bei $<\mathrm{ch}>$ nach Vorderzungenvokalen und Konsonanten; $[\mathrm{x}]$ bei $<\mathrm{ch}>$ nach Hinterzungenvokalen. Für $<\mathrm{ch}>$ in fremden Wörtern (außer z. B. in französischen oder englischen) würden laut Siebs meist die gleichen Regeln gelten. Im Anlaut fremder Wörter werde $<\mathrm{ch}>$ zwar meist als [k] realisiert (Charakter, Chronik), in einigen Fällen aber auch als [ç] (Chemie, Cherub, China, Chirurgie) (vgl. Grabow 1877, 352c; Siebs 1900, 41). Einige Wörter sind strittig. So werde Chaos laut Grabow mit [ç], laut Siebs aber mit [k] realisiert. Der Lenisfrikativ [j] werde realisiert bei $<\mathrm{j}>(\mathrm{j} a$, Major) und $<\mathrm{y}>$ in einigen fremden Wörtern (Yukata, loyal) (vgl. Viëtor 1885, 54; Hoffmann 1888, 39; Siebs 1900, 41). Darüber hinaus müsse <g > in bestimmten Positionen durch [ç] oder [j] realisiert werden, z. B. [ç] in Berg (vgl. Viëtor 1885, 53) oder [j] in ew'ge (vgl. Siebs 1900, 41). Da die Aussprache von $<\mathrm{g}>$ aber insgesamt strittig ist, wird sie weiter unten in einem gesonderten Absatz behandelt.

\section{e) Das R}

Bezüglich des R existierten im 19. Jahrhundert diverse Abweichungen von der heutigen Standardaussprache. Deshalb kann hier nicht ex ante ein gegenwärtiger Laut zugeordnet werden. Das Deutsche Aussprachewörterbuch (Krech et al. 2010, 85) empfiehlt, bei konsonantischem R das Reibe-R /в/ bzw. an entsprechender Position das reduzierte [ $\left.{ }^{ }\right]$zu verwenden, da dies die heute vorherrschende Form darstelle. Es handelt sich um einen dorsal-velaren Lenis-Frikativ, also um das stimmhafte Gegenstück zu /x/. Für vokalisches R wird in den Affixen <er-, -er> [e] und in nichtsilbischer Position $\left.{ }^{[}{ }^{\mathrm{B}}\right]$ empfohlen (vgl. ebd. 58 ff.). Trotzdem wird auch heute, besonders auf der Bühne und im klassischen Gesang, das Zungenspitzen- oder Zäpfchen-R verwendet. Das Zungenspitzen-R [r] ist ein apikal-alveolarer Vibrant, das Zäpfchen-R [R] ein uvularer Vibrant (vgl. ebd. 86).

Diverse Autoren beschreiben einen stimmhaften velaren Frikativ $(\rightarrow[\mathrm{b}])$, so z. B. Grabow (1877a, 50), der einen stimmhaften, gleichbleibenden Laut nennt, welcher bei Artikulationsstellung von $[\mathrm{x}]$ entstehe. Allerdings finde dieses [в] nur Anwendung für $\langle$ g $>$ nach $<$ a, o, u, au $>$ (sagen, Bogen, schlugen, Augen) und nie bei $<\mathrm{r}>$. Ansonsten geht Grabow mit allen anderen 
Autoren konform, dass der richtige zu verwendende R-Laut nur das vibrierende ZungenspitzenR [r] sein könne (vgl. Grabow 1877a, 54; Hey 1882, 66; Viëtor 1885, 48; Siebs 1900, 31). Lediglich Hoffmann $(1888,40)$ erkennt das Zäpfchen- $R$ [R] neben dem Zungenspitzen- $R$ [r] als legitime Form an. Viëtor $(1885,48)$ weist auf die zunehmende Verbreitung des [R] hin, betont aber trotzdem, dass für Kunstgesang und Bühnensprache nur [r] empfohlen werden könne.

Die Schreibung des R wird einheitlich folgendermaßen angegeben: $<\mathrm{r}>$ (schwer), $<\mathrm{rr}>$ (Narr), $<$ rh $>$ (Rhein), <rrh> (Pyrrhus) (vgl. Viëtor 1885, 48; Hoffmann 1888, 41; Siebs 1900, 31). Die Vokalisierung des R in nicht akzentuierten Silben (z. B. <-er>) sei zwar durchaus bei deutschen Sprechern zu hören, dürfe aber noch nicht als korrekt bezeichnet werden (vgl. Viëtor 1885, 48). Laut Siebs $(1900,16,31)$ dürfe der R-Laut nicht vermindert werden (das [r] in schwer oder Narr sei also genauso auszusprechen wie in Rhein). Außerdem dürfe das [r] nicht durch Elision des

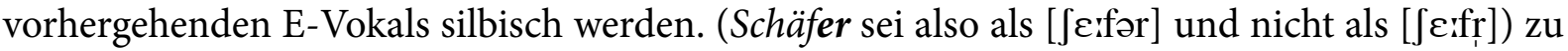
realisieren). Diese Regelungen können als Hinweise dafür genommen werden, dass die bemängelten Ausspracheformen im 19. Jahrhundert auf Bühnen zu hören waren, aber eben von den zitierten Autoren nicht als angemessen empfunden wurden.

\section{f) Glottaler Frikativ}

Das leichte, meist stimmlose Hauchgeräusch des glottalen Frikativs [h] wird bei ausströmender Luft im Kehlkopf erzeugt. Das entsprechende Graphem $<$ h $>$ kommt im Schriftbild zwar häufig vor, wird im heutigen Aussprachestandard aber durch $[\mathrm{h}]$ nur im Silbenanlaut vor Vokalen realisiert (Hand, human), außer vor [ə] und nicht akzentuiertem $<\mathrm{u}, \mathrm{i}>$ in Suffixen (Mühe, fähig, Begehung). Sonst ist $<\mathrm{h}>$ stumm (vgl. Krech et al. 2010, 88).

Der Laut wird in der Fachliteratur des 19. Jahrhunderts unterschiedlich beschrieben, das lautliche Ergebnis dürfte aber immer ähnlich sein. So sei der Laut ein »Lungenhauchlaut « (Grabow 1877a, 52), ein »stimmloses Hauchgeräusch « (Schmolke, 1890, 31), ein stimmloser Vokal (vgl. Hoffmann 1888, 32), der aber ein konsonantisches Geräusch erzeuge (vgl. Viëtor 1885, 56), oder einfach eine "gesteigerte, entweder ruhige oder stossweise Ausathmung (Hey 1882, 111).

Auch die Phonem-Graphem-Beziehung betreffend, versuchen die Autoren Regelhaftigkeiten zu beschreiben, die fast alle auf das gleiche Ergebnis zielen: die heutige Ausspracheregelung. Die Ausnahme stellt Grabow (1877a, 53) dar, der behauptet, das [h] sei in Haar deutlich zu hören, in nahe weniger deutlich und in gedeihn fast gar nicht. Den anderen Autoren zufolge müssten die letzten beiden Wörter jedoch überhaupt kein [h] enthalten. Hey $(1882,112)$, Viëtor $(1885$, 58) und Hoffmann $(1888,33)$ sind sich darüber einig, dass $[\mathrm{h}]$ nur in Verbindung von $<\mathrm{h}>$ mit folgendem Vokal auftreten könne, wobei lediglich Hey auf die Einhaltung der richtigen Silbengrenze verweist. Laut Siebs $(1900,33)$ könne $[\mathrm{h}]$ darüber hinaus nur vor »vollstimmigem Vokal « und laut Hoffmann $(1888,33)$ nur vor Vokalen auftreten, die entweder Haupt- oder Nebenakzent tragen. Vermutlich ist damit gemeint, dass $\langle\mathrm{h}>$ vor nicht akzentuierten Vokalen (z. B. [ə]) nicht realisiert werde, quasi stumm sei (ruhig, sehen, Ehe). Laut Schmolke (1890, 31 f.) 
werde $<$ h $>$ nur im Wortanlaut (habe, Hunger), in der Silbe $<$-heit $>$ (Gescheitheit) und im Anlaut von Zusammensetzungen (anderthalb) als [h] realisiert. Im In- und Auslaut sei es stumm (gedeihen, weiht, roh, Kuheuter). Schließlich wurde innerhalb der verwendeten Literatur (von Grabow 1877a abgesehen) kein Beispiel dafür gefunden, das die Realisation von $<\mathrm{h}>+$ Vokal von der heutigen Aussprache abweicht. Darüber hinaus gebe es etablierte Schreibungen, die ein $<\mathrm{h}>$ beinhalteten, das unabhängig von der Position entweder stumm sei oder in Kombination mit weiteren Graphemen anderweitig realisiert werde. Dazu gehören: $<$ th $>$ (Mathilde, Walther, Thee); <rh> (Rhein, Rhone); <ch> (Molch, Chaos) (vgl. Grabow 1877b, 422; Viëtor 1885, 76; Schmolke 1890, 32; Siebs 1900, 43).

\section{g) Labiale Plosive}

Heutiges Standarddeutsch enthält die Konsonantenphoneme /p/ (fortis) und /b/ (lenis). Der Fortiskonsonant ist stimmlos, der Leniskonsonant stimmhaft. Es handelt sich um bilabiale Plosive. Sie werden oral gesprengt (Wespe [v'espe]) oder nasal, wenn ihnen ein silbisches [m] folgt (z. B. haben [h'a:bm]). Der Fortisplosiv [p] kann bei oraler Sprengung aspiriert sein. Der Lenisplosiv [b] kann bei vorhergehendem Fortiskonsonanten stimmlos sein (Bassbariton [b'asba:sit,on]) (vgl. Krech et al. 2010, 29, 89).

Im 19. Jahrhundert scheinen die beiden entsprechenden labialen Plosive in Bildung und Verwendung weitestgehend mit den heutigen übereinzustimmen. Sie werden meist als Verschlusslaute bezeichnet, wobei [p] stimmlos und aspiriert, [b] stimmhaft und mit weniger Kraft gebildet werden solle (vgl. Grabow 1877a, 43; Hey 1882, 117; Viëtor 1885, 37 f.; Hoffmann 1888, 43 f.; Siebs 1900, 44 f.). Viëtor (ebd. 37) behauptet als einziger der Autoren, dass bei [pf] (Apfel) beide Laute labiodental gebildet würden, also [p] regressiv assimiliert werde. Hoffmann (ebd. 43) bezeichnet diese Aussage Viëtors jedoch als falsch. Die Möglichkeit der nasalen Sprengung wird von keinem der Autoren erwähnt. Wie die Sprengung der Plosive bei folgenden Nasalen verläuft, bleibt damit unklar (haben bei Schwa-Elision, abnehmen). Die Autoren sind sich auch weitestgehend darüber einig, dass der Fortisplosiv [p] bei $<\mathrm{p}>$ oder $<\mathrm{pp}>(\boldsymbol{P} a a r, k n a p \boldsymbol{p})$ und der Lenisplosiv [b] bei $\langle\mathrm{b}\rangle$ im Anlaut $(\boldsymbol{B} \ddot{a} r)$ oder $\langle\mathrm{bb}\rangle($ Eb b $e$ ) realisiert werden. Im Silbenauslaut werde $<\mathrm{b}>$ in der Regel als [p] realisiert (vgl. Grabow 1877b, 413 ff.; Viëtor 1885, 37; Hoffmann 1888, 44; Schmolke 1890, 22). Laut Siebs werde $<$ b $>$ im In- oder Auslaut nach langem Vokal oder nach kurzem Vokal und $<\mathrm{l}, \mathrm{r}>$ als [p] ausgesprochen (Grab, gabst, herb, halb). Laut Schmolke $(1890,22)$ gelte $<$ b $>$ bei Vokalschwund vor $<1, n, r>$ nicht als Auslaut und werde demnach als [b] realisiert (nebelig $\rightarrow$ neblig; Schnäbelein $\rightarrow$ Schnäblein). Die Aussagen der Autoren stimmen mit der heutigen Aussprache überein. Es sei jedoch darauf hingewiesen, dass laut Grabow (1877b, 416 f.) einige Sprecher:innen fälschlicherweise versuchen würden, auslautendes $<$ b $>$ stimmhaft als [b] zu realisieren. Tatsächlich empfiehlt z. B. Benedix $(1859,21)$ genau diese Form. Die meisten Autoren bevorzugen jedoch die Auslautverhärtung. 


\section{h) Alveolare Plosive}

Das heutige Standarddeutsch enthält die Konsonantenphoneme /t/ (fortis) und /d/ (lenis). Der Fortiskonsonant ist stimmlos, der Leniskonsonant stimmhaft. Es handelt sich um alveolar/dentale Plosive. Der Verschluss wird entweder koronal-alveolar/dental (vorderer Zungensaum an Alveolen und oberen Schneidezähnen) oder dorsal-alveolar/dental (Vorderzungenrücken an Alveolen und oberen Schneidezähnen, vorderer Zungensaum an unteren Schneidezähnen) gebildet. Die Plosive können auf dreierlei Art gesprengt werden: oral, wobei [t] aspiriert sein kann ( Wut [vu:t]); nasal, bei folgendem silbischen [n] (Schatten [ ['atn]); lateral, bei folgendem [1] oder silbischem [1] (entlang [entl'aj], Wandel [v'andl]). Der Lenisplosiv [d] kann bei vorher-

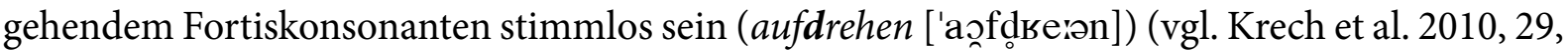
$90 \mathrm{ff}$.$) .$

Auch bei den alveolaren Plosiven verhält es sich ähnlich wie heute: So handele es sich hier um an Schneidezähnen und Alveolen gebildete Verschlusslaute, wobei [t] stimmlos und aspiriert, [d] hingegen stimmhaft sei (vgl. Grabow 1877a, 43; Hey 1882, 114; Viëtor 1885, 40 f.; Hoffmann 1888, 44 f.; Siebs 1900, 45). Viëtor weist darauf hin, dass die Laute mit Zungenspitze oder vorderem Zungenrücken gebildet werden können. Auch bei den alveolaren Plosiven wurden keine Aussagen zu nasaler oder lateraler Sprengung gefunden. Siebs betont aber, dass $[\mathrm{t}]$ immer aspiriert sein müsse. Demnach werde wahrscheinlich unabhängig von folgenden Konsonanten nur die orale Sprengung akzeptiert. Der Fortisplosiv [t] werde realisiert bei $\langle\mathrm{t}\rangle$ (teilen), $<\mathrm{tt}\rangle$ (Ratte), $<$ th $>$ (thun) oder $<\mathrm{dt}>($ Stadt). Ebenso käme [t] zusammen mit [s] in [ts] vor bei $<\mathrm{z}>($ Zahl), $<\mathrm{tz}>$ (setzen) oder $\langle\mathrm{c}>$ in einigen fremden Wörtern und Namen (Cäsar). Der Lenisplosiv [d] werde realisiert bei $<\mathrm{d}>$ im Anlaut (Dame) oder $<\mathrm{dd}>$ (Widder) (vgl. Grabow 1877b, 422 ff.; Viëtor 1885, 41 f.; Hoffmann 1888, 45; Siebs 1900, 45). Die Auslautverhärtung von <d $>$ zu [t] verhält sich wie die von $<\mathrm{b}>\mathrm{zu}[\mathrm{p}]$. Demnach sind bei den Phonem-Graphem-Beziehungen von /t/ und /d/ im Vergleich zum heutigen Aussprachestandard keine auffälligen Abweichungen zu verzeichnen.

\section{i) Velare Plosive}

Das heutige Standarddeutsch enthält die Konsonantenphoneme /k/ (fortis) und /g/ (lenis). Der Fortiskonsonant ist stimmlos, der Leniskonsonant stimmhaft. Es handelt sich je nach Lautumgebung um Plosive, die dorsal-postpalatal (Zungenrücken und hinterer harter Gaumen) oder dorsal-velar (Zungenrücken und weicher Gaumen) gebildet werden. Die Plosive werden entweder oral gesprengt, wobei $[\mathrm{k}]$ aspiriert sein kann (kalt [kalt]), oder bei folgendem silbischen [’ं] nasal gesprengt (sagen [z'a:gì]). Der Lenisplosiv [g] kann bei vorhergehendem Fortiskonsonanten stimmlos sein (abgießen ['apg̊i sn]) (vgl. Krech et al. 2010, 29, 92 ff.).

Auch in diesem Fall decken sich die Beschreibungen mit heutigen Anforderungen: Es handele sich um Verschlusslaute, die je nach lautlicher Umgebung (z. B. Vorder- oder Hinterzungenvokale) am harten oder weichen Gaumen gebildet werden (vgl. Grabow 1877c, 348; Jung 1879, 
306; Viëtor 1885, 50 f.; Hoffmann 1888, 45). Der Fortisplosiv [k] sei laut Siebs $(1900,46)$ immer gehaucht, was erneut auf eine ausschließlich orale Sprengung hinweist. Hoffmann (1888) behauptet jedoch, dass bei der Verbindung von [k] und [n] sowie [g] und [n] »keine Lösung des Mundverschlusses « (ebd. 46) stattfinde. Wann dies eintrete, bleibt offen. Hoffmann empfiehlt keine Schwa-Elision, die eine solche Verbindung ermöglichen würde (vgl. ebd. 31), und er gibt keine Wortbeispiele, die das obige Zitat veranschaulichen könnten.

Der Fortisplosiv [k] werde realisiert bei: $\langle\mathrm{k}>$ (kalt); $<\mathrm{ck}>$ (lecken); $<$ chs $>$ oder $<\mathrm{x}>$ als $[\mathrm{ks}]$ (sechs, Axt); <qu> als [kv] (quälen) (vgl. Viëtor 1885, 50 f.; Hoffmann 1888, 46; Siebs 1900, 46). Viëtor und Hoffmann nennen darüber hinaus weitere Schreibungen, zum Teil in fremdsprachlichen Wörtern, die durch [k] realisiert würden: $<\mathrm{ch}>$ (Chor); $\langle\mathrm{c}\rangle$ (Cognac); $\langle\mathrm{cc}\rangle$ (Accord); $<$ gs $>$ als [ks] (flugs); <gg > im Auslaut (Brigg). Der Lenisplosiv [g] werde bei $<$ g $>$ im Anlaut oder $<$ gg > im Inlaut realisiert (geben, Flagge) (vgl. Grabow 1877c, 348 f.; Viëtor 1885, 51; Hoffmann 1888, 46; Schmolke 1890, 23; Siebs 1900, 46). Laut Schmolke werde $<$ g $>$ (analog zu $<$ b $>$ und $<\mathrm{d}>$ ) bei Vokalschwund vor $<\mathrm{l}, \mathrm{n}, \mathrm{r}>$ als Lenisplosiv [g] realisiert, obwohl es nun scheinbar im Silbenauslaut steht (hügelig $\rightarrow$ hüglig; ebenso Vöglein, Segler, Gegner). Die Aussprache von $<\mathrm{g}>$ in allen anderen Positionen ist strittig und wird noch gesondert behandelt.

\section{j) Nasale}

Der gegenwärtige deutsche Aussprachestandard beinhaltet drei nasale Konsonantenphoneme: den bilabialen Nasal /m/; den koronal/dorsal-alveolaren Nasal /n/ (vorderer Zungensaum oder Vorderzungenrücken an den Alveolen); den dorsal-postpalatal/velaren Nasal/y/ (Artikulationsstelle variiert je nach Lautumgebung). Die Nasale sind stimmhaft und können jeweils auch silbisch auftreten: haben [h'a:bm]; raten [в'a:tn]; biegen [b'ign'] (vgl. Krech et al. 2010, 29, 95 ff.).

Bezüglich der Aussprache der Nasale gibt es für das 19. Jahrhundert kaum Auffälligkeiten zu verzeichnen. Es handle sich eindeutig um Nasale, bei denen der Mundraum durch die Lippen (bei [m]), durch [t]-Stellung der Zunge (bei [n]) oder durch [k]-Stellung der Zunge (bei [n]) abgeschlossen sei (vgl. Grabow 1877a, 51; Viëtor 1885, 38, 41, 52; Hoffmann 1888, 47 f.; Siebs 1900, 32 f.). Grabow weist auch auf die je nach Lautumgebung variierende Artikulationsstelle von [n] hin. Laut Siebs dürften die Nasale jedoch nicht silbisch sein oder assimiliert werden (graben nicht mit [m], lecken nicht mit [ì], jedoch bei Siebs anders transkribiert).

Nur zwei Autoren geben die Schreibung von [m] und [n] an, sodass sich vermuten lässt, dass sie so unstrittig war, dass die meisten Autoren es nicht für nötig befanden, überhaupt auf sie zu rekurrieren. Demnach werde $[\mathrm{m}]$ gesprochen bei $<\mathrm{m}>$ (mir) oder $<\mathrm{mm}>$ (Lamm); [n] werde gesprochen bei <n> (nie) oder <nn> (Mann) (vgl. Viëtor 1885, 38, 42; Hoffmann 1888, 47 f.). Zur Schreibung von $[\eta]$ äußern sich jedoch mehrere der Autoren. Hier wird beinahe einheitlich $<$ ng $>$ angegeben (lang, singen, Engel). Treffen jedoch $<\mathrm{n}>$ und $<\mathrm{g}>$ wegen einer Zusammensetzung aufeinander (Angesicht, eingehen), müsse [ng] (anstatt [n]) realisiert werden (vgl. Diederichs 1884, 30). Bei <nk> werde [ฤk] realisiert (Dank, links, Anker) (vgl. Diederichs 1884, 
30; Viëtor 1885, 52; Hoffmann 1888, 48; Siebs 1900, 33). Schmolke (1890, 35) behauptet als einziger, dass auslautendes $<\mathrm{ng}>$ ebenfalls als [ $\mathrm{\eta k}$ ] realisiert werden müsse (sang, Ding). Strittig ist auch die Aussprache von <gn> (Agnes, Magnet). Während Viëtor $(1885,52)$ und Hoffmann $(1888,48)$ hier [y] empfehlen, warnt Siebs $(1900,33)$ vor dieser Aussprache und empfiehlt [gn].

\section{k) Lateral}

Es handelt sich hierbei um einen stimmhaften koronal-alveolaren Lateral. Es legen sich also Zungenspitze oder vorderer Zungensaum an die Alveolen der oberen Schneidezähne an, wobei die Luft seitlich an den Zungenrändern vorbeiströmt. Der Laut kann auch silbisch auftreten

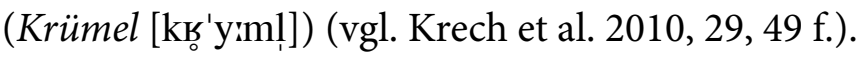

In der Fachliteratur des 19. Jahrhunderts sind keine Abweichungen zu Bildung oder Schreibung von [1] zu finden. Verwiesen sei jedoch darauf, dass bei nicht vorhandener Schwa-Elision kein silbisches [1] auftreten kann.

\section{l) Aussprache von $\langle g\rangle$}

Im gegenwärtigen Aussprachestandard können bei $<\mathrm{g}>$ in deutschen Wörtern die folgenden vier Laute gesprochen werden: [g], [k], [̊̊g] , [ç]. Im Wort- und Silbenanlaut vor Vokalen und stimmhaften Konsonanten wird [g] realisiert (Galle [g'alə], begreifen [bəgь'aع̨fn]). Im Silbenauslaut bei folgendem zum Stamm gehörenden $<1, n, r>$ (Schmuggler [ [m'vgle], aneignen ['an'açgnən]) sowie bei Nebenformen mit entfallenem $<\mathrm{e}>($ segele $\rightarrow$ segle [z'e:glə], baggere $\rightarrow$ baggre [b'agьə]) wird ebenfalls [g] realisiert. Ansonsten wird im Wort- und Silbenauslaut [k] gesprochen (Weg [ve:k], biegsam [b'ikza:m]), auch im gedeckten Auslaut (magst [ma:kst]). Nach stimmlosen Konsonanten wird $<\mathrm{g}>$ im Silbenanlaut als entstimmlichtes [̊ํ] realisiert (Aufgabe ['aoffg̊a:bə]) (vgl. Krech et al. 2010, 93 f.). Lediglich in der Silbe <-ig $>$ wird $<$ g $>$ als [ç] realisiert (ewig ['erviç], König [k' $\phi$ :niç]). Folgt <-ig > jedoch <-lich > oder eine auf [ç] endende Silbe, wird < g > als [k] gesprochen (ewiglich ['e:viklıç], Königreich [k'ф:nıkı̋ą̧ç]) (vgl. ebd. 84).

Im 19. Jahrhundert war die Aussprache von $<\mathrm{g}>$ höchst strittig. Allein die Anzahl der Laute, die für $<\mathrm{g}>$ an bestimmten Positionen realisiert werden sollen, variiert stark. So unterscheidet $\mathrm{z}$. B. Kräuter (1879) zwei Laute. Jung (1879) nennt drei Laute und kritisiert Heinrich Dorn, der bei $<\mathrm{g}>$ ganze sieben Laute unterscheide (ebd. 294). Herausfordernd bei der vergleichenden Sicht auf die Aussprache von $<\mathrm{g}>$ ist zudem, dass in der Fachliteratur des 19. Jahrhunderts zwar die Termini Anlaut, Inlaut und Auslaut verwendet werden, es jedoch selten direkt ersichtlich ist, ob diese auf Silbe oder Wort bezogen sind. Der Unterschied ist folgender: Beide $<\mathrm{g}>$ von gegen stehen im Silbenanlaut. Im Wortanlaut steht jedoch nur das erste $<\mathrm{g}>$. Das zweite $<\mathrm{g}>$ steht (dem Verständnis der meisten zitierten Autoren nach) im Inlaut des Wortes. Außerdem kann die Position von $<\mathrm{g}>$ in sagt und trägst als Inlaut oder als gedeckter Auslaut bezeichnet werden. In den meisten Fällen geben die Beispiele der Autoren darüber Auskunft, wie die jeweiligen 
Termini zu verstehen sind. Tatsächlich wird sich meistens auf das gesamte Wort bezogen. Trotzdem soll versucht werden, durch das Einfügen entsprechender Hinweise (z. B. Wortanlaut oder Anlaut des Wortes) keine Missverständnisse aufkommen zu lassen.

Das einfachste System beschreibt Kräuter (1879, 395 f.) mit zwei möglichen Lauten. Hier werden $<$ g $>$ im An- und Inlaut des Wortes immer als [g] realisiert (gegen, egal). Im Wortauslaut müsse $<$ g $>$ wie $<$ b $>$ und $<$ d $>$ behandelt werden, wobei vermutet werden kann, dass Kräuter sich damit auf die Auslautverhärtung bezieht. Demnach müsste im Wortauslaut [k] realisiert werden (Weg, Krug).

Diederichs $(1884,29)$ nennt drei Laute. Im Wortanlaut müsse [g] realisiert werden. Im In- und Auslaut des Wortes müssten hingegen »Kehl-Reibelaut[e] «, vermutlich [х] und [в], realisiert werden. Aus Diederichs Transkription lässt sich ableiten, dass die drei $\langle\mathrm{g}\rangle$ in seinem Wortbeispiel gegenwärtig mit folgenden Lauten gesprochen werden müssten (in dieser Reihenfolge): [g], [в], [х].

Auch laut Hoffmann $(1888,39)$ müsse im Wortanlaut immer [g] gesprochen werden. Im Inund Auslaut des Wortes entscheide die lautliche Umgebung: Nach Vorderzungenvokalen und vor einfachen Konsonanten werde [ç] realisiert (trägt, legt, Zweig, ruhig, Berg); nach Hinterzungenvokalen werde [x] gesprochen (Lage, Bogen, Kugel, Tag, log, Zug).

Jung $(1879,306)$ unterscheidet bei $<$ g $>$ drei, Siebs $(1900,46$ f.) vier Laute. Die Ergebnisse ihrer Regelungen sind sich jedoch ähnlich. Auch hier werde im Wortanlaut [g] gesprochen. Im Wortauslaut werde das verhärtete $[\mathrm{k}]$ realisiert $($ Weg, Tag). $<\mathrm{g}>$ im Inlaut des Wortes müsse laut Jung (ebd.) auch vor $<\mathrm{t}$, st $>$ ein stimmhaftes [g] sein (sagt, zeigte, trägst). Laut Siebs (ebd.) sei aber auch inlautendes $<\mathrm{g}>$ als $[\mathrm{k}] \mathrm{zu}$ sprechen (sagt, trägst). Um diesen Unterschied zu verdeutlichen, lohnt es sich, eine andere Terminologie anzuwenden: Im gedeckten Auslaut werde $<\mathrm{g}>$ (flugs, sagt, sagst) laut Siebs mit Auslautverhärtung und laut Jung ohne Auslautverhärtung gesprochen. Beide Autoren behandeln das Suffix $<-$ ig $>$ gesondert. Hier müsse $<$ g $>$ laut Jung in jedem Fall als [ç] realisiert werden. Siebs' Regelung für <-ig> ist differenzierter: [g] vor Vokal (Königen, freudige, ewiges); [ç] im Silbenauslaut und vor Konsonant (König, freudig, ewig, Königreich); [k] bei anschließendem <-lich> (ewiglich, königlich). Darüber hinaus weist Siebs darauf hin, dass $<\mathrm{g}>$ beim apostrophierten Ausfall von $<\mathrm{i}>\left(e w^{\prime} \boldsymbol{g} e\right.$, sel'ge, blut'ge) als [j] realisiert werde.

Grabow (1877c, 368 ff.) und Viëtor (1885, 73 f.) unterscheiden je fünf Laute und sind sich, was deren Verwendung angeht, praktisch einig (auch wenn sie unterschiedliche Erklärungen geben). Im Wortanlaut werde [g] gesprochen. Im Inlaut, hier vermutlich zu verstehen als Silbenanlaut im Wortinlaut, werde gesprochen: $[\dot{j}]$ nach Vorderzungenvokalen und Konsonanten (Siege, betrügen, Berge); [в] nach Hinterzungenvokalen (Tage, zogen, Magen). Im Silben- und Wortauslaut werde gesprochen: [ç] nach Vorderzungenvokalen und Konsonanten (Sieg, Berg, Zweig); [x] nach Hinterzungenvokalen, auch bei folgenden Konsonanten (zog, Tag, Wagnis, zogst). Die fünf verschiedenen Laute kommen hier also durch den Einbezug von Lenis-frikativen ([j], [в]), 
die Unterscheidung ihrer Artikulationsstelle bei entsprechender lautlicher Umgebung (Vorderzunge $[\dot{j}]$, Hinterzunge [в]) sowie ihrer Auslautverhärtung zustande ([ç], [х]).

Was diese Regelungen für die Aussprache von $<\mathrm{g}>$ gemeinsam haben, ist die Realisation von [g] im Wortanlaut. Davon abgesehen sind sich die Autoren in verschiedenen Punkten uneinig: ob und welche Frikative einbezogen werden müssen; ob und wie bei Frikativen die Unterscheidung fortis-lenis gemacht wird; in welchen Fällen [g] von Auslautverhärtung betroffen ist; ob und wie das Suffix <-ig> gesondert behandelt werden muss. Diese Faktoren haben Einfluss auf Anzahl und Gestalt der bei $<\mathrm{g}>\mathrm{zu}$ realisierenden Laute und sind für die zum Teil großen Unterschiede verantwortlich. Insgesamt kommen folgende sechs Laute für die Realisierung von $<\mathrm{g}>$ im 19. Jahrhundert in Frage: [g], [k], [j], [ç], [в], [x].

Der Regelung des heutigen Aussprachestandards sind nun Siebs' (1900) Ausführungen am ähnlichsten. Dafür scheinen Grabow (1877c) und Viëtor (1885) ein schlüssiges System erarbeitet zu haben, das viele der zur damaligen Zeit bei $<$ g $>$ verwendeten Laute einbezieht. Sicherlich konnte jeder beschriebene Merkmalskomplex bei deutschen Sprecher:innen im 19. Jahrhundert beobachtet werden. Zudem glaubte jeder Autor, sich auf sprachgeschichtliche Gegebenheiten zu berufen, die nur für die eine oder die andere Regelung sprechen könnten. 


\subsection{Suprasegmentalia}

Nachdem im Bereich der Segmentalia die Einzellaute verglichen wurden, soll dies nun auch für suprasegmentale Aussprachestrukturen und -merkmale erfolgen. Hier ist der Fokus auf Laut-, Silben-, Wort- und Satzebene übergreifende Merkmalskomplexe gelegt, die die Aussprache maßgeblich charakterisieren:
a) Wortakzentuierung,
b) Satzakzentuierung,
c) Rhythmisierung,
d) Melodisierung.

Die Wort- und Satzakzentuierung wird in früherer Literatur (und so auch hier) oft als Betonung bezeichnet. Es wird zwischen Akzentsilben und akzentlosen Silben unterschieden. Akzentsilben werden in der deutschen Sprache mit besonderer Präzision, Lautheit, Tonhöhenverlauf und Dehnung gesprochenen. Akzentlose Silben werden im Vergleich eher geschwächt und flüchtig artikuliert (vgl. Krech et al. 2010, 42). Diese Akzentuierung wird innerhalb der Beispiele im Folgenden so gekennzeichnet: der Vokal einer Akzentsilbe ist unterstrichen (스fang, Malerei); bei Nebenakzenten und einem Hauptakzent ist der Hauptakzent doppelt unterstrichen, (Eier, Millch und Mẹhl).

\section{a) Wortakzentuierung}

Die Wortakzentuierung des Deutschen ist komplex. Daher werden die Akzentregeln des heutigen Aussprachestandards hier zu Vergleichszwecken nur verkürzt und in Auszügen dargestellt. Die Verteilung von Wortakzenten ist folgendermaßen geregelt:

- In einfachen deutschen Wörtern wird meist der Wortstamm bzw. die erste Silbe akzentuiert. Dem Wortstamm angehängte Affixe und Partikel sind meist akzentlos (fangen, gefangen) (vgl. Krech et al. 2010, 39). Bestimmte Affixe tragen oft den Hauptakzent: die Affixe <ur-,

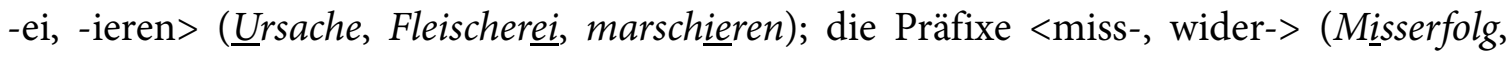
Wíderrede, misstrauisch, wi iderwärtig, misssgestalten); das Präfix $<$ un- $>$ (Untreue, unngekocht); trennbare Präfixe von Verben (ablaufen $\rightarrow$ es läuft $\underline{a} b$, nachgeben $\rightarrow$ ich gebe nach) (vgl. ebd. 46). Diese Regeln unterliegen weiteren Bedingungen und beinhalten Ausnahmen, die hier nicht dargestellt sind.

- Die häufigsten Komposita im Deutschen sind zweigliedrige Determinativkomposita. Hier wird der Akzent des (meist an erster Stelle stehenden) determinierenden Wortes zum Hauptakzent (Apotheke + Reise (determinierend) $\rightarrow$ Reiseapotheke). Für andere und mehrgliedrige Komposita gelten weitere Regeln (vgl. ebd. 47 f.).

- In fremden Wörtern wird bei jüngeren Entlehnungen das originale Akzentmuster beibehalten, in älteren Entlehnungen wird oft die letzte Silbe akzentuiert (Idee, kompakkt) (vgl. ebd. 39 f.). 
- Zudem werden für zahlreiche deutsche und fremde Wörter Varianten angegeben, die eine alternative Wortakzentuierung vorschlagen (gewissermaßen - gewissermaßßen, aalglatt aalglatt, Neujahr - Neujahhr, geozentrisch - geozentrisch).

Die in der Fachliteratur des 19. Jahrhunderts dargestellte Wortakzentuierung deckt sich weitestgehend mit der heutigen. So sei in einfachen deutschen Wörtern meist die Stammsilbe betont (vgl. Benedix 1862, 27; Minkwitz 1863, 3 f.; Viëtor 1885, 94; Siebs 1900, 50). Benedix erwähnt etwa, dass zweisilbige Wörter meist trochäisch seien, also die Betonung auf der ersten Silbe liege. Bestimmte Silben werden genannt, die immer betont seien: <-ei> (Schalmei , Wüstenei, Malerei);

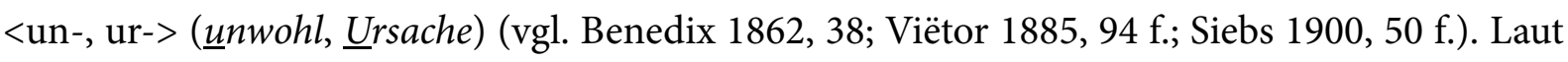
Siebs seien die Vorsilben <an-, bei-, im-> in Nomen betont (스fang, Beispiel, Imbiss). Ebenso die Vorsilben < durch-, wider-, über-, um-, voll-, miss-> in Verben, sofern sie von diesen trenn-

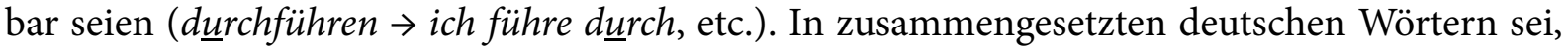
wenn es ein neues bzw. bestimmendes Wort gebe, dieses zu betonen (Laubholz, We hrmann). Verstärke oder vergleiche ein Wort das andere, müssten anders als im heutigen Aussprache-

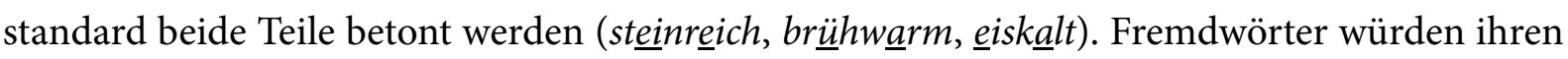
ursprünglichen Akzent beibehalten (vgl. Viëtor 1885, 95; Siebs 1900, 51 f.). Es handelt sich hier offensichtlich um Determinativ- und Kopulativkomposita - diese Termini finden in der verwendeten Literatur jedoch keine Verwendung. Auch variable Wortakzente, wie sie für einige Wörter im Deutschen Aussprachwörterbuch (Krech et al. 2010) angegeben sind, werden in der früheren Fachliteratur nicht thematisiert oder als Beispiele aufgeführt.

\section{b) Satzakzentuierung}

Das Deutsche Aussprachewörterbuch beschäftigt sich zwar nicht explizit mit der Satz-, dafür aber mit der Wortgruppenakzentuierung. Freies oder reproduzierendes Sprechen werde in Wortgruppen gegliedert (Krech et al. 2010, 40). In diesem Sinne können auch Sätze als (potenziell komplexere) Wortgruppen oder Aneinanderreihungen solcher betrachtet werden. Allemal lassen sich im Bereich der heutigen Wortgruppenakzentuierung Aussagen finden, die mit der Satzakzentuierung des 19. Jahrhunderts vergleichbar sind:

- Autosemantische Wörter können Wortgruppenakzente tragen, synsemantische Wörter nur bei hinweisender oder kontrastierender Sprechabsicht (Die Katze ist schwarrz. - Welche? Die Katze ist schwarz.).

- Akzenttragende Wörter sind verschieden gewichtet. Es entsteht immer ein Hauptakzent, und es können Nebenakzente entstehen (wieder auf dem Damm sein; ein Buch aus der Bibliothek).

- Diese sind nach Regeln abgestuft: Bei einem Verb mit Ergänzungen erhält die letzte Ergänzung den Hauptakzent (ich werde morgen meinen Vater besuchen); bei einem Substantiv mit Ergänzungen erhält das letzte akzentuierbare Wort den Hauptakzent (eine Menge bunter 
Kuggeln); bei Aufzählungen erhält das letzte Glied den Hauptakzent (Eier, Millch und Mẹhl) (vgl. ebd. 40, 48).

Nicht allen Texten des 19. Jahrhunderts, die sich mit Satzbetonung beschäftigen, lassen sich Regeln entnehmen, die Aufschluss über konkrete Aussprachemerkmale geben. Rötscher (1842, 159) beschäftigt sich z. B. eingehend mit der Rolle des »logischen Accents«. Diese bestehe darin, Satzgefüge aus mehreren Gliedern durch vielfache Bewegungen von Arsis und Thesis zu einem geistigen Ganzen zu verbinden. Dies geschehe durch "Betonung (ebd. 169) und wechselnde »Tonschwingung " (ebd. 168). Auf welche Art sich dies aber praktisch verhalte, bleibt offen. Der logische Akzent ergebe sich aus theoretischer Kenntnis von Satzbau und Grammatik der Muttersprache (vgl. ebd. 159) sowie tiefem Textverständnis (vgl. ebd. 169). Ebenso auf grammatikalische Gegebenheiten berufen sich Benedix (1862, 14 ff.), Hey (1882, 145 ff.) und Viëtor (1885, 98 f.). Hier würde die grammatikalische Funktion jedes Wortes dessen Betonungsgrad im Satz beeinflussen. Laut Benedix hätten »Begriffswörter« (ebd., 18) (Substantive, Adjektive, Verben, Adjektivadverbien) die Grundstufe der Betonung. Hingegen hätten »Verhältnißwörter« (Artikel, Zeitwörter, Pronomina, Partikeln, einige Adverbien) eine niedrige Betonungsstufe. Dazwischen lägen Begriffswörter, die durch ein Ergänzungswort an Betonung verlieren würden (Der Jäger schießt Hassen. $\rightarrow$ grundbetontes Wort schießt tritt gegenüber Ergänzungswort Hasen etwas zurück). Verändernde Attributive würden die gleiche Betonung wie das veränderte Wort erhalten (das schwarze Pferd). Hey (1882, 151 f.) nimmt eine andere Einteilung vor. Hier hätten: Substantive die stärkste Betonung; Adjektive, Adverbien und Zeitwörter eine geringere Betonung; Artikel, Pronomen und Präpositionen die schwächste Betonung. Laut Viëtor (1885, 98 f.) liege die Betonung meist auf Prädikat oder Objekt des Satzes. Attributive Adjektive würden - anders als bei Benedix - weniger Betonung erhalten als das beschriebene Wort (das schwarze Pferd).

Benedix (1862), Hey (1882) und Viëtor (1885) sind sich darüber einig, dass die Betonung der Wörter eines Satzes nach ihren grammatischen Eigenschaften nur eine Ebene der Satzbetonung darstellt. Übergeordnet gebe es den »Beziehungston «(Benedix 1862, 19; Hey 1882, 152), der die Bedeutung eines einzelnen Wortes auf Wörter oder Gedanken außerhalb des eigenen Satzes beziehe (vgl. Benedix 1862, 19). Laut Benedix (ebd., 20) sei der Beziehungston stärker akzentuiert als die Grundstufe, auf der sich Begriffswörter befänden. Dank ihm könne in einem "ungebundenen Satze" (Hey 1882, 152) jedes Wort "schwerbetont hervorgehoben werden" (ebd.), um den Sinn jedes Mal zu verändern (Die Katze ist schwarz. Die Kâtze ist schwarz. Die Katze ist schwarz. usw.). In einem metrisch gegliederten Satz (womit hier vermutlich ein Vers gemeint ist) würden sich Haupt- und Nebenbetonungen jedoch eindeutig aus Inhalt und Wortstellung ergeben. Viëtor $(1885,98)$ spricht von einem logischen Akzent, der auf dem wichtigsten Wort mit der größten Bedeutung läge, während alle anderen Wörter weniger oder gar nicht betont würden. Die Autoren beschreiben also eine Satzbetonung mit unterschiedlichen Betonungsstufen, die sich aus der grammatikalischen Struktur des Satzes ergeben, sowie einen übergeordneten logischen, bedeutungsbestimmenden Hauptakzent. Siebs (1900, 50) bezeichnet nach »Wortklassen oder Satzteilen bestimmte Betonungsgrade» hingegen als »überflüssig und 
irreführend « (ebd.). Es sei lediglich die wichtige, neue Information zu akzentuieren, die weitere Betonung ergebe sich aus der natürlichen Sprechweise von selbst.

Die von Benedix (1862) und Hey (1882) vorgenommene und von Rötscher (1842) und Viëtor (1885) angedeutete Einteilung der Betonungsstufen nach der grammatischen Funktion der Wörter erinnert an die heutige Einteilung, nach der autosemantische Wörter Akzente tragen können, synsemantische jedoch nicht. Der Unterschied ist, dass die heutige Regelung lediglich bestimmt, wo Akzente sein könnten. Benedix’ und zum Teil Heys Ausführungen lassen jedoch vermuten, dass die von ihnen dargestellte Abstufung für jedes Wort eines Satzes angewendet werden müsse. Das Ergebnis wäre ein wenig freies und von zahlreichen Akzenten durchsetztes Betonungsmuster, das sich ungeachtet des Tempos und der allgemeinen Sprechspannung durchsetzen müsste. Die Regelung, dass bei verändernden Attributiven das veränderte Wort den Akzent trägt (das schwarze Pferd) (vgl. Viëtor 1885, 98) bzw. Attributiv und ergänztes Wort den gleichen Akzent tragen (das schwarze Pferd) (vgl. Benedix 1862, 18), ähnelt im Ansatz der heutigen Regel, bei Substantiv mit Ergänzungen das letzte Wort zu akzentuieren. Bei Verben mit Ergänzungen, wo heute nicht das veränderte Wort, sondern die letzte Ergänzung akzentuiert wird, würden sich die Regeln wiederum nicht decken.

Verschiedene Versuche, Regelhaftigkeiten festzustellen führten zu unterschiedlich komplexen und teils starr wirkenden Erklärungen. Was die Satzbetonung betreffend von Interesse ist, ist die Idee des übergeordneten Beziehungstons oder logischen Akzents. Dieser erinnert sehr an die Thema-Rhema-Gliederung, die im 19. Jahrhundert wie auch heute in der Leselehre etabliert war. Schließlich kann für das 19. Jahrhundert zusammengefasst werden, dass der Beziehungston den Hauptakzent eines Satzes darstellt, während die Verteilung von Nebenakzenten von der grammatischen Funktion der jeweiligen Wörter abhängt. So gesehen deckt sich auch die Satzbetonung des 19. Jahrhundert mit der heutigen Aussprache.

\section{c) Rhythmisierung}

Die deutsche Sprache hat eine Schwer-Leicht-Kontur, die aus dem Kontrast von akzentuierten und akzentlosen Silben entsteht. Wortgruppenakzente binden akzentlose Silben an sich und können durch Zusammenfügen zweier oder mehrerer Verbindungen rhythmische Gruppen bilden. Diese rhythmischen Gruppen sind durch Pausen voneinander abgegrenzt (vgl. Krech et al. 2010, 42). So entsteht durch die Akzentstruktur und dazugehörige Pausen die Rhythmisierung der deutschen Sprache. Die Häufigkeit und Intensität von Akzenten und Pausen ist durch die Sprechsituation bedingt oder beim reproduzierenden Sprechen (z. B. auf der Bühne) typisiert nachgebildet. Da reproduzierendes Sprechen weniger von Schwierigkeiten bei der Produktion von Aussagen beeinflusst ist, basiert der Rhythmus hier primär auf dem syntaktischen Bau und der Aussageabsicht (vgl. ebd. 43). 
Im 19. Jahrhundert wurde die deutsche Rhythmisierung zum Teil noch auf Silbenmessung zurückgeführt, die versuchte, die Länge oder Kürze von Silben oder Wörtern zu bestimmen. Dieses System fußt entweder auf der Quantität der entsprechenden Vokale oder auf grammatischen Gegebenheiten. So seien laut Minckwitz (1863, 5 ff.) etwa alle einsilbigen Substantive und Adjektive lang (Buch, Hass, groß, dick) oder alle bestimmten Artikel kurz (der, daß), unabhängig von der Quantität der betroffenen Vokale. Laut Hey $(1882,146)$ sei die Silbenmessung aus dem Griechischen und Lateinischen übernommen worden. Er und Benedix (1862, $21 \mathrm{ff}$.) sind sich jedoch darüber einig, dass der deutsche Rhythmus nicht auf Länge oder Kürze von Silben, sondern vielmehr auf ihrer unterschiedlich starken Betonung basiere. Der Rhythmus sei »die geordnete und festgehaltene Folge bestimmter Zeittheile« und entstehe »aus dem geordneten Wechsel von betonten und unbetonten Silben und Wörtern « (Hey 1884, 150). Auch laut Benedix $(1862,23)$ sei »die Tonstärke, nicht die Tondauer das erste rhythmische Element der deutschen Sprache«. Daher werde "statt der bisherigen Bezeichnung von Länge und Kürze die der Schwere und Leichtigkeit der Sylben« (ebd. 25) gewählt. Wie sich die jeweilige Betonung und damit die Rhythmisierung in Wort und Satz verhalte, wurde oben dargestellt. Demnach basiert die deutsche Rhythmisierung auf dem Kontrast von schwer und leicht betonten Silben, die nach grammatischen und logischen Betonungsregeln angeordnet sind. Die zum Teil starken rhythmischen Schwankungen, denen Spontansprache unterliegen kann, werden dabei nicht berücksichtigt, was bei Benedix’ und Heys Bezug zur Bühnensprache aber nicht verwundert. Ihre Ausführungen sind dem heutigen Verständnis der deutschen Rhythmisierung sehr ähnlich, obwohl die Rolle von rhythmisierenden Pausen hier keine Beachtung findet.

Die Lyrik betreffend sei darauf hingewiesen, dass im 19. Jahrhundert noch versucht wurde, das quantitierende Versprinzip auf die eigentlich akzentzählende deutsche Sprache anzuwenden (vgl. Minckwitz 1863, 5 ff.). Dies muss nicht unbedingt zur Folge haben, dass der eigentlichen Vokalquantität widersprechende Vokaldehnungen entstehen, wie man vermuten könnte (List [list] $\rightarrow$ [lirst] oder [liist]). Minckwitz' Ausführungen lassen eher vermuten, dass lange (damit akzentuierte) Silben durch eine generelle zeitliche Dehnung gekennzeichnet seien, vermutlich einfach durch langsameres Sprechen, und daher auch kurze Vokale beinhalten können. Auch muss das klangliche Ergebnis nicht zwingend sehr auffällig sein. In der heutigen Aussprache sind akzentuierte Silben ebenfalls von einer gewissen Dehnung gekennzeichnet (vgl. Krech et al. 2010, 42). Das Ausmaß der Silbendehnung des quantitierenden Prinzips ist jedoch ungewiss. So wird im Lexikon lyrischer Formen (Knörrich 1992) darauf hingewiesen, dass man sich die entsprechende Rezitationsweise "als eine Art psalmodierenden Sprechgesang vorzustellen hat" (ebd. 175), der gegenüber der akzentuierenden Versgestaltung eine "größere Künstlichkeit« (ebd. 176) aufweise.

\section{d) Melodisierung}

Auf das Hörverstehen hat der Endverlauf der Melodie den größten Einfluss (vgl. Krech et al. 2010, 43). Der Melodieendverlauf kann darauf hinweisen, ob es sich um Aussage, Aufforderung 
oder Frage handelt, ob die Aussage abgeschlossen ist und welche Haltung Sprechende gegenüber den Hörenden einnehmen. Die Basis stellt die Akzentverteilung in den entsprechenden rhythmischen Gruppen dar, da der Endverlauf der Melodie in oder vom letzten Wortgruppenakzent aus beginnt. Die Melodie kann:

- in kleinem oder großem Intervall bis in die Lösungstiefe fallen (sachliche oder erregte Abgeschlossenheit),

- in großem Intervall ins obere Drittel des Sprechstimmumfangs steigen (kontaktbetonte, freundliche Ergänzungsfragen und Anreden),

- in kleinem Intervall steigen oder fallen (nicht abgeschlossen, unsicher) (vgl. ebd. 43 f.).

Die Melodisierung wurde im 19. Jahrhundert weniger komplex dargestellt. Laut Benedix (1862, 15 f.) steige die Tonhöhe am Ende eines fragenden Satzes und falle am Ende eines behauptenden Satzes. Innerhalb des Satzes bleibe die Tonhöhe immer gleich. Hey $(1882,160)$ kritisiert dieses System, da es lediglich drei Tonhöhen beschreibe. Vielmehr sei eine auf- und absteigende Reihe von Tönen vonnöten, die je nach Sprechendem und Text variiere. Konkrete Melodieverläufe beschreibt er nicht. Dafür nennt er eine Reihe von Regeln, etwa das Vermeiden von grundlosen übermäßigen Intervallsprüngen oder Vokaldehnungen über mehrere Töne hinweg. Laut Viëtor (1885, 99 f.) gleite die Tonhöhe ständig nach oben und unten. Er unterscheidet drei Bewegungen: schwebend, steigend, fallend. Diese könnten über verschiedene Intervalle variiert werden. Steigende Bewegungen würden in Fragen, fallende in Antworten und Aussagen verwendet, wodurch die Bedeutung von Sätzen modifiziert werde. Siebs (1900, 48 f.) ergänzt das Element der Abgeschlossenheit eines Gedankens. Sei dieser nicht abgeschlossen, halte sich die Stimme; sei er abgeschlossen, senke sie sich. Da der Sinn einer Rede durch den »Tonfall oder den musikalischen Accent « (ebd. 48) vielfach variiert werden könne, könnten keine allgemeingültigen Gesetze aufgestellt werden. Es gelte jedoch zu beachten: In gewöhnlichen Aussagesätzen sowie in Fragesätzen mit Fragewort sinke der Ton (Karl ist krank gewesen.; Wer hat das getan?); in gewöhnlichen Fragesätzen ohne Fragewort steige der Ton (Ist er hier gewesen?); Parenthesen würden oft mit tieferer Stimmlage gesprochen (Das ist - ich bemerke das nur nebenbei - unmöglich.) (vgl. ebd. 48 f.). Die Notation der von Siebs gegebenen Beispiele liefert Hinweise darauf, wo die entsprechenden Melodieverläufe beginnen würden: »Karl• ist. krank. ge.we.sen.«; «ist. er. hier·ge.we.sen·? ( (ebd., 48). Demnach würde der entsprechende Endverlauf, wie es auch für die heutige Aussprache beschrieben ist, in oder von der letzten Akzentsilbe aus beginnen. Erneut würde Benedix' (1862) Beschreibung beim Sprechen ein eher starr wirkendes Klangbild erzeugen. Die anderen Autoren weisen hingegen darauf hin, dass die deutsche Melodisierung komplexer und abwechslungsreicher sei. Und auch wenn Viëtors (1885) eigene Beobachtung zwar eher ungenau ist, deutet er schon an, dass die Beziehung von Tonhöhe und Satzbedeutung noch unzureichend untersucht sei (vgl. ebd. 100). Siebs' (1900) Ausführungen kommen dem heutigen Aussprachestandard letztlich relativ nahe. 


\section{Besonderheiten der Bühnenaussprache in der Fachliteratur des 19. Jahrhunderts}

Im letzten Abschnitt wurden Texte untersucht, die Schlüsse für allgemeine Aussprachenormen des Deutschen im 19. Jahrhundert zulassen. Dabei wird hier davon ausgegangen, dass die dargestellten Aussprachenormen auch für die Bühne empfohlen werden können. So beziehen sich einige der Autoren explizit auf einen künstlerischen Anwendungsbereich (z. B. Benedix 1859; Hey 1882; Siebs 1900). Auch jene, die eher eine allgemeine und fachübergreifend gültige Aussprache darzustellen versuchen (z. B. Grabow 1875) oder sich spezialisierter auf die DaF(Viëtor 1885) oder Volksschullehre (Hoffmann 1888) beziehen, weisen oft mindestens einmal auf die Gültigkeit und Notwendigkeit der Normen für die Bühne hin - meist mit Hinblick auf den Anspruch der Dialektfreiheit (vgl. Grabow 1875, 368 f.; Viëtor 1885, 4).

Dennoch hebt sich die Bühnenaussprache von anderen Bereichen, die einer genormten Aussprache bedürfen, durch weitere Anforderungen ab. Diese sollen nun untersucht werden:

a) Anforderungen an die Bühnenaussprache,

b) allgemeine Ausspracheregeln für die Bühne,

c) Aussprache von Vokalen auf der Bühne,

d) Aussprache von Konsonanten auf der Bühne,

e) suprasegmentale Aussprache auf der Bühne,

f) Erlernen bühnentauglicher Aussprache.

\section{a) Anforderungen an die Bühnenaussprache}

Der Anspruch der Dialektfreiheit an die Bühnenaussprache findet sich im gesamten 19. Jahrhundert (vgl. Goethe 1803 [im Folgenden: 1970], 83; Rötscher 1841, 114 f.; Benedix 1870, 8; Viëtor 1885, 4; Siebs 1900, 5). Weiterhin sind die Sprechenden angehalten, auf Fernwirkung und daher besondere Deutlichkeit bedacht zu sein (vgl. Siebs 1900, 5). Der Sinn des Gesagten müsse durch besonders reine Aussprache von den Hörenden stets leicht und bestimmt zu ergreifen sein (vgl. Goethe 1970, 83). Bühnentaugliche Aussprache beruhe aber nicht nur auf inhaltlicher Verständlichkeit. Rötscher $(1841,123)$ und Hey $(1882,55)$ weisen darauf hin, dass Laute nicht nur inhaltliche, sondern auch (laut-)symbolische Bedeutung tragen, die nur durch kunstgerechte Aussprache verdeutlicht werden könne. Beispielsweise sei das I der »Empfindungslaut für Verwunderung, Neugierde; halbgläubiges Zuerkennen einer uns unerwartet entgegentretenden Thatsache" (Hey 1882, 55), während das U für »Völliges Unbehagen; Ausdruck verhaltenen Schmerzes« (ebd.) stehe.

\section{b) Allgemeine Ausspracheregeln für die Bühne}

Eine für die Bühne geeignete Aussprache erfordere laut Siebs $(1900,5)$ zunächst einen im Gegensatz zur Konversation gesteigerten Kraftaufwand. Goethe fordert eine reine und vollständige Aussprache jedes Wortes. Diese werde erreicht, indem jeder einzelne Buchstabe realisiert werde 
(vgl. Goethe 1970, 83; Benedix 1859, 3), wobei die Verwendung des Terms »Buchstabe« in einem phonetischen Sachverhalt zu Ungenauigkeiten führen kann. So weist etwa Benedix darauf hin, dass einige Buchstaben bloß eine Vokallängung anzeigen würden oder rein orthografische Funktionen hätten und damit gerade von der Ausspracheregel ausgenommen seien (Liebe, Rath). Es scheint insgesamt, als könne sich Benedix nicht für eine treffende Terminologie entscheiden: »jeder Buchstabe (Laut), der geschrieben wird, wird auch ausgesprochen « (ebd.). Die genaue Realisation jedes Lautes beinhaltet dabei auch, dass keine Laute verwechselt werden (Leben $\rightarrow$ [b] nicht wie [v]) (vgl. Goethe 1970, 84; Rötscher 1841, 119). Rötscher $(1841,131)$ und Siebs $(1900,6)$ fordern zudem, dass einzelne Laute nicht von ihren angrenzenden Lauten beeinflusst werden. Folglich dürfte auf der Bühne keine Koartikulation (Kuh $\rightarrow[\mathrm{k}]$ mit Lippenrundung von $\left[\mathrm{ur}_{\mathrm{i}}\right]$ ) oder, was klanglich von größerer Bedeutung ist, keine Assimilation (Festsaal $\rightarrow[\mathrm{z}]$ durch $[\mathrm{t}]$ progressiv entstimmlicht) stattfinden. Ebenso dürften aufeinandertreffende Laute benachbarter Wörter nicht übergebunden werden (seit ich; deines Auges; traf ihn). Hier müssten durch Auslautverhärtung an Wortende und Glottisschlageinsatz an folgendem Wortanfang entsprechende Überbindungen und Assimilationen verhindert werden (vgl. Guttmann 1882, 153 f.; Siebs 1900, 7). Laut Goethe dürften auch »Endsilben und Endbuchstaben « (1970, 85) nicht undeutlich ausgesprochen werden. Besondere Deutlichkeit bräuchten Hauptwörter, Eigennamen und Bindewörter (vgl. ebd., 85, 91). Lediglich Siebs $(1900,6)$ äußert sich zur Aussprache von Fremdwörtern. Diese schwanke nach momentanem Eindeutschungsgrad des jeweiligen Wortes. Anstatt sich an einer besonders originalnahen Aussprache zu versuchen, müsse sich hier an der Ausspracheform orientiert werden, die momentan etabliert sei.

\section{c) Aussprache von Vokalen auf der Bühne}

Hier setzt sich die Forderung nach genauer Realisation jedes einzelnen Lautwertes fort. So dürften Vokale nicht zu offen (Gott $\rightarrow$ [o] zu sehr wie [a]) oder zu gespannt (legen $\rightarrow$ [e:] zu sehr wie [ii]) realisiert werden (vgl. Rötscher 1841, 128; Benedix 1859, 3; Siebs 1900, 10). Ebenso müsse

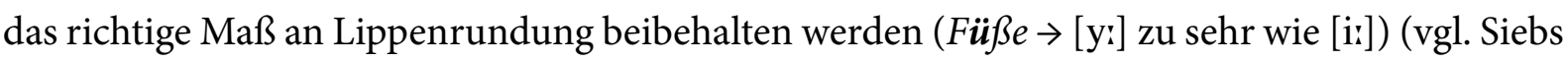
1900, 10). Der feste Stimmeinsatz (Glottisschlageinsatz) müsse zwar beachtet, aber nicht übertrieben werden (vgl. ebd.). Guttmann $(1882,156)$ weist darauf hin, dass auf der Bühne oftmals zwischen Wörtern eingeschobene E- oder A-Vokale zu hören seien. Dies sei zu unterlassen. Vermutlich handelt es sich hierbei nicht etwa um Häsitationspartikel, wie sie in Spontansprache häufig vorkommen (Ich meine, äh, dass, äh, ...), sondern um mehr oder weniger bewusste Einschübe, die dem Gesagten durch häufige auslautende Vokale mehr Wohlklang verleihen sollen (ich war aufe deme Dache). Das Streben nach möglichst viel Klangfülle könnte hier vom Gesang, genauer vom Operngesang hergeleitet sein, der im 19. Jahrhundert vom italienischen Bel canto beeinflusst war. Dem Prinzip, jeden Laut genau und ohne Überbindungen zu realisieren, würden entsprechende Vokaleinschübe widersprechen, was Guttmanns Kritik untermauert. 


\section{d) Aussprache von Konsonanten auf der Bühne}

Auch hier wird Genauigkeit der Artikulation gefordert. Benedix (1859, 3 f.) warnt vor »Nachlässigkeit und Maulfaulheit« (ebd. 4). Laut Guttmann (1882, 152 f.) dürfe kein Konsonant zu weich oder zu hart ausgesprochen werden. Ebenso müsse unbedingt die Auslautverhärtung eingehalten werden. Er weist darauf hin, dass Sprechende gezielt im Auslaut weiche, stimmhafte Konsonanten zu sprechen versuchen, was falsch sei. Eine übertriebene Auslautverhärtung sei jedoch auch zu vermeiden. Stimmhafte Konsonanten am Wortanfang bräuchten einen direkten Einsatz, es dürfe keine Stimme vorausgehen (Brot $\rightarrow$ [bro:t] und nicht [mbro:t]; Dach $\rightarrow$ [dax] und nicht [ndax]) (vgl. ebd. 155). Bei gleichen Konsonanten mit dazwischen liegender Wortgrenze, also wenn ein Wort mit dem Laut endet, mit dem das nächste beginnt, müsse laut Goethe $(1970,85)$ und Benedix (1870, 35 f.) zwischen den beiden Lauten kurz abgesetzt werden. Beide Laute müssten einzeln und deutlich realisiert werden. Dies treffe auch zu, wenn sich die Laute durch fortis und lenis unterscheiden (z. B. bei Auslautverhärtung: schließt sie blühend den Kreis).

\section{e) Suprasegmentale Aussprache auf der Bühne}

Benedix (1870, 37 f.) warnt vor rhythmischen Missverständnissen, die auftreten können, wenn mehrere unbetonte oder mehrere betonte Silben aufeinander folgen und so scheinbar den natürlichen Rhythmus der deutschen Sprache stören. Vortragende seien dazu angehalten, keine unsinnigen Akzente zu setzen, in dem Versuch einen flüssigen Rhythmus herzustellen. An dieser Stelle sei darauf hingewiesen, dass die deutsche Rhythmisierung von antiken Versmaßen insofern beeinflusst sein kann, dass bei strikter Umsetzung sinnwidrige Akzentuierungen entstehen können. Minckwitz, ein Verfechter der antiken Verslehre, geht davon aus, dass der »Accent, den der gebildete Sprecher einem Worte giebt, mit dem Accent des angewendeten Versmaßes übereinstimmen und zusammentreffen « $(1863,22)$ muss. Benedix $(1862)$ fragt jedoch: »Wenn nun in diesen Versmaßen die Wortfolge, der Satzbau, die Wortbildung allen Regeln zum Trotz geübt, wenn der deutsche Rhythmus absichtlich verletzt wird, heißt das nicht die Sprache mißhandeln?« (114 f.). Die Gefahr rhythmischer Eintönigkeit müsse einerseits durch Reim und inhaltliche Abwechslung vom Dichter, andererseits durch entsprechende Pausensetzung, Temposchwankung und Tonfarbe vom Sprechenden abgewendet werden (115 f.). Laut Goethe $(1970,88)$ und Rötscher $(1841,145)$ müssten vor und nach Parenthesen Pausen gesetzt werden. Auch nach dem Ausruf Oh! müsse laut Goethe (1970, 90 f.) kurz abgesetzt werden. Die Melodisierung betreffend, warnen Goethe (ebd., 88), Siebs (1900, 49 f.) und zum Teil Hey (1882, 145) vor bestimmten Tendenzen. Bei zu schnellen oder zu vielen Tonsprüngen sowie zu tiefem oder zu hohem Sprechen bestehe die Gefahr in das "Singen " (Goethe 1970, 88) zu kommen. Bei zu wenig Melodisierung geraten Sprechende jedoch in »Monotonie« (ebd.). Dazwischen liege der nicht näher erläuterte »Predigerton« (ebd.). Diese Arten der Melodieführung seien zu vermeiden. Siebs $(1900,49)$ gibt zudem Hinweise, wie sich die Melodisierung bei Anführungssätzen zu verhalten habe (Er sagte: "gehen Sie mit!«). Diese sollen nun nicht mehr vereinzelt 
aufgeführt werden. Es sei lediglich darauf hingewiesen, dass die Regelungen der heute gängigen Melodisierung ähnlich sind.

\section{f) Erlernen bühnentauglicher Aussprache}

Rötscher (1841, 132), Rocca $(1889,107$ ff.) und Siebs $(1900,5)$ empfehlen für das Erlernen einer dialektfreien Aussprache, sich theoretisch mit dem deutschen Lautsystem auseinanderzusetzen. Laut Rötscher müsse das Gehör für lautliche Unterschiede sensibilisiert werden. Rocca empfiehlt, das Lesen der von ihm verwendeten Lautschrift zu erlernen und sich bestenfalls an eigenen Transkriptionen zu versuchen. Goethe (1970, 83 ff.) gibt diverse Hinweise, wie die "reine und vollständige Aussprache« geübt werden solle. Er rät hier, wie auch Hey $(1882,145)$, zu größter Genauigkeit und Übertreibung, die sich später wieder ausgleiche. Außerdem müsse sehr langsam und deutlich geübt werden, besonders bei den Endsilben, da diese schnell unverständlich würden (Goethe 1970, 86). Das Textlernen müsse mit größter Sorgfalt und zunächst ohne Leidenschaft oder Deklamation erfolgen, da hier oft die Ursache für Aussprachefehler läge. 


\section{Ergebnisse}

\section{a) Vokale}

In ihren distinktiven Merkmalen sind die in der Fachliteratur des 19. Jahrhunderts beschriebenen Einzelvokale weitgehend unstrittig. Es waren meist Vokalpaare zu finden, die sich aus einem langen gespannten Vokal und einem kurzen ungespannten Vokal zusammensetzen. Diese Distinktion war lediglich in Beschreibungen und Beispielen zu erkennen - die Bezeichnungen gespannt und ungespannt werden in der Fachliteratur nicht verwendet. Darüber hinaus wird oft ein kurzer oder gekürzter gespannter Vokal genannt, der nur in nicht akzentuierter offener Silbe vorkommt. Auch werden bei den A-Vokalen meist nur eine Vokalqualität und bei den E-Vokalen zusätzlich ein langer offener Vokal beschrieben. Für die Phonem-Graphem-Beziehungen der Vokale und die Frage nach zu unterscheidender Vokalqualität und -quantität werden von verschiedenen Autoren oft unterschiedliche Regelhaftigkeiten aufgestellt, teils strittig sind die Phonem-Graphem-Beziehungen der E-Vokale und des Schwa.

Die Vokalregeln sind in der folgenden Tabelle zusammengefasst und den deutschen Vokalen des heutigen Aussprachestandards gemäß dem Deutschen Aussprachewörterbuch (Krech et al. 2010, 56 ff.) gegenübergestellt. Die in Klammern stehenden Transkriptionen bezeichnen weniger oft auftretende kurze gespannte oder unsilbische Vokale (wobei Letztere in der Fachliteratur des 19. Jahrhundert nicht erwähnt wurden): 


\begin{tabular}{|c|c|c|}
\hline Vokale • DAWB & Vokale • 19.Jh. & Phonem-Graphem-Beziehungen • 19.Jh. \\
\hline [a:], [a] & [a:], [a] & den heutigen ähnlich \\
\hline$[\mathrm{e}],\left[\varepsilon^{\prime}\right],[\varepsilon],([\mathrm{e}])$ & {$[\mathrm{e}],[\varepsilon \mathrm{l}],[\varepsilon],([\mathrm{e}])$} & $\begin{array}{l}\text { [e:] oder [ع:] zum Teil strittig (Kehle, Beere); } \\
\text { sonst den heutigen ähnlich }\end{array}$ \\
\hline [ə] & {$[ə]$} & 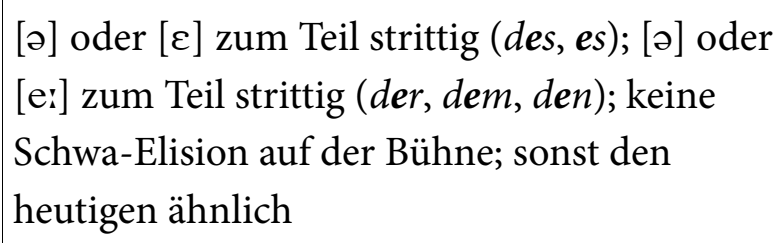 \\
\hline [ii], [I], ([i], [i] $])$ & {$[\mathrm{i}],[\mathrm{I}],([\mathrm{i}])$} & den heutigen ähnlich \\
\hline [o:], [॰], ([o], [ొ्र] $)$ & {$[\mathrm{o:}],[\mathrm{o}],([\mathrm{o}])$} & den heutigen ähnlich \\
\hline$[\mathrm{u}],[\mathrm{v}],([\mathrm{u}],[\mathrm{u}])$ & {$[\mathrm{u}],[\mathrm{v}],([\mathrm{u}])$} & den heutigen ähnlich \\
\hline$[\phi:],[œ],([\phi])$ & {$[\phi:],[œ],([\phi])$} & den heutigen ähnlich \\
\hline$[\mathrm{y}:],[\mathrm{y}],([\mathrm{y}],[\breve{y}])$ & {$[\mathrm{y}:],[\mathrm{y}],([\mathrm{y}])$} & den heutigen ähnlich \\
\hline
\end{tabular}

Tab. 1: Vokale der Bühnenaussprache im 19. Jahrhundert

Bei den Diphthongen sind die Qualitäten der jeweils zweiten Vokale strittig. In der folgenden Tabelle sind jedem im Deutschen Aussprachewörterbuch (Krech et al. 2010, 72 f.) beschriebenen Diphthong zwei in der Fachliteratur des 19. Jahrhunderts beschriebene Varianten zugeordnet:

\begin{tabular}{|c|c|c|}
\hline Diphthonge • DAWB & Diphthonge $\bullet$ 19.Jh. & Phonem-Graphem-Beziehungen • 19.Jh. \\
\hline$[a \varepsilon$ & [aen], [aIn] & $<$ ei $>,<$ ai $>$ (den heutigen ähnlich) \\
\hline [aon] & [aod, [aven] & $<$ au > (den heutigen ähnlich) \\
\hline [oœ] & {$[\supset \emptyset],[\supset Y]$} & $<$ eu $>,<$ äu $>$ (den heutigen ähnlich) \\
\hline
\end{tabular}

Tab. 2: Diphthonge der Bühnenaussprache im 19. Jh. 
Vokaleinsatz und Nasalität werden in der Fachliteratur des 19. Jahrhunderts ähnlich dem heutigen Aussprachestandard empfohlen. Vokalen im Wortanlaut gehe ein Glottisplosiv voraus. Gleiches gelte für Vokale, die auf bestimmte Vorsilben folgen (Arbeit, bearbeiten). Auf der Bühne müssten diese besonders beachtet werden, da deutlich markierte Wort- und Silbengrenzen einer größeren Verständlichkeit zuträglich seien. Deutsche Vokale werden ohne Nasalität realisiert. Lediglich Nasalvokale in ursprünglich französischen Wörtern müssten nasaliert werden.

Da für die Bühnenaussprache im 19. Jahrhundert größte Genauigkeit gefordert war, müssten alle Vokale mit der richtigen Qualität, Quantität und an entsprechender Position mit genauem Glottisschlageinsatz realisiert werden. Darüber hinaus dürfen keine Vokale eingeschoben oder elidiert werden. Auch das im heutigen Standard oft elidierte Schwa ist somit an jeder gegebenen Position zu realisieren. Abweichungen von diesen Forderungen waren zwar auf Bühnen des 19. Jahrhunderts sicher in mannigfacher Form zu vernehmen gewesen, galten aber scheinbar als mehr oder weniger inadäquat. Regional-dialektal bedingte Merkmale, wie die strittige Verwendung des einen oder anderen E-Vokals, waren in ihrer Akzeptanz vermutlich Schwankungen ausgesetzt.

\section{b) Konsonanten}

Viele der Konsonanten ähneln in ihrer artikulatorischen Bildung und ihren Phonem-GraphemBeziehungen dem heutigen Aussprachestandard. Es sind aber auch Unterschiede zu verzeichnen (z. B. das Zungenspitzen-R und die strittige Aussprache von $\langle\mathrm{g}>$ ). Einige Merkmale wurden aufgrund ihrer weiten Verbreitung näher beschrieben, schließlich jedoch als dialektal eingestuft. Dazu zählen der bei <qu> und <schw> realisierte bilabiale Frikativ [ $\beta$ ] (quer [kßerr]) sowie bei $<$ st $>$ und $<$ sp $>$ am Wortanfang realisiertes [st] und [sp] (stark [stark]; Sport [sport]). Aufgrund des Anspruchs der Dialektfreiheit werden diese Merkmale für die Bühnenaussprache des 19. Jahrhunderts nicht berücksichtigt. In der folgenden Tabelle sind die erarbeiteten Konsonanten zusammengefasst und jenen des heutigen Aussprachestandards gemäß dem Deutschen Aussprachewörterbuch (Krech et al. 2010, 78 ff.) gegenübergestellt. 


\begin{tabular}{|c|c|c|}
\hline Konsonanten • DAWB & Konsonanten • 19.Jh. & Phonem-Graphem-Beziehungen • 19.Jh. \\
\hline$[\mathrm{f}],[\mathrm{v}],[\mathrm{v}]$ & {$[\mathrm{f}],[\mathrm{v}]$} & den heutigen ähnlich \\
\hline$[\mathrm{s}],[\mathrm{z}],[\mathrm{z}]$ & {$[\mathrm{s}],[\mathrm{z}]$} & den heutigen ähnlich \\
\hline []], [3], [3̊] & {$\left[\int\right],[3]$} & den heutigen ähnlich \\
\hline [ç], [j], [ [o & [ç], [j] & strittig bei $<\mathrm{g}>$; sonst den heutigen ähnlich \\
\hline [x] & [x] & strittig bei $<\mathrm{g}>$; sonst den heutigen ähnlich \\
\hline $\begin{array}{l}{[\mathrm{b}],\left[^{\mathrm{b}}\right],[\mathrm{b}],[\mathrm{R}],[\mathrm{r}],[} \\
\mathrm{e}],\left[^{\mathrm{p}}\right]\end{array}$ & [r], [в] & $\begin{array}{l}{[\mathrm{r}] \text { immer bei }\langle\mathrm{r}\rangle,\langle\mathrm{rr}\rangle,\langle\mathrm{rh}\rangle,\langle\mathrm{rrh}\rangle ;[\mathrm{r}] \text { nie }} \\
\text { vokalisiert oder vermindert; [в] strittig bei } \\
<\mathrm{g}>\text {, sonst nicht verwendet }\end{array}$ \\
\hline [h] & [h] & den heutigen ähnlich \\
\hline [p], [b], [b] & [p], [b] & den heutigen ähnlich \\
\hline$[\mathrm{t}],[\mathrm{d}],[\mathrm{b}]$ & {$[\mathrm{t}],[\mathrm{d}]$} & den heutigen ähnlich \\
\hline [k], [g], [̊̊g] & {$[\mathrm{k}],[\mathrm{g}]$} & strittig bei $\langle\mathrm{g}\rangle$; sonst den heutigen ähnlich \\
\hline$[\mathrm{m}],[\mathrm{n}],[\mathrm{y}]$ & {$[\mathrm{m}],[\mathrm{n}],[\mathrm{y}]$} & 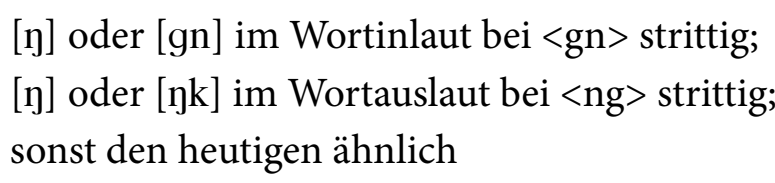 \\
\hline [1] & [1] & den heutigen ähnlich \\
\hline
\end{tabular}

Tab. 3: Konsonanten der Bühnenaussprache im 19. Jh.

Für die strittige Aussprache von $<\mathrm{g}>$ sind in der folgenden Tabelle zwei Empfehlungen dargestellt. Dabei handelt es sich auf der einen Seite um die (sich gleichenden) Empfehlungen von Grabow (1877c, 368 ff.) und Viëtor (1885, 73 f.), auf der anderen Seite um die von Siebs (1900, $46 \mathrm{f}$.$) .$ 


\begin{tabular}{|c|c|c|c|}
\hline Position von $\langle g\rangle$ & Grabow,Viëtor & Siebs & Beispiele \\
\hline Wortanlaut & [g] & [g] & gut [gutt] / [guit] \\
\hline $\begin{array}{l}\text { Silbenanlaut im } \\
\text { Wortinlaut }\end{array}$ & 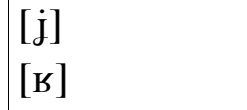 & [g] & $\begin{array}{l}\text { Liege [l'i:jə] / [l'igg] } \\
\text { zogen [ts'о:Бən] / [ts'orgən] }\end{array}$ \\
\hline Silbenauslaut & $\begin{array}{l}\text { [ç] } \\
{[\mathrm{x}]}\end{array}$ & [k] & $\begin{array}{l}\text { Berg [berç] / [berk] } \\
z o g \text { [tso:x] / [tso:k] } \\
\text { Wagnis [v'a:xnIs] / [v'a:knis] }\end{array}$ \\
\hline$<$-ig $>,<$-iglich $>$ & $\begin{array}{l}{[c ̧]} \\
{[\dot{j}]} \\
{[c ̧]}\end{array}$ & $\begin{array}{l}{[c ̧]} \\
{[g]} \\
{[\mathrm{k}]}\end{array}$ & 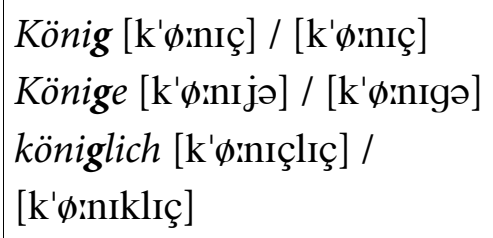 \\
\hline $\begin{array}{l}\text { apostrophierter Ausfall } \\
\text { von }<i>\end{array}$ & [j] & [ذ] & ew'ge ['e:vjə] / ['e:vjə] \\
\hline
\end{tabular}

Tab. 4: Empfehlungen für die Aussprache von $<\mathrm{g}>$

Die Auslautverhärtung von Konsonanten wurde in der Literatur des 19. Jahrhunderts explizit nur für einige Plosive beschrieben. Diverse Beispiele weisen jedoch darauf hin, dass diese auch bei Frikativen umgesetzt werden müsse.

Für die Bühne wurde empfohlen, jeden Laut einzeln und genau zu realisieren. Dies hätte zur Folge, dass Konsonanten sich nicht gegenseitig beeinflussen dürften. So würden Konsonanten nicht durch progressive Assimilation entstimmlicht (ratsam). Da Plosive immer aspiriert sein sollen, müsste bei folgendem Konsonanten vermutlich immer kurz abgesetzt werden (täg-lich). Der entsprechenden Literatur war nicht zu entnehmen, ob und wie deutlich zwei stimmlose Konsonanten voneinander getrennt werden müssten (Apfel, Katze, wachsen). Der Begriff »Affrikate«, welcher heute oft verwendet wird, um solche Verbindungen zu beschreiben, war in der Fachliteratur des 19. Jahrhunderts nicht zu finden. An Wortgrenzen dürften keine Laute übergebunden werden. Dazu müsse die Auslautverhärtung beachtet und zwischen benachbarten ähnlichen Lauten kurz abgesetzt werden (dankend dir). Somit war die Bühnenaussprache im 19. Jahrhundert vermutlich durch eine häufige und deutliche Trennung einzelner Konsonanten gekennzeichnet. 


\section{c) Suprasegmentalia}

Die in der Fachliteratur beschriebene Wort- und Satzakzentuierung ähnelt dem heutigen Aussprachestandard. So könnte angenommen werden, dass auch die generelle Rhythmisierung der Bühnenaussprache im 19. Jahrhundert betreffend keine Auffälligkeiten gegenüber der heutigen Aussprache zu verzeichnen seien. Tatsächlich konnten der verwendeten Literatur aber zu wenige genaue Aussagen zu rhythmischen Mitteln (Akzentuierungsmittel, Pausensetzung) entnommen werden, um aussagekräftige Vergleiche anstellen zu können. Es kann vermutet werden, dass in der Bühnenaussprache im 19. Jahrhundert versucht wurde, jedes akzentuierbare (in der Regel autosemantische) Wort zu akzentuieren, unabhängig von Sprechausdruck und Tempo. Diese Annahme könnte aber auch nur auf zu strikt formulierte Regeln in der entsprechenden Literatur zurückgeführt und der tatsächlichen Bühnenaussprache des 19. Jahrhunderts nicht gerecht werden.

Lyrische Darbietungsformen schienen maßgeblich von der antiken Verslehre beeinflusst zu sein. Strittig ist, ob entsprechende Betonungen durch Länge und Kürze der Silben oder primär durch Tonstärkeakzente gekennzeichnet sind. In beiden Fällen wurde für die Bühne eine regelhafte Umsetzung der entsprechenden Versmaße gefordert.

Auch die beschriebene Melodisierung ähnelt zunächst der des heutigen Aussprachestandards. Trotzdem fehlen weitere, genauere Anhaltspunkte, um differenzierte Aussagen zu Form und Ausmaß einer damaligen bühnengerechten Melodisierung geben zu können. Extreme wie singende oder monotone Melodisierungen seien jedoch zu vermeiden gewesen. 


\section{Anwendbarkeit der Ergebnisse}

Zu Beginn wurde das Ziel formuliert, Ergebnisse zu erarbeiten, die im Rahmen künstlerischer Arbeit anwendbar gemacht werden können. Daher sollen nun Hinweise formuliert werden, mit deren Hilfe Schauspieler:innen unter fachlicher Anleitung eine historisch informierte Aussprache des Deutschen erarbeiten können, die sich den Idealen im 19. Jahrhundert weitestgehend annähert. Natürlich ist dies nicht als eine Art Lehrwerk zu verstehen. Es werden lediglich Merkmale genannt, die die damalige Bühnenaussprache maßgeblich von der heutigen Standardaussprache unterscheiden, sowie Hinweise gegeben, wie diese sprecherisch umgesetzt werden können. Zusätzlich werden Beispielwörter transkribiert, um eine mögliche Aussprache zu veranschaulichen.

\section{a) Vokale}

Eine der Bühnenaussprache des 19. Jahrhunderts ähnliche Realisierung von Vokalen dürfte von qualifizierten Sprecher:innen relativ schnell zu erlernen sein. Als Referenz kann Siebs' Grundzüge der Bühnenaussprache (1900) empfohlen werden. Da die dort beschriebene Aussprache von Vokalen sich weitgehend mit dem heutigen Aussprachestandard deckt, dürfte die Wahl der jeweils richtigen Vokalqualität und -quantität keine große Hürde darstellen. Im Zweifelsfall könnte es auch lohnenswert sein, Einträge des Deutschen Aussprachewörterbuchs (Krech et al. 2010) mit Siebs' Empfehlungen und Beispielen abzugleichen. In einzelnen Fällen können hier Abweichungen gefunden werden (kurzer Vokal in Walfisch, Herzog; langer Vokal in tätscheln, Börse).

Die E-Vokale unterlagen im 19. Jahrhundert einigen regionalen Schwankungen. So könnte etwa in der Auseinandersetzung mit Werken des in Dresden aufgewachsenen Richard Wagner untersucht werden, ob Dresden und auch Gewehr, Kehle oder Beere anstelle des geschlossenen Vokals mit $[\varepsilon:]$ realisiert werden, wie es gegenwärtige regionale Aussprachformen in und um Dresden nahelegen würden. Da im 19. Jahrhundert noch nicht geklärt war, ob dieses Merkmal als dialektal zu gelten hatte, könnte die Verwendung von [ $[\varepsilon$ : in diesen Beispielen durchaus als adäquat betrachtet werden:

- Dresden [dr'eisdən] (heute [ds'eisdn]);

- Gewehr [gəv'Err] (heute [gəv'e:: $\left.\left.{ }^{\mathrm{E}}\right]\right)$;

- Kehle [k'c:lə] (heute [k'e:lə]);

- Beere [b'crrə] (heute [b'e:sə]).

Häufiger auftretende Merkmale, die die damalige Bühnenaussprache deutlich vom heutigen Aussprachestandard unterscheiden, sind die durchgängige Realisation des Schwa und das Fehlen von vokalisiertem R. So sollten alle Silben (<-er>, <-el $>,<-$ en $>$ ) mit [ə] und folgendem Konsonanten realisiert werden. Ebenso sollte in der Vorsilbe $<$ er- $>$ vokalisiertes $\mathrm{R}[\mathrm{e}]$ durch [ $[\varepsilon \mathrm{r}]$ ersetzt werden: 
- Gabel [g'a:bəl] (heute [g'a:bl]);

- fliegen [fl'irgən] (heute [fl'irgì]);

- lieber [l'ibər] (heute [l'ibbe]);

- erfragen [erfr'a:gən] (heute [efu'a:gì]);

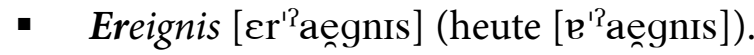

Die Fachliteratur des 19. Jahrhunderts legt nahe, dass die zweiten Vokale der deutschen Diphthonge gespannter waren als die Vokale, die im Deutschen Aussprachewörterbuch (Krech et al. 2010) transkribiert werden. Auch wird hier zum Teil zwischen $<$ ei $>$ (dunkler) und $<$ ai $>$ (heller) unterschieden. Anhand von transkribierten Beispielwörter soll gezeigt werden, wie Diphthonge realisiert werden könnten:

- Eisen ['aenzən] (heute ['açzn]);

- Kaiser [k'arzər] (heute [k'aęze]);

- Laute [1'auntə] (heute [1'aontə]);

- heute [h'oфtə] (heute [h'oœtə]);

- äußern ['oỵsərn] (heute ['oœesen]).

Insgesamt sollte eine gleichbleibend hohe Artikulationsspannung und -präzision gewährleistet sein, um dem Anspruch nach größter Genauigkeit auf der Bühne gerecht zu werden. Tatsächlich dürfte es sich lohnen, gemäß Goethes Empfehlung eine übertrieben genaue Aussprache jedes Vokals anzustreben. Dies mag aus heutiger Sicht selbst auf der Bühne unangemessen unnatürlich wirken, entspricht aber vermutlich eher der Bühnenaussprache im 19. Jahrhunderts.

\section{b) Konsonanten}

Auch hier kann der Großteil der Laute gemäß dem heutigen Aussprachestandard realisiert werden. Der Bühnenaussprache des 19. Jahrhunderts wird sich durch das Realisieren einiger bestimmter Merkmale genähert.

Am auffälligsten ist das immer gleich zu realisierende Zungenspitzen- $\mathrm{R}$ [r]. Die Anweisung ist einfach, die Umsetzung bedarf jedoch einiger Übung. Jedes $<\mathrm{r}>$ sollte als $[\mathrm{r}]$ mit gleicher deutlicher Qualität realisiert werden. Auch vokalisiertes oder vermindertes $\left.R\left([\mathrm{~b}],\left[^{\mathrm{b}}\right],{ }^{[}\right]\right)$sollte durch $[r]$ ersetzt werden:

- jeder [j'e:dər] (heute [j'e:de]);

- erfragen [erfr'a:gən] (heute [efu'a:gì]);

- Arbeit ['arbaent] (heute ['a $\left.{ }^{\mathrm{b}} \mathrm{bac} \mathrm{t} t\right)$ );

- vorher [f'orrhe:r] (heute [f'o: $\left.\left.{ }^{\mathrm{p}} h \mathrm{I}^{\mathrm{e}}\right]\right)$.

Da die Aussprache von $<\mathrm{g}>$ in verschiedenen Positionen strittig war, sollte sich hier für eine Empfehlung entschieden werden. Der einfachste Weg wäre, sich an Siebs (1900) zu orientieren, dessen Empfehlungen für die Aussprache von $<\mathrm{g}>$ mit dem heutigen Aussprachestandard übereinstimmen. Es wäre jedoch ebenso legitim, Grabows (1877c) und Viëtors (1885) Empfehlungen 
$\mathrm{zu}$ folgen, die ein durchaus logisches, wenn auch weniger schriftnahes System für die Aussprache von $<\mathrm{g}>$ erarbeitet haben. Die auffälligen Abweichungen vom heutigen Aussprachestandard durch den Einbezug mehrerer Konsonanten machen dieses System für den Versuch, die Bühnenaussprache des 19. Jahrhundert zu präsentieren, durchaus reizvoll.

Einen Merkmalskomplex, der die Bühnenaussprache des 19. Jahrhundert deutlich von der heutigen Standardaussprache unterscheidet, stellt die einzelne sowie genaue Realisierung jedes Konsonanten dar. So sollte auf Assimilationen und Überbindungen verzichtet werden. Ebenso sollte versucht werden, Fortisplosive auch bei folgenden Konsonanten so oft es geht deutlich zu aspirieren. Es dürfte eine Herausforderung darstellen, Lautgrenzen zwischen Konsonanten nicht durch allzu deutliche Pausen zu realisieren. Trotz genauer Lautgrenzen einen angemessenen Sprechfluss beizubehalten, ist anspruchsvoll und muss ausgiebig geübt werden. Die folgenden Beispiele sind sehr genau transkribiert. Stimmhafte Konsonanten sind also bewusst nicht entstimmlicht, gleiche Konsonanten nicht übergebunden und die Aspiration von Fortisplosiven ist angegeben (außer bei fraglichem [pf], [ts], [ks]):

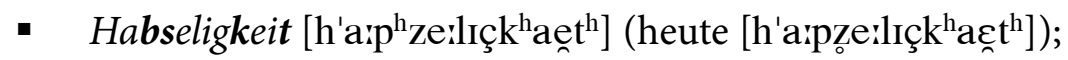

- dies sei [dirs zaen] (heute [dirš zą] ]);

- $\boldsymbol{q u e r}\left[\mathrm{k}^{\mathrm{h}} \mathrm{ver}\right]$ (heute $\left.\left[\mathrm{kve:}^{\mathrm{e}}\right]\right)$;

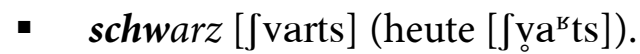

Auch bei der Aussprache der Konsonanten ist sehr hohe Artikulationsspannung und -präzision gefordert. Die zu realisierenden Aussprachemerkmale treten in der deutschen Sprache mit einer solchen Häufigkeit auf, dass es zunächst kaum möglich sein wird, einen natürlichen Sprechfluss herzustellen. Eine bühnentaugliche Umsetzung der Besonderheiten der Bühnenaussprache des 19. Jahrhunderts bedarf wahrscheinlich ausgiebiger Übung.

\section{c) Suprasegmentalia}

Bei der Erarbeitung von Stücken in Versform ist das entsprechende Versmaß einzuhalten. Dies setzt voraus, dass sich die Schauspieler:innen mit dem Erkennen und Realisieren auch antiker Versmaße auseinandersetzen. Die gesteigerte Konzentration, die nötig ist, um die genannten segmentalen Aussprachemerkmale zu realisieren, führt vermutlich zunächst dazu, dass der gesamte Sprechvortrag an Lebendigkeit einbüßt. Dies könnte sich in einer monotonen Melodisierung äußern, vor der einige zeitgenössische Autoren warnen. Trotz des notwendigen Fokus auf einzelne Laute, Lautübergänge und kurze Phrasen sollte ein kunstfertiger und bühnentauglicher Sprechvortrag angestrebt werden, der entsprechend lebendiger Rhythmisierung und Melodisierung bedarf. 


\section{Zusammenfassung und Fazit}

Bevor ein Fazit formuliert wird, soll eine Auswahl der auffälligsten Ergebnisse der Untersuchung noch einmal zusammengefasst werden:

- Viele der beschriebenen Vokale und Konsonanten gleichen in ihrer Bildung und Verwendung weitgehend der heutigen deutschen Standardaussprache.

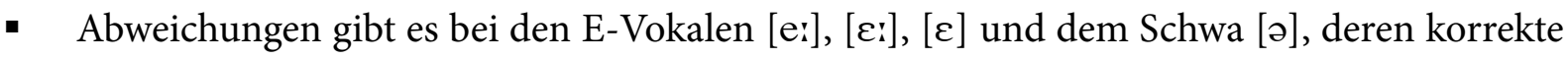
Verwendung auch innerhalb der Literatur des 19. Jahrhunderts unterschiedlich beschrieben wird.

- Bei den Konsonanten fallen die konsequente Verwendung des Zungenspitzen- $\mathrm{R}$ [r] und die Uneinigkeit über die Aussprache von $<\mathrm{g}>$ auf.

- In der analysierten Literatur wird mehrfach der Anspruch an die Bühnenaussprache formuliert, jeden Laut einzeln und deutlich auszusprechen. Dies legt die Vermutung nahe, dass Koartikulations- und Assimilationsprozesse vermieden werden sollten.

- Die im 19. Jahrhundert für das Sprechen auf der Bühne beschriebenen Suprasegmentalia Wort- und Satzakzentuierung, Rhythmisierung und Melodisierung stimmen in ihren Grundzügen mit der heutigen Standardaussprache überein.

Diese Aussagen sind das Ergebnis einer Untersuchung, welche in dem begrenzten Rahmen einer Masterarbeit stattfand. Es handelt sich um Normen deutscher Bühnenaussprache, die mit Hilfe einer kleinen Auswahl von Fachliteratur des 19. Jahrhunderts erarbeitet wurden. Wie einleitend erwähnt, können die hier beschriebenen Aussprachemerkmale sicher nicht die tatsächliche Bühnenaussprache im 19. Jahrhundert darstellen. Trotzdem sind die Ergebnisse insbesondere im segmentalen Bereich bereits aussagekräftig, wobei Tendenzen zum einen oder anderen Merkmal noch weiter untersucht werden müssten. Die Suprasegmentalia des Bühnensprechens im 19. Jahrhundert konnten nur in ihren grundlegenden Strukturen beschrieben werden. Hier sind künftig detailliertere Ergebnisse zu erhoffen. Noch fast gänzlich steht eine sprechwissenschaftliche Auseinandersetzung mit der Gesangsaussprache im 19. Jahrhundert aus, bei der gegenüber der Sprechbühne weitere Faktoren zu berücksichtigen sind.

Die Gemeinsamkeiten der beschriebenen Aussprachenormen lassen insgesamt die Vermutung $\mathrm{zu}$, dass sich das bisher entstandene Bild der damaligen Bühnenaussprache bei weiterführender Analyse festigen wird. Eine solche Analyse ist in Planung: Ziel des an diese Arbeit anschließenden Promotionsvorhabens soll sein, die gesamte zur Verfügung stehende Literatur des 19. Jahrhunderts auf Aussagen zu Merkmalen zeitgenössischer Aussprachenormen für das Sprechen und Singen auf der Bühne zu untersuchen. Die bereits erarbeiteten Ergebnisse sollen dabei genutzt, überprüft und erweitert werden. Im Sinne einer Orientierung an den Zielen von Wagner-Lesarten ist hier auch eine detaillierte Auseinandersetzung mit der Gesangsaussprache im 19. Jahrhundert geplant. 


\section{Verzeichnis der verwendeten Literatur}

Benedix, Roderich (1870): Katechismus der Redekunst. Anleitung zum mündlichen Vortrage. Verlagsbuchhandlung J. J. Weber Leipzig.

Benedix, Roderich (1862): Das Wesen des deutschen Rhythmus. Beitrag zur deutschen Verslehre. Johann Friedrich Hartknoch Leipzig.

Benedix, Roderich (1859): Der Mündliche Vortrag. Erster Theil. Die reine und deutliche Aussprache des Hochdeutschen. Verlagsbuchhandlung J. J. Weber Leipzig.

Bose, Ines / Hirschfeld, Ursula / Neuber, Baldur / Stock, Eberhard (2013): Einführung in die Sprechwissenschaft. Phonetik, Rhetorik, Sprechkunst. Narr Francke Attempto Verlag GmbH + Co. KG Tübingen.

Diederichs, Aug. (1884): Über die Aussprache von sp st, g und ng. Ein Wort zur Verständigung zwischen Nord und Süd. Karl J. Trübner Strassburg.

Ebel, Alexandra / Hirschfeld, Ursula / Stock, Eberhard (2013): Zusatzmaterial zu Bose et al., Einführung in die Sprechwissenschaft, Kap. B. Glossar.

$<$ http://meta.narr.de/9783823367703/B_Glossar.pdf> (10.02.2021)

Goethe, Johann Wolfgang von (1970): Berliner Ausgabe 17. Kunsttheoretische Schriften und Übersetzungen. Aufbau-Verlag Berlin und Weimar.

Grabow, August (1877a): Die dialektfreie Aussprache des Hochdeutschen nach physiologischen, sprachgeschichtlichen und statistischen Thatsachen. Von den Consonanten. I. Abschnitt. Physiologie der Consonanten. In: Archiv für das Studium der neueren Sprachen und Literaturen. XXXI. Jahrgang, 57. Band. George Westermann Braunschweig, 41-58.

Grabow, August (1877b): Die dialektfreie Aussprache des Hochdeutschen nach physiologischen, sprachgeschichtlichen und statistischen Thatsachen. Von den Consonanten. II. Abschnitt. Von der Darstellung der Consonantlaute durch die Schrift. In: Archiv für das Studium der neueren Sprachen und Literaturen. XXXI. Jahrgang, 57. Band. George Westermann Braunschweig, 411-440.

Grabow, August (1877c): Die dialektfreie Aussprache des Hochdeutschen nach physiologischen, sprachgeschichtlichen und statistischen Thatsachen. Von den Consonanten. Capitel III. Von der Aussprache des K, G, Ch, den Schriftzeichen für die Gaumen- und Kehllaute. In: Archiv für das Studium der neueren Sprachen und Literaturen. XXXI. Jahrgang, 58. Band. George Westermann Braunschweig, 345-378.

Grabow, August (1875): Die dialektfreie Aussprache des Hochdeutschen nach physiologischen, sprachgeschichtlichen und statistischen Thatsachen. In: Archiv für das Studium der neueren Sprachen und Literaturen. XXX. Jahrgang, 54. Band. George Westermann Braunschweig, 367-392.

Grimm, Jacob / Grimm, Wilhelm (1852-1960): Deutsches Wörterbuch [Online-Version]. $<$ http://woerterbuchnetz.de/cgi-bin/WBNetz/wbgui_py?sigle=DWB $>(10.02 .2021)$ 
Guttmann, Oskar (1882): Die Gymnastik der Stimme, gestützt auf physiologische Gesetze. Eine Anweisung zum Selbstunterricht in der Übung und dem richtigen Gebrauche der Sprach- und Gesangsorgane. Verlagsbuchhandlung J. J. Weber Leipzig.

Hey, Julius (1882): Deutscher Gesangsunterricht. Lehrbuch des sprachlichen und gesanglichen Vortrags. I. Sprachlicher Theil. B. Schott's Söhne Mainz.

Hoffmann, Hugo (1888): Einführung in die Phonetik und Orthoepie der deutschen Sprache. Für Volksschullehrer, angehende Taubstummenlehrer, wie für alle Freunde der Phonetik unter Benutzung der besten Quellen. N. G. Elwert'sche Verlagsbuchhandlung Marburg.

Jung, Erdmann (1879): Die Aussprache des deutschen Buchstaben G und Herr Professor Heinrich Dorn. In: Musikalisches Wochenblatt. X. Jahrgang, No. 25. E. W. Fritzsch Leipzig, 293-306.

Knörrich, Otto (1992): Lexikon lyrischer Formen. Alfred Kröner Verlag Stuttgart.

Kräuter, J. F. (1879): Das neuhochdeutsche G. In: Blätter für das Bayerische Gymnasial- und RealSchulwesen. Fünfzehnter Band. J. Lindauer'sche Buchhandlung München, 393-395.

Krech, Eva-Maria / Stock, Eberhard / Hirschfeld, Ursula / Anders, Lutz Christian (2010): Deutsches Aussprachewörterbuch. Walter de Gruyter Berlin / New York.

Michaelis, G. (1862): Über den Unterschid der Consonantes Tenues und Mediae und über die Unterscheidung des Ach- und Ich-Lautes. Ferd. Dümmler's Verlagsbuchhandlung Berlin.

Minckwitz, Johannes (1863): Lehrbuch der deutschen Verskunst oder Prosodie und Metrik. Arnoldische Buchhandlung Leipzig.

Rocca, Otto (1889): Die richtige Aussprache des Hochdeutschen. Wilhelm Werthers Verlag Rostock.

Rötscher, Heinrich Theodor (1841): Die Kunst der dramatischen Darstellung. Verlag von Wilhelm Thome Berlin.

Schmolke, Hermann (1890): Regeln über die deutsche Aussprache. R. Gaertners Verlagsbuchhandlung Berlin.

Siebs, Theodor (1900): Grundzüge der Bühnenaussprache. Verlag von Albert Ahn Berlin, Köln und Leipzig.

Trautmann, Moritz (1884-1886): Die Sprachlaute im Allgemeinen und die Laute des Englischen, Französischen und Deutschen im Besonderen. Verlag von Gustav Fock Leipzig.

Viëtor, Wilhelm (1885): German Pronunciation: Practice and Theory. Henninger Bros. Heilbronn. 


\section{Weiterführende Literatur}

Hirschfeld, Ursula / Müller, Kai Hinrich (2018): »Wer g nicht von ch zu unterscheiden vermag, ist ein undeutscher Barbar ... . - Richard Wagner und die (Gesangs-)Aussprache des Deutschen im mittleren 19. Jahrhundert [Online-Version].

$<$ https://wagner-lesarten.de/bd-1-wagner-und-aussprache.html> (10.02.2021)

Knust, Martin (2016): Musical and Theatrical Declamation in Richard Wagner's Works and a Toolbox for Vocal Music Analysis. In: Danish Musicology Online Special Edition. Proceedings of the 17th Nordic Musicological Congress.

$<$ http://www.danishmusicologyonline.dk/arkiv/arkiv_dmo/dmo_saernummer_2016/dmo_saer nummer_2016_NMC_05.pdf> (10.02.2021)

Schafroth, Elmar (2013): Sprache und Musik. Zur Analyse gesungener Sprachen anhand von Opernarien. (Erweiterte Fassung [33 S.]).

$<$ http://www.romanistik.hhu.de/fileadmin/redaktion/Fakultaeten/Philosophische_Fakultaet/R omanistik/Romanistik_4_Sprachwissenschaft/Dateien/Schafroth_Detailseite/Publikationen/Sp rache_und_Musik_Erweitere_Fassung_2013_02_01_korr_01.pdf> (10.02.2021)

Weithase, Irmgard (1961): Zur Geschichte der gesprochenen deutschen Sprache. Bd. 1 \& 2. Max Niemeyer Verlag Tübingen.

Weithase, Irmgard (1940): Die Geschichte der deutschen Vortragskunst im 19. Jahrhundert. Anschauungen über das Wesen der Sprechkunst vom Ausgang der deutschen Klassik bis zur Jahrhundertwende. Verlag Hermann Böhlaus Nachfolger Weimar. 


\section{Anhang}

Anhang 1: Glossar

Anhang 2: Abbildungen zu Lautsystemen in der Fachliteratur des 19. Jahrhunderts

\section{Anhang 1: Glossar}

Das Glossar entstammt dem Zusatzmaterial zu Bose et al. (2013): Einführung in die Sprechwissenschaft. Es wurde den Zwecken dieses Aufsatzes entsprechend gekürzt. Das vollständige Glossar kann unter http://meta.narr.de/9783823367703/B_Glossar.pdf (10.02.2021) eingesehen werden.

Akzent, Akzentuierung - Hervorhebung (Betonung) von Lauten, Silben oder Wörtern durch phonetische Auszeichnung meist mittels suprasegmentaler Merkmale, Typisch für das Deutsche ist eine starke, zentralisierende Akzentuierung. Dadurch entsteht eine rhythmische Kontur, die als Schwer-Leicht-Struktur wahrgenommen wird und sich beim Sprechen als unregelmäßiger, aber nicht regelloser Wechsel von akzentuierten und akzentlosen Silben zeigt. $\rightarrow$ Wortakzent, Wortgruppenakzent

Allophon - Realisierungsvariante eines $\rightarrow$ Phonems. Jedes Phonem hat mehrere Allophone, die dadurch entstehen, dass ein Phonem in verschiedenen Lautumgebungen und unter verschiedenen prosodischen Bedingungen realisiert wird, z. B. gibt es stimmhafte und stimmlose Lenisplosive und Lenisfrikative. Ein anderes Beispiel sind die R-Realisationen ( $\rightarrow$ Reibe-R). Jede Lautumgebung beeinflusst einen Laut auf spezifische Weise. Außerdem wirkt sich aus, ob die Silbe, zu der der Laut gehört, akzentuiert oder akzentlos ist. Laute in Akzentsilben werden im Deutschen viel präziser als in akzentlosen Silben artikuliert. $\rightarrow$ Artikulation, Assimilation

Artikulation - Bewegungen und Einstellungen der $\rightarrow$ Artikulationsorgane zur Erzeugung von sprachlichen Lauten und Lautfolgen.

Artikulationsorgane - Organe, mit denen sprachliche Laute als Schallereignisse erzeugt werden können. Es gibt passive und aktive Organe. Passiv beteiligt sind der Rachenraum, die Nasenhöhlen und der Mundraum mit Zähnen und Alveolen, aktiv dagegen die Atmungsorgane, der Kehlkopf mit den Stimmlippen, der weiche Gaumen mit dem Zäpfchen (Uvula), der Unterkiefer, die Lippen und vor allem die Zunge, die als das beweglichste Artikulationsorgan mit Zungenspitze, Zungenrücken und Zungenwurzel artikuliert.

Aspiration $\rightarrow$ Behauchung 
Assimilation - Angleichung der Laute während der Artikulation. Es gibt mehrere Arten der Assimilation. Bei der progressiven Assimilation beeinflusst ein Laut den oder die folgenden Laut(e), z. B. geht die Stimmhaftigkeit des [z] nach [k] in wegsehen verloren (vorwärts wirkende Lautangleichung). Wirkt ein Laut auf einen vorausgehenden Laut ein, spricht man von regressiver Assimilation (rückwärts wirkende Lautangleichung). Ein Beispiel hierfür ist die nasale Verschlusslösung des [t] vor [n] nach Schwa-Elision in bitten. Die Angleichung ist meist partiell, d. h. sie erfolgt nur bei bestimmten Artikulationsmerkmalen. Bei einer Totalassimilation wird dagegen ein Laut einem anderen Laut, der die Assimilation bestimmt, vollkommen angeglichen,

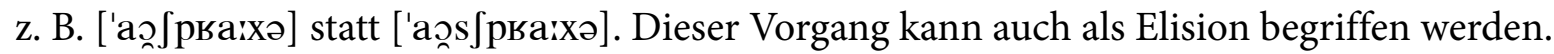
$\rightarrow$ Elision, Koartikulation

Auslautverhärtung - Verhärtung der Leniskonsonanten [b d g v z] am Wort- und Silbenende $\mathrm{zu}$ den entsprechenden Fortiskonsonanten [p t k f s]: (er) leb-te, Haus. Bei Verschiebung der Silben- oder Wortgrenze durch Flexion entfällt die Verhärtung: le-ben, Häu-ser.

Behauchung - Erzeugung eines deutlichen Sprenggeräuschs bei den Fortisplosiven. Bei der Sprengung des Verschlusses wird die angestaute Ausatmungsluft mit einem verstärkten kräftigen Hauchgeräusch herausgepresst. $\rightarrow$ Plosive

Dauer - In der Phonetik die subjektiv bewertete Sprechzeit, d. h. die Zeit, die gebraucht wird, um einen Laut, eine Silbe usw. zu erzeugen (akustisch: gemessene zeitliche Länge von Signalabschnitten). Sie hängt von der Sprechgeschwindigkeit ab, aber auch von der Wortlänge. Im Deutschen wird sie als distinktives Merkmal der Vokale gebraucht (Quantitätsdistinktion lang vs. kurz, z. B. Staat - Stadt); sie dient aber auch lautübergreifend der Hervorhebung (Akzentuierung) in Wort, Wortgruppe und Äußerung. $\rightarrow$ distinktiv

Diphthonge - Zwielaute; enge Verbindung von zwei kurzen Vokalen, die innerhalb einer Silbe wie ein langer Vokal verwendet werden. Dabei gleiten die Artikulationsorgane von der Stellung für den ersten Vokal stufenlos in die Stellung für den zweiten Vokal. Die deutschländische Standardsprache hat nur »fallende« Diphthonge, das heißt, der erste Vokal wird mit größerer Lautheit gebildet als der zweite Vokal. Bei »steigenden« Diphthongen hat der zweite Vokal größeres Gewicht. Phonologisch können die deutschen Diphthonge als eine Verbindung von zwei Phonemen (biphonematisch) oder als ein Phonem (monophonematisch) gewertet werden. $\rightarrow$ Phonem

distinktiv - bedeutungsunterscheidend, vor allem für die Bewertung der Lautmerkmale verwendet. Als distinktiv werden diejenigen Merkmale bezeichnet, die für die phonologischen Oppositionen einer Sprache relevant sind. Phonologische (distinktive) Oppositionen bestehen zwischen zwei Lauten, die in einem Paar von Wörtern mit ungleicher Bedeutung allein den 
Lautbestand dieser Wörter unterscheiden, z.B. Deck/dek/ vs. Dock/d॰k/. Die Gesamtheit der distinktiven Merkmale, mit der ein Laut eine phonologische Opposition zu allen anderen Lauten der jeweiligen Sprache bildet, wird als $\rightarrow$ Phonem bezeichnet. Unterscheiden Lautmerkmale nur die $\rightarrow$ Sprach-/Sprechlaute ( $\rightarrow$ Allophone) für ein Phonem, dann sind sie phonologisch irrelevant (belanglos, unbedeutend), d. h. sie haben für die Phonemunterscheidung keine Bedeutung.

Elision - Ausfall eines Lautes oder einer Lautgruppe. $\rightarrow$ Koartikulation, Assimilation

Endlauf - Verlauf der Sprechmelodie in einer Äußerung von der letzten Akzentstelle an [...]. Der Endlauf zeigt an, ob eine Wortfolge abgeschlossen (fallende Melodie) oder nichtabgeschlossen ist (schwebende Melodie), ob sie eine Aussage (fallende Melodie) oder eine Ja-NeinFrage darstellt (steigende Melodie). Außerdem ist am Endlauf zu erkennen, ob der Sprecher sachbetont (Bevorzugung der fallenden Melodie in allen Äußerungen, auch bei Fragen) oder kontaktbetont (Bevorzugung der steigenden Melodie, auch bei kurzen Aussagen), mit wenig Emotion (kleiner Melodiefall oder kleine Melodieintervalle) oder mit viel Emotion (großer Melodiefall oder große Melodieintervalle) spricht.

fortis - stark gespannt. Bei der Bildung von Plosiven und Frikativen deutliche Anspannung der Artikulationsmuskulatur, was zu einem kräftigen Explosionsgeräusch (bei $\rightarrow$ Plosiven, Behauchung) oder einem kräftigen Reibegeräusch (bei $\rightarrow$ Frikativen) führen kann. Wegen des kräftigen Ausatmungsstroms bei der Geräuschbildung sind die so artikulierten Konsonanten stimmlos. Gegensatz: $\rightarrow$ lenis

Frikative - Konsonanten, die durch spezifische Reibegeräusche gekennzeichnet sind. Die jeweiligen Geräusche entstehen durch die Ausatmungsluft in einer Enge, die an verschiedenen Artikulationsstellen gebildet wird: labio-dental, alveolar, präpalatal, palatal, velar. Das Geräusch kann kräftig (Fortis-Frikative) oder schwach sein (Lenis-Frikative). Das Deutsche hat fünf Paar Frikative. Die Fortisplosive sind immer stimmlos, die Lenis-Frikative treten stimmhaft und stimmlos (entstimmlicht) auf. $\rightarrow$ Stimmhaftigkeit, Stimmlosigkeit, Stimmlosigkeitsassimilation, fortis, lenis

geschlossene Silbe $\rightarrow$ offene Silbe, Silbe

gespannte Vokale - Im Unterschied zu den $\rightarrow$ ungespannten Vokalen werden die gespannten Vokale mit etwas geringerer Mundöffnung, etwas stärkerer Hebung des Zungenrückens und etwas gespannterer Artikulationsmuskulatur gebildet. Dies bewirkt einen deutlichen Klangunterschied zwischen den gespannten und den entsprechenden ungespannten Vokalen. Für die 
Standardaussprache ist dieser Unterschied charakteristisch. Mit Ausnahme des langen ungespannten [E:] sind im Deutschen die gespannten Vokale lang. Die ungespannten Vokale sind kurz. [a:] und [a] werden jedoch nur quantitativ, nicht qualitativ unterschieden. In Pronomen, Artikeln, Präpositionen und Konjunktionen, die einen langen gespannten Vokal enthalten, wird der Vokal oft gekürzt oder als kurzer ungespannter Vokal gesprochen. Das geschieht, wenn diese meist nichtakzentuierten Wörter schnell gesprochen werden. $\rightarrow$ Vokal, Qualität, Quantität

Hauptakzent - In einem zusammengesetzten Wort ( $\rightarrow$ Kompositum) oder in einer zusammenhängend realisierten Wortgruppe erhält eines der beteiligten Wörter den Hauptakzent. Es wird stärker hervorgehoben als die anderen Wörter, die entweder unbetont sind oder nur einen Nebenakzent erhalten.

\section{Kehlkopfknacklaut (Glottisplosiv) $\rightarrow$ Neueinsatz}

Koartikulation - Lautübergreifende Bewegung und Einstellung der $\rightarrow$ Artikulationsorgane bei der Lauterzeugung. Beim Sprechen wird nicht Laut für Laut als diskrete Einheit erzeugt, Lautfolgen entstehen vielmehr in einem kontinuierlichen Bewegungsprozess der Artikulationsorgane, die präzise gesteuert zusammenspielen und deren fließender Bewegungsablauf kaum unterteilt werden kann. Für die $\rightarrow$ Artikulation eines Lautes sind meist nicht alle Artikulationsorgane notwendig. Die nicht direkt beteiligten Organe haben deshalb oft noch die Einstellung für die vorausgehenden Laute, oder sie bereiten die folgenden Laute vor. Im Wort Tor z. B. ist für $[t]$ nur die Verschlussbildung im Mundraum erforderlich. Die Lippen stellen sich folglich bereits auf das [o:] ein und wölben sich vor. Das Sprenggeräusch des Plosivs hat demzufolge einen dunklen Beiklang. $\rightarrow$ Assimilation

Kompositum - Zusammensetzung von zwei oder mehreren selbständigen Wörtern zu einem neuen Wort, dessen Akzentuierung von der Art der Zusammensetzung abhängt. In Determinativkomposita (= Bestimmungswort + Grundwort, z. B. Bücherregal) trägt das erste Glied als das bestimmende, determinierende Wort den Hauptakzent, das zweite Glied einen Nebenakzent; in Kopulativkomposita (Zusammensetzung durch Aneinanderreihung, z. B. Nord-Ost) liegt der Hauptakzent auf dem letzten Glied.

Konsonant - Sprachlaut, der sich nach der Bildung, dem Klang und der Verwendung von einem $\rightarrow$ Vokal unterscheidet. Verschluss- und Engebildung im Mund sind die kennzeichnenden Artikulationsmerkmale. $\mathrm{Zu}$ den Konsonanten zählen die nur mit Geräusch gebildeten Laute (stimmlose Plosive und Frikative sowie der Hauchlaut), die mit Klang und Geräusch gebildeten Laute (stimmhafte Plosive und Frikative) und Konsonanten, die nur mit Klang gebildet werden 
(Nasale, Liquide). Konsonanten können im Allgemeinen ohne Vokal keine Silbe bilden. $\rightarrow$ Plosive, Frikative, Nasale, Silbe

Konsonantenhäufungen - Kombinationen von Konsonanten, die entweder zum Wortstamm gehören oder durch Flexion bzw. Zusammensetzung entstehen: kämpfen, (du) kämpfst, Kampfplatz. Zahl und Art dieser Konsonantenhäufungen sind für das Deutsche besonders charakteristisch. Sie erfordern vom Lernenden meist große Aufmerksamkeit.

Laut (Sprech- oder Sprachlaut) - Grundbegriff der Phonetik, kleinstes artikuliertes Element gesprochener Sprache, steht dem zum Gegenstand der Phonologie gehörenden $\rightarrow$ Phonem gegenüber. Wird ein Wort gesprochen, so werden seine $\rightarrow$ Phoneme mit Lauten (in der Phonologie als $\rightarrow$ Allophone, sonst auch als Sprach- oder Sprechlaute bezeichnet) wiedergegeben - die Phoneme werden »realisiert«. Bei der Realisierung werden aufeinanderfolgende Sprechlaute aneinander angeglichen; je nach der Lautumgebung verändert sich die Aussprache. $\rightarrow$ Assimilation

Laut-Buchstaben-Beziehung [Phonem-Graphem-Beziehung] - Regelsystem für die schriftliche Wiedergabe der Laute mit Hilfe von Buchstaben. Dieses Regelsystem ist sprachspezifisch. Es gibt Sprachen (z. B. das Finnische), in denen für einen Laut meist nur ein Buchstabe oder eine Buchstabenverbindung zur Verfügung stehen. Im Deutschen gibt es für die meisten Laute zwei oder mehr Wiedergabemöglichkeiten (z. B. für [v] die Buchstaben $<$ v, w $>$ Vera, Walther). Im Englischen und Französischen sind die Beziehungen noch komplizierter. Hier können manche Laute mit fünf und mehr verschiedenen Buchstaben oder Buchstabenverbindungen ausgedrückt werden. $\rightarrow$ Laut, Phonem

lenis - schwach gespannt, Gegensatz: $\rightarrow$ fortis. Bei der Bildung von $\rightarrow$ Plosiven und $\rightarrow$ Frikativen geringe Anspannung der Artikulationsmuskulatur, so dass die Laute nur schwach geräuschhaft sind und nach stimmhaften Lauten stimmhaft werden können. Nach Sprechpause und stimmlosen Lauten sind sie aber $\rightarrow$ stimmlos. $\rightarrow$ Stimmhaftigkeit, Stimmlosigkeitsassimilation

Lippenrundung (Lippenstülpung) - Artikulationsmerkmal, das in den Standardaussprachen des Deutschen für alle mit der Hinterzunge gebildeten Vokale charakteristisch, aber phonologisch irrelevant ist. Phonologisch relevant ist die Lippenrundung dagegen bei den Vorderzungenvokalen des Deutschen; sie ist hier ein Pol des distinktiven Merkmals "gerundet vs. ungerundet" (= labial vs. illabial). Bei diesen Vokalen gibt es zwei Phonemreihen: eine Reihe mit Lippenrundung /y: y $\phi$ : œ/ und parallel dazu eine Reihe ungerundeter Vokalphoneme /i: I e: $\varepsilon / . \rightarrow$ Vokale, distinktiv 
Melodie, Melodisierung (Intonation i. e. S.) - Tonhöhenbewegung der Stimme innerhalb einer Äußerung; Hauptmerkmal der Intonation i. w. S. Die Melodie ist vor allem für die Kennzeichnung der Akzentstellen und am Ende einer Wortfolge oder eines Satzes von Bedeutung. $\rightarrow$ Endlauf

Nasale - Klanglaute, bei deren Artikulation der weiche Gaumen gesenkt ist und der im Kehlkopf gebildete Stimmklang durch die Nase strömt, wo er seinen charakteristischen nasalen Klang erhält. Die Mundpassage ist durch unterschiedliche Verschlussbildungen (im Deutschen: labial, alveolar, velar) verlegt, wodurch der nasale Klang modifiziert wird.

Nebenakzent $\rightarrow$ Hauptakzent, Kompositum

Neueinsatz - allgemein phonetisches Signal für eine Grenze zwischen Wörtern oder Silben. Im engeren Sinne wird als Neueinsatz das Einsetzen der Stimmlippenschwingungen bei einem Vokal bezeichnet, der am Beginn einer Silbe oder eines Wortes steht und an einen vorausgehenden Vokal oder Konsonanten gebunden werden könnte, z. B. Bettecke [b'ct $\left.{ }^{2} \varepsilon k ə\right]$, nicht Bettdecke [b'عtddkkə]. Dabei können die Stimmlippen allmählich, weich und sanft oder, wie in der Standardaussprache des Deutschen vorgesehen, mit dem Verschluss der Stimmlippen und nachfolgender Sprengung (Glottisplosiv) zu schwingen beginnen. Das bei der Sprengung entstehende leise Explosionsgeräusch heißt auch $\rightarrow$ Kehlkopfknacklaut (Zeichen: [ $\left.{ }^{3}\right]$ ). Er ist im Deutschen jedoch kein selbständiger Laut. Bei langsamem und sorgfältigem Sprechen wird der Neueinsatz durch Kehlkopfknacklaut (= Glottisplosiv) häufiger gebraucht, besonders wenn der Vokal zu einer akzentuierten Silbe gehört. Beim schnellen Sprechen wird er dagegen oft nicht beachtet.

offene Silbe - Silbe, die auf Vokal endet: ha - ben. Im Gegensatz dazu endet eine geschlossene Silbe auf Konsonant: hal - ten.

Pause, Pausierung - Unterbrechung des fließenden Sprechens. Die Pause (akustisch: Schallabwesenheit) ist ein wichtiges Gliederungs- und damit Strukturierungssignal, das semantische und gleichzeitig rhythmisch-melodische Einheiten voneinander abgrenzt. Pausen können gefüllt sein (Atmung, Gestik/Mimik, Füllwörter wie »äh«, »hm«); in der Regel werden sie durch andere Merkmale begleitet, die auch ohne Schallabwesenheit als Grenzsignal fungieren können.

Phonem - kleinstes wortunterscheidendes (bedeutungsunterscheidendes) Element des Sprachsystems; zentraler Begriff der Phonologie, von den verschiedenen phonologischen Schulen nicht einheitlich definiert. Für N. S. Trubetzkoy, einen der Begründer der Phonologie, ist das Phonem 
kein konkreter Laut, sondern lediglich die "Gesamtheit der phonologisch relevanten Eigenschaften« des Lautes, der als artikulatorisch erzeugter Sprach- oder Sprechlaut immer auch irrelevante Eigenschaften hat. Die phonologisch relevanten Eigenschaften sind diejenigen Lautmerkmale, die die Unterscheidungsfunktion tragen und deshalb als distinktive Merkmale $(\rightarrow$ distinktiv) bezeichnet werden. Sie unterscheiden den Laut, zu dem sie gehören, zunächst von allen anderen Lauten der jeweiligen Sprache und können folglich (für die Analyse in Minimalpaaren) auch wort-/bedeutungsunterscheidend wirken. Für die Erforschung und Beschreibung wird das Phonem, also der Unterscheidungswert der einzelnen Laute, in der Prager Schule der Phonologie als »Bündel distinktiver Merkmale« gehandhabt. Da jede Sprache die physiologisch möglichen Lautgegensätze unterschiedlich ausnutzt, hat ein Laut in verschiedenen Sprachen, auch wenn er phonetisch gleich klingt, einen unterschiedlichen Phonemgehalt. Im Deutschen z. B. gehört zum Phonem /a/ wegen des Gegensatzes zu /a:/ das distinktive Merkmal lang vs. kurz, im Russischen dagegen gibt es keine phonologische Opposition der Vokalquantität, folglich gibt es im Phonem /a/ auch dieses Merkmal nicht. Alle Phoneme, die für eine Einzelsprache ermittelt worden sind, bilden zusammen das Phonemsystem dieser Sprache. Die Phoneme werden nach sprachspezifischen Regeln miteinander kombiniert [...]. Für jedes Phonem gibt es mehrere Realisierungsklassen ( $\rightarrow$ Allophone). Wird ein Wort gesprochen, so werden seine Phoneme mit $\rightarrow$ Lauten (Sprach-/Sprechlauten) wiedergegeben.

Phonetisches Zeichen $\rightarrow$ Transkription

Plosive - Konsonanten, die durch spezifische Explosionsgeräusche gekennzeichnet sind. Die jeweiligen Geräusche entstehen durch die Sprengung eines Verschlusses, der im Deutschen an drei Artikulationsstellen gebildet wird: labial, alveolar, velar. Das Sprenggeräusch kann kräftig (Fortis-Plosive) oder schwach sein (Lenis-Plosive). Das Deutsche hat drei Paar Plosive. Die Lenis-Plosive treten stimmhaft und stimmlos auf. Ist das Sprenggeräusch auffallend kräftig, so wird es als $\rightarrow$ Behauchung bezeichnet. Die Fortis-Plosive werden insbesondere behaucht, wenn sie im Anlaut akzentuierter Silben und im Wortauslaut stehen: packen, Kraft, Musik, Gewalt. $\rightarrow$ Behauchung, Stimmhaftigkeit, Stimmlosigkeitsassimilation, fortis, lenis

Qualität - Bezeichnung für die Klang- oder Geräuschfarbe der Laute. Der Begriff Qualität wird für das Deutsche vor allem verwendet, um die Klangbesonderheiten der gespannten und ungespannten $\rightarrow$ Vokale zu benennen.

Quantität - Bezeichnung für die Lautdauer. $\rightarrow$ Dauer

Reduktion $\rightarrow$ Assimilation 
Reibe-R - als Reibelaut ( $\rightarrow$ Frikativ) gebildete Realisationsvariante des Phonems /в/. Statt eines Reibelautes wird im Süden des deutschen Sprachgebiets auch ein Zungenspitzen-R mit einem Vibrieren der Zungenspitze oder ein Zäpfchen-R mit Vibrationen des Zäpfchens gebildet. Nach langen Vokalen und in den Vorsilben er-, her-, ver-, zer- sowie der Nachsilbe -er wird das $\mathrm{R}$ vokalisiert, d. h., statt eines Konsonanten wird ein Vokal gesprochen. $\rightarrow$ vokalisiertes R

Rhythmus, Rhythmisierung - dynamisch-temporale Gestaltung des Gesprochenen mittels der Gliederung in rhythmische Gruppen, die durch ihren Silbenumfang und die Zahl und Position der Akzente charakterisiert sind. Im Deutschen wird der Rhythmus dadurch geprägt, dass die Akzentstellen prosodisch deutlich ausgezeichnet werden, während die akzentlosen Silben daneben abfallen und flüchtiger artikuliert werden. Akzentlose Silben werden deshalb häufig reduziert.

Satzakzent, Satzakzentuierung - In Lehrbüchern oft verwendete Bezeichnung für die Betonung einzelner Wörter in der Äußerung. Günstiger ist der Bezug auf Wortgruppen, aus denen sich längere Äußerungen zusammensetzen. $\rightarrow$ Wortgruppenakzent

Schwa-Laut - Mittelzungenvokal [ə], auch Zentralvokal, Murmelvokal, Reduktionsvokal, gebildet mit geringer Mundöffnung, halbhoch aufgewölbter Zunge und ungespannter Artikulationsmuskulatur. Im Deutschen wird er nur in akzentlosen Vor- und Nachsilben (z. B. be-, ge-, -ne, -te) verwendet. In den Endungen -en und - $e l$ wird er häufig weggelassen. In den Vorsilben er-, ver-, zer-verschmilzt er mit dem R-Allophon, es wird [e- fe- tse-] gesprochen. Allerdings wird

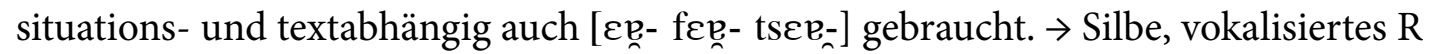

segmental - Segmente, d. h. Vokale und Konsonanten betreffend.

Silbe - kleinste Einheit der gesprochenen Sprache, die suprasegmentale Merkmale tragen kann, Grundeinheit des Wortes, Element der Rhythmisierung. Silben bestehen aus dem Silbenkern und den beiden Silbenrändern: dem Silbenanlaut oder Silbenkopf vor dem Kern und dem Silbenauslaut oder Silbenschwanz nach dem Kern. Der Kern ist der Lautheits- und Sonoritäts(Stimmhaftigkeits-)gipfel der Silbe, er wird im Allgemeinen durch einen Vokal oder Diphthong gebildet; an ihm wird die Silbe beim Hören erkannt. Fällt in -en und -el der $\rightarrow$ Schwa-Laut aus, so können auch die Nasale oder der L-Laut einen solchen Lautheitsgipfel tragen und somit eine Silbe bilden. Die Grenzen der Silbenränder werden beim langsamen silbischen Sprechen (z. B. wenn Kinder Abzählreime aufsagen) erkennbar. Der Silbenkopf kann mit 0 bis 3 Konsonanten, der Silbenschwanz mit 0 bis 5 Konsonanten besetzt sein. Die in den Silbenrändern auftretenden Konsonantenverbindungen unterliegen Kombinationsregeln, die durch die Sonoritätsverteilung 
in der Silbe bestimmt werden: Vom Sonoritätsgipfel im Kern sinkt die Sonorität zu den Silbengrenzen hin stufenweise ab; das bedeutet, stimmhafte Konsonanten stehen dem Kern immer näher als stimmlose, Nasale und Liquide stehen ihm am nächsten. $\rightarrow$ offene Silbe

Sprachlaut/Sprechlaut - kleinstes artikuliertes Element der gesprochenen Sprache, gehört zum Gegenstand der Phonetik und steht dem $\rightarrow$ Phonem der Phonologie gegenüber. Im Sprechprozess werden Phoneme mit Sprachlauten/Sprechlauten, die in der Phonologie $\rightarrow$ Allophone heißen, realisiert. $\rightarrow$ Laut, Artikulation, Assimilation

Stimmhaftigkeit - allgemein Bezeichnung für den möglichen Stimmanteil bei der Lautbildung. Bei den $\rightarrow$ Plosiven und $\rightarrow$ Frikativen können im Deutschen nur die Lenis-Laute stimmhaft sein. Sie sind es, wenn ein Klanglaut vorausgeht: mein Brot. Geht dagegen eine Sprechpause oder ein stimmloser Laut voraus, so werden die Lenis-Frikative und die Lenis-Plosive stimmlos gesprochen: das Brot. Die Fortiskonsonanten sind immer stimmlos. $\rightarrow$ Stimmlosigkeitsassimilation

Stimmlosigkeit - Abwesenheit von Stimmklang, Merkmal der Fortis-Plosive und der FortisFrikative.

Stimmlosigkeitsassimilation - Angleichung von stimmhaften Leniskonsonanten an vorausgehende stimmlose Fortiskonsonanten durch Verlust der Stimmhaftigkeit. Im Deutschen sind die Leniskonsonanten in dieser Position immer stimmlos. Es handelt sich um eine progressive Assimilation: Der vorausgehende Laut beeinflusst den folgenden Laut. Eine umgekehrt wirkende Stimmhaftigkeitsassimilation (der vorausgehende Fortis-Laut wird lenisiert und stimmhaft: das Brot) ist im Deutschen fehlerhaft. $\rightarrow$ Assimilation

suprasegmental - Bezeichnung für die phonetischen Merkmale, die die Segmente verbinden, überlagern, d. h. Melodie (= Intonation i. e. S.), Lautstärke, Sprechtempo, Spannung.

Transkription - Verschriftung des Gesprochenen mit einem festgelegten Inventar phonetischer Zeichen. Ein bestimmtes phonetisches Zeichen steht immer nur für einen Laut.

ungespannte Vokale - Im Unterschied zu den gespannten Vokalen werden die ungespannten Vokale mit etwas größerer Mundöffnung, etwas geringerer Hebung des Zungenrückens und etwas weniger gespannter Artikulationsmuskulatur gebildet. Dies bewirkt einen deutlichen Klangunterschied zwischen den ungespannten und den entsprechenden gespannten Vokalen. Für die deutschländische und schweizerdeutsche Standardaussprache ist dieser Unterschied 
charakteristisch, in der österreichischen Standardaussprache ist er geringer. Die ungespannten Vokale sind mit Ausnahme von [E:] kurz. $\rightarrow$ Vokal

Vokal - Mundöffnungslaut. Die verschiedenen Vokalklänge entstehen dadurch, dass der Resonanzraum des Mundes durch die Stellung der Zunge, der Lippen und des Unterkiefers verschieden geformt wird. Im Gegensatz zu mehreren anderen Sprachen kennt das Deutsche keine Nasalvokale, die mit Beteiligung der Nasenhöhlen hervorgebracht werden. Vokale sind Silbenträger. Sie können auch ohne Konsonant eine Silbe bilden: $\boldsymbol{a}$-ber. $\rightarrow$ gespannte, ungespannte Vokale

\section{Vokalneueinsatz $\rightarrow$ Neueinsatz}

vokalisiertes $\mathbf{R}$ - Mittelzungenvokal [e], der zwischen [a], [ə] und [॰] liegt. Er wird nach langen Vokalen und in den Vorsilben er-, her-, ver-, zer- sowie der Nachsilbe -er gesprochen. $\rightarrow$ SchwaLaut

Wortakzent, Wortakzentuierung - Hervorhebung einer Silbe im Wort als Akzentstelle. Die Festlegung dieser Stelle erfolgt nach Regeln, die für jede Sprache spezifisch sind. Im Deutschen herrscht der Stammsilbenakzent vor, d. h. in der Regel liegt der Akzent auf dem Wortstamm. Das Russische z. B. hat dagegen einen freien Akzent, der für die Unterscheidung unterschiedlicher grammatischer Formen eines Wortes genutzt wird und deshalb auch grammatischer Akzent heißt. Dagegen liegt der Akzent z. B. im Ungarischen immer auf der ersten Silbe, im Polnischen immer auf der vorletzten Silbe. Diese Akzentuierung wird als fest oder delimitativ bezeichnet, weil der Akzent als Signal für die Wortgrenze fungiert. Im Deutschen wirkt die Wortakzentuierung nur in wenigen Fällen wortunterscheidend. Der wichtigste Fall ist die Unterscheidung von trennbar und untrennbar zusammengesetzten Verben, z. B. Akzent auf der ersten Silbe: umfahren (ich fahre den Baum um) - Akzent auf dem Wortstamm: umfahren (ich umfahre den Baum). In der Äußerung wird die Akzentsilbe gegenüber den anderen Silben phonetisch abgesetzt. Sie hebt sich meist melodisch sowie durch vergrößerte Lautstärke, Spannung, Dehnung und präzisere Artikulation von den benachbarten Silben ab.

Wortgruppenakzent - Hervorhebung eines Wortes in einer zusammenhängend hervorgebrachten Wortgruppe (auch Akzentgruppe). Die Wortakzentsilbe dieses Wortes wird gegenüber allen anderen Silben und Wörtern der Gruppe melodisch sowie durch vergrößerte Lautstärke, Dehnung und präzisere Artikulation verstärkt abgesetzt. Die Wortakzente der anderen Wörter in der Gruppe werden als Nebenakzente bewertet.

Zäpfchen-R $\rightarrow$ Reibe- $R$ 


\section{Anhang 2: Abbildungen zu Lautsystemen in der Fachliteratur des 19. Jahrhunderts}

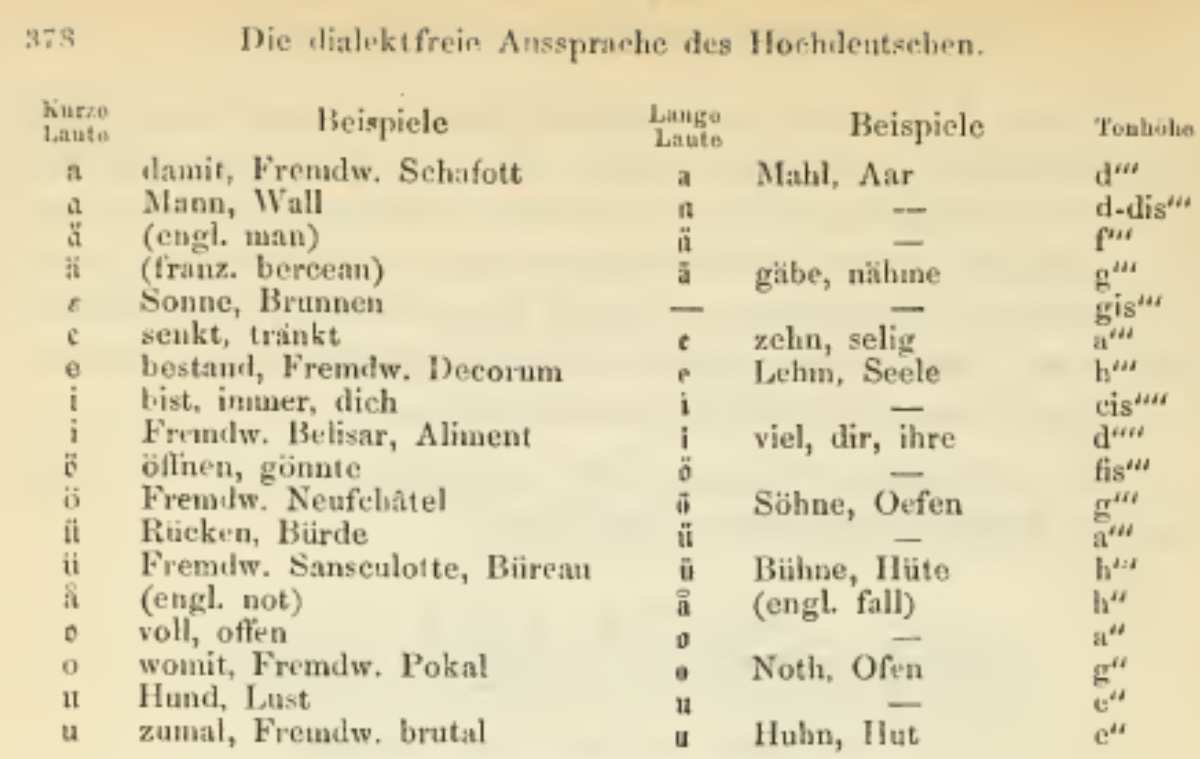

Anmerkung. Da die abgetönten dunkleren Laute fast uur in den germanischen, die hellklingenden dagegen auch in den romanischen Wörteru vorkommen, so sind die ersteren mit deutschen, die anderen mit lateinischen Lettern ansgedrückt, und zwar sind die kurzen Vokale durch gewöhnliche, die langen durch fette Schrift bezeichnet.

Die Tonhöhe der Vokale kann auch auf folgende Weise leicht veranschaulicht werden:

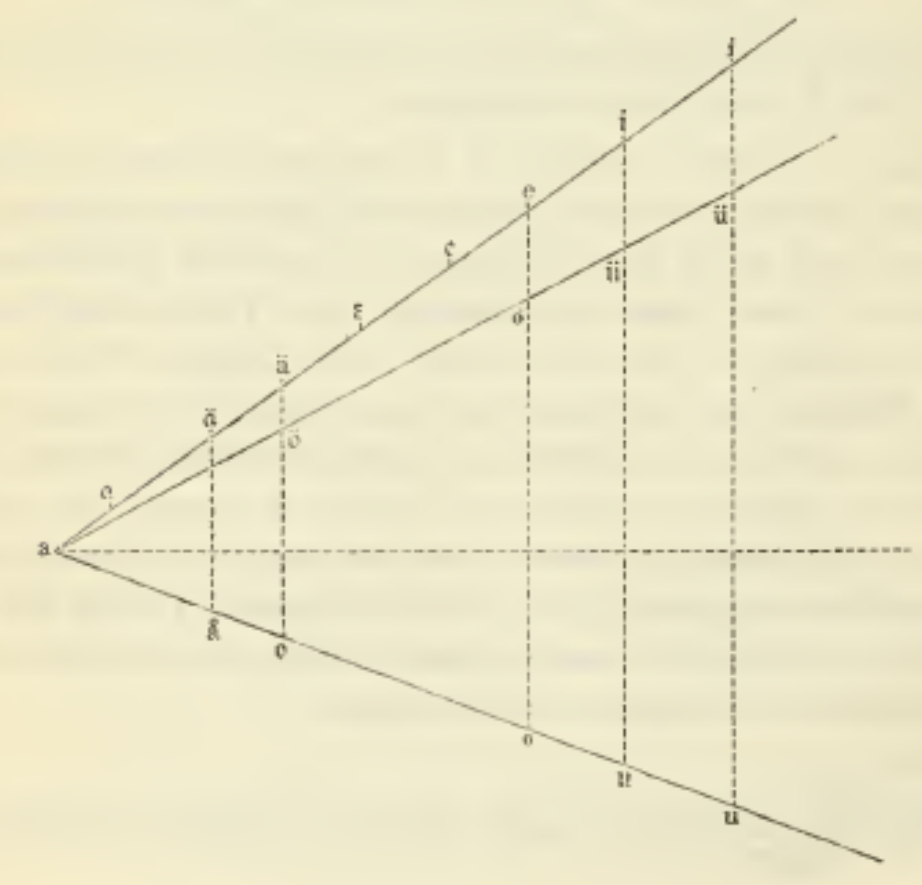

Grabow (1875, 378): Tonhöhe der Vokale 
$\$ 15$. Wir teilen die Consonanten nach den Organen, mit welchen sie gesprochen werden, in Lippen-, Zahn-, Gaumen- und Kehllaute:

I.

Lippenlaute
II.

Zahnlante
III.

Gaumen- u. Kehllaute

1. p packen

t Tag

k Leck

k Lack

2. b backen

d Dach

g egal

g. Agent

3.

f fand

s los

s̀ rasch

$x$ ich

$\chi$ ach

4. $v$ quer

w Wand

z lose

¿̀ (Genie)

y Könige $\mathfrak{g}$ lagen

ĩ enge ĩ bange denke Bank

Hierzı kommen noch 6 . h in hier

7. 1 in Loch

8. $\mathbf{r}$ in Riese.

Grabow (1877a, 42): Konsonanten

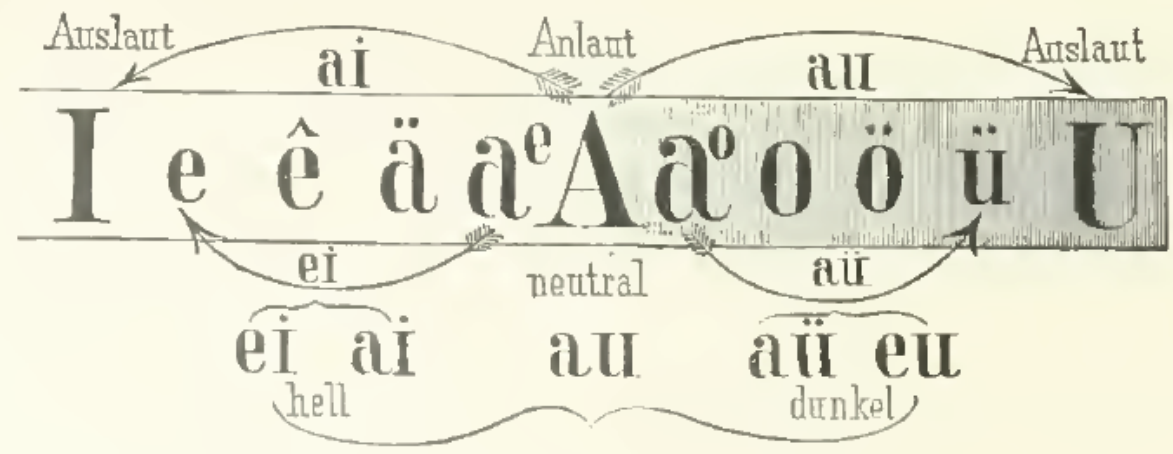

Hey 1882, 12: Diphthongbildung

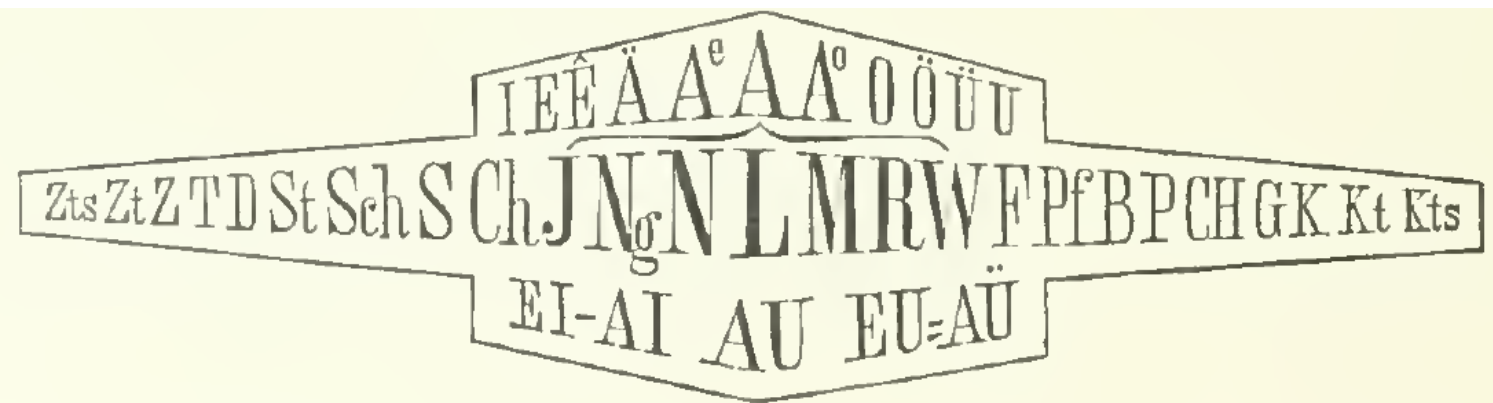

Hey 1882, 58: Zusammenhang von Konsonanten und Vokalen 


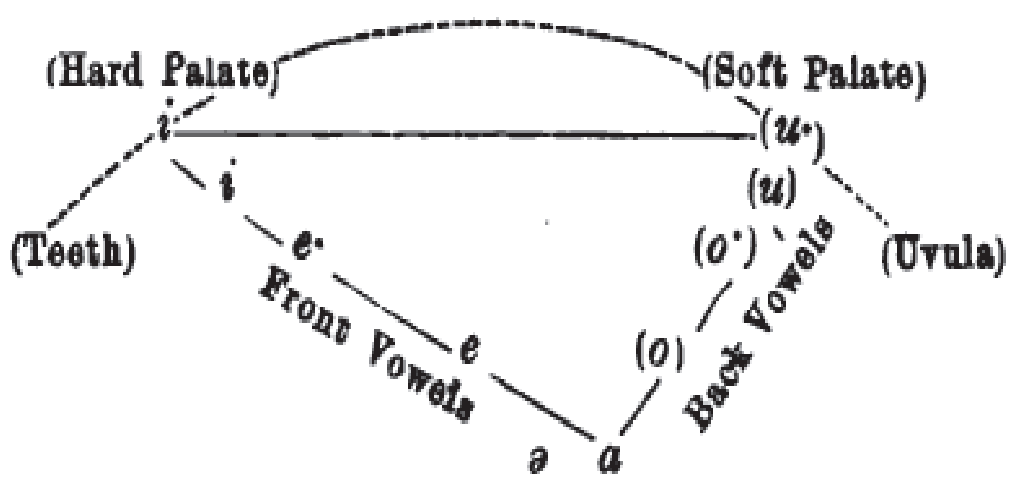

Viëtor 1885, 9: Vokale

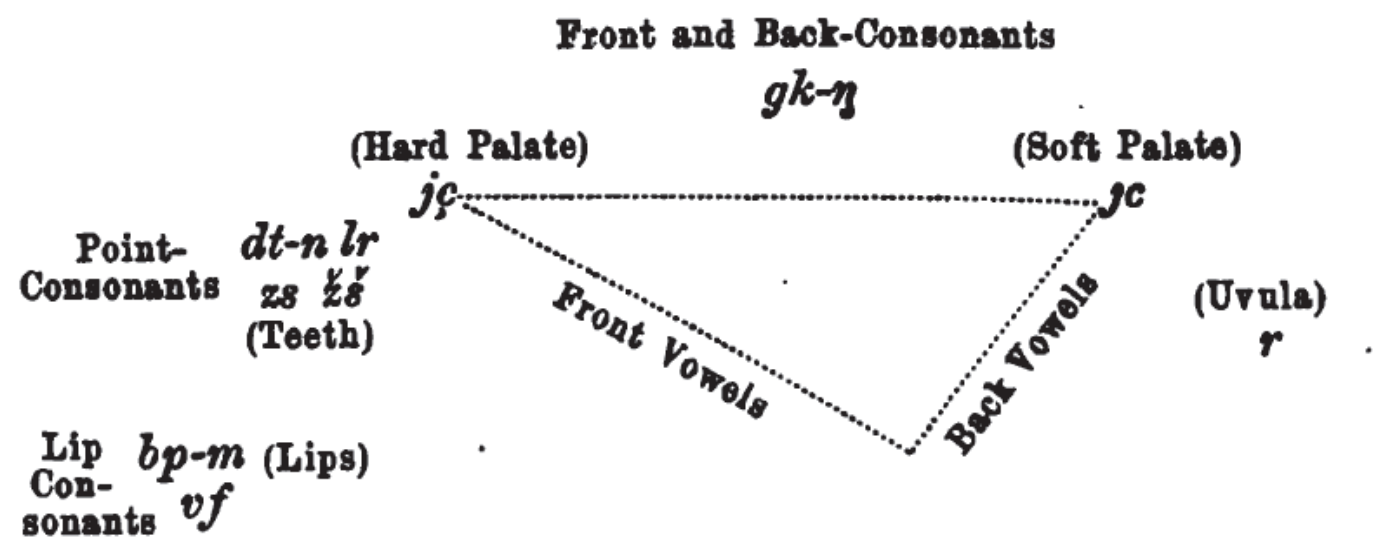

Viëtor 1885, 36: Konsonanten

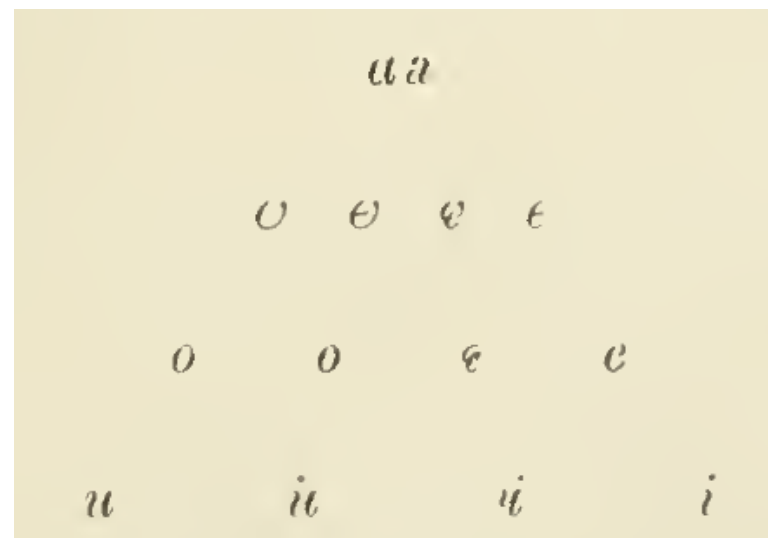

Trautmann 1886, 43: Tafel der Vokalreihen 


\section{Mundöffner:}

1. mit Stimmme: $a, u, o, e, i, \ddot{o}, \ddot{u},(e)$.

2. olıne Stimme: $h$ (mit entsprechenden Mundstellungen.)

II. Mundschliesser :

a. Engelaute: $\left\{\begin{array}{l}\text { 1. mit Stimme: } w, s, l, r \text { als Zungen- } \\ \text { und Gaumen-r. }\end{array}\right.$

2. ohne Stimme: $f, s, s c h, c h$.

b. Schlusslaute: $\{1$. nit Stimme: $b, d, g, m, n, \eta(n g)$.

2. ohne Stimme: $p, t, k$.

Kurze Vokale: Lange Vokale: Gemurmelter Vokal:

$a$ in matt, Mann. $\quad \bar{a}$ in Saat, Gram, lahm.

$e$ in Held, hält. $\quad \hat{e}$ in legen, heben, See, $e$ in Gabe, leben, hehr. Chance. $\bar{e}$ in mähen, gebären, Portière.

$i$ in Fisch, ich. $\quad \hat{\imath}$ in Liebe, ihn, mir.

$o$ in doch, Spott. $\quad \hat{o}$ in vor, Mohr; Moos.

$\ddot{o}$ in Mö̀dder, Löcher. $\hat{o}$ in Söhne, töten, schön.

$u$ in Hund, durch. $\hat{u}$ in Huhn, suchen, gut.

ï in Mütter, schützen. $\hat{\imath}$ in kïhn, fïr, Mühe.

Dazu die Nasalvokale $a$ in Orleans, Champ, Rouen; $e$ in Saint Quentin=se kate, Refrain, vin, Saint, Teint; $\rho$ in Garcon, Nom, Condé; ge in Parfum, Verdun. 


\section{Zusammenfassung}

Die deutsche Standardaussprache unterliegt heute relativ festen Normen, die zum großen Teil das Ergebnis langjähriger Bemühungen um eine überregionale Bühnenaussprache insbesondere im 19. Jahrhundert sind. An einer Erforschung historischer Aussprachenormen findet nicht nur die Sprechwissenschaft Interesse, sondern jüngst auch die Musikwissenschaft im Rahmen der historisch informierten Aufführungspraxis. Die Entwicklung der deutschen Standardaussprache ist seit längerem Gegenstand der Orthoepieforschung der halleschen Sprechwissenschaft, Schwerpunkte waren bislang jedoch das 20. und 21. Jahrhundert. Ziel dieser Arbeit war es, Normen der deutschen Bühnenaussprache im 19. Jahrhundert in Form möglichst konkreter phonetischer Merkmale zu rekonstruieren. Dazu wurde eine Auswahl zeitgenössischer Publikationen verschiedener Disziplinen einer Inhaltsanalyse unterzogen, Aussprachenormen mit fachübergreifender Gültigkeit verglichen und konkrete Aussagen zu speziellen Anforderungen der Bühne einbezogen. Die Analyse zeigt, dass viele der damaligen Normen in zahlreichen Merkmalen mit der heutigen Standardaussprache übereinstimmen, besonders auf lautlicher Ebene jedoch mehr oder weniger prägnante Abweichungen $\mathrm{zu}$ finden sind. Dazu gehören differenziertere Unterscheidungen von Lauten bei geschriebenem $\langle\mathrm{g}>$ und von E-Vokalen, die durchgehende Verwendung des Zungenspitzen- $\mathrm{R}$ und das Fehlen von Elisions- und Assimilationsprozessen. Ausgehend von den Ergebnissen der Literaturanalyse wurden schließlich Überlegungen zur praktischen Anwendbarkeit der Aussprachemerkmale im Rahmen historisch informierter Bühnenprojekte angestellt.

The standard German stage pronunciation today is governed by relatively fixed norms, which are largely the result of many years devoted to establishing a supra-regional stage pronunciation, especially in the 19th century. Research into historical pronunciation norms is not only of interest to speech science, but also recently to musicology within the field of historically informed performance practice. The evolution of standard German pronunciation has been the subject of orthoepy research in the speech science department at Halle for some time, but until now the areas of focus have been on the 20th and 21st centuries. The aim of this work was to reconstruct norms of German stage pronunciation in the 19th century using the most specific phonetic traits possible. This involved a content analysis of a selection of contemporary publications from various fields, a comparison of pronunciation norms with interdisciplinary applicability, and the inclusion of explicit statements regarding requirements particular to the stage. The analysis indicates that while many of the norms from that time are consistent with current standard pronunciation in many respects, more or less striking deviations can be found, especially at the phonetic level. These include more differentiated distinctions of sounds in written $\langle g\rangle$ and of $E$ vowels, the use of apical $R$ throughout, and the absence of elision and assimilation processes. Lastly, based on the results of the literature analysis, considerations were made concerning the practical applicability of the pronunciation traits within the context of historically informed stage projects.

Übersetzung: Jennifer Smyth 